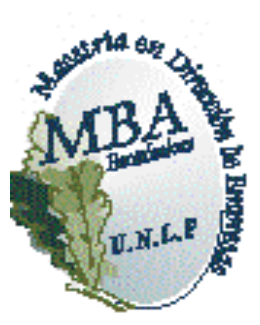

Universidad Nacional de La Plata

Facultad de Ciencias Económicas

MBA - Maestría en Dirección de Empresas

\title{
La Calidad educativa de los Centros Regionales de Educación Superior
}

Autor: Cr. Gustavo Oosterbaan

Director: Dr. Daniel Alberto Lauría

La Plata

Mayo 2015 


\section{Índice}

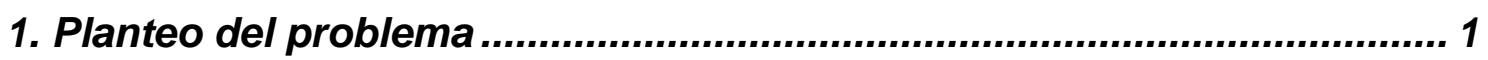

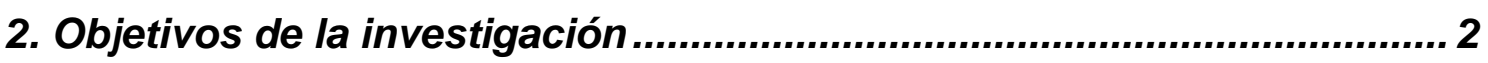

3. Evaluación del problema ................................................................... 3

4. Limitaciones y alcance de la investigación ......................................... 3

5. Marco teórico de referencia...................................................................... 4

5.1. Antecedentes de la investigación.............................................................. 4

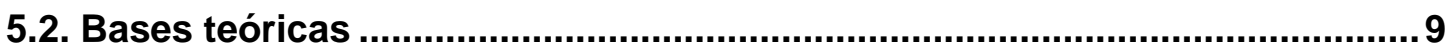

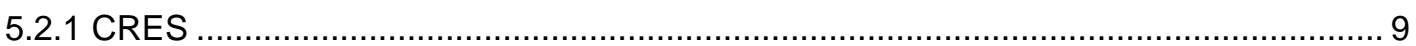

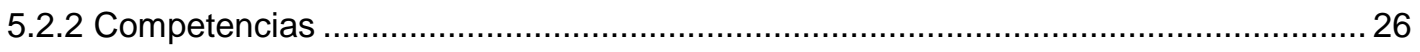

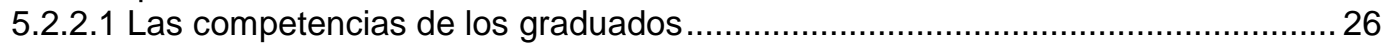

5.2.2.2 ¿Qué es lo que verdaderamente esperamos de nuestras escuelas? ................ 28

5.2.2.3 Conocimiento práctico para el puesto de trabajo........................................... 29

5.2.2.4 Competencias proyecto Tuning-Europa, Tuning-America Latina ...................... 32

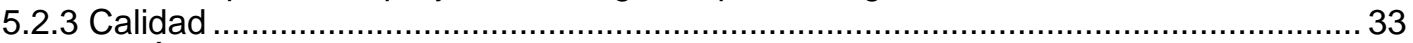

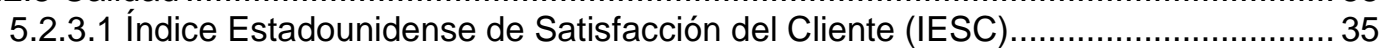

5.2.3.2 Calidad en educación desde la óptica de la Institución y el alumno................... 39

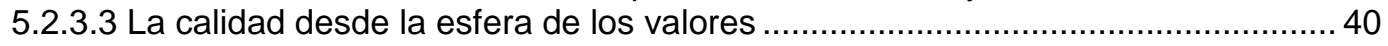

5.2.3.4 Definición de cliente .......................................................................... 41

5.2.3.5 Calidad en educación desde el punto de vista del cliente .................................. 44

5.2.3.6 Los sistemas de calidad según las normas ISO 9000 ..................................45

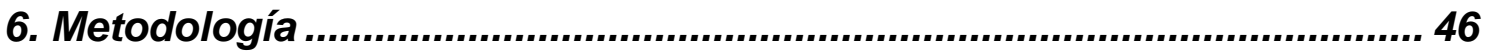

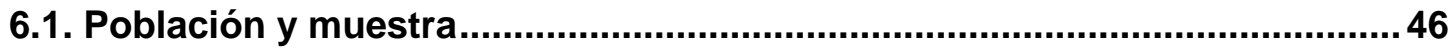

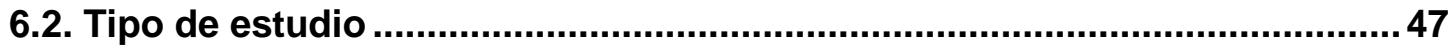

6.3. Técnicas de Recolección de Datos .......................................................... 47

6.4. Técnicas de análisis .....................................................................................4 49

7. Resultados de la Investigación ..........................................................53

7.1.- Capacidad para planificar y utilizar el tiempo de manera efectiva (de tal forma que se logren los objetivos planteados) .....................................................53

7.2.- Capacidad para comunicar por escrito........................................................ 55

7.3.- Capacidad para comunicarse oralmente de tal forma que los demás

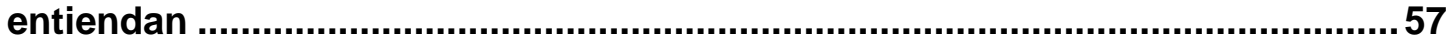

7.4.- Capacidad para hablar y escribir en un idioma extranjero..........................59

7.5.- Capacidad para utilizar herramientas informáticas básicas (procesador de palabra, hojas de cálculo, etc.)

7.6.- Capacidad para utilizar herramientas informáticas especializadas (paquetes estadísticos, programas de diseño, etc.)

7.7.- Capacidad para asumir responsabilidades y tomar decisiones (establecer metas, identificar limitaciones y riesgos, y generar, evaluar y elegir las mejores alternativas)

7.8.- Capacidad para trabajar en equipo para alcanzar una meta común. 67

7.9.- Capacidad para trabajar de forma independiente (sin necesidad de supervisión permanente) 
7.10.- Formación en valores y principios éticos..................................................... 71

7.11.- Capacidad para identificar, plantear y resolver problemas.......................73

7.12.- Disposición para aprender y mantenerse actualizado/a............................75

7.13.- Capacidad para manejar información procedente de áreas y fuentes

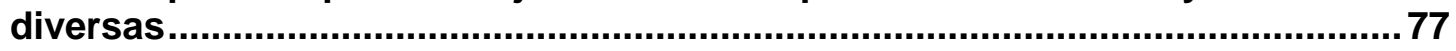

7.14.- Capacidad creativa e innovadora ............................................................ 79

7.15.- Capacidad para formular y gestionar proyectos .................................... 81

7.16.- Capacidad de abstracción, análisis y síntesis ........................................ 83

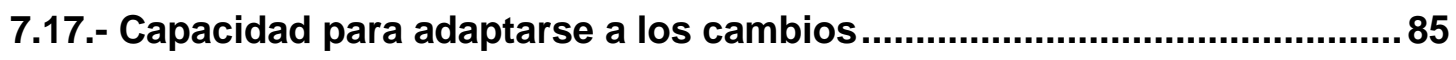

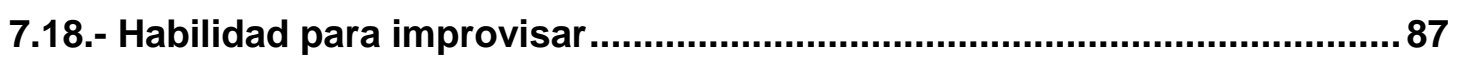

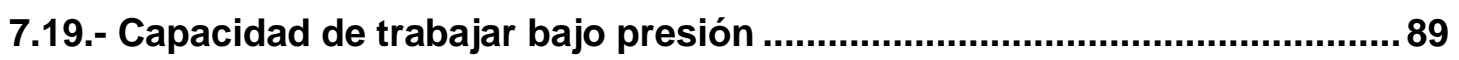

7.20.- Capacidad para presentar y sustentar en público informes e ideas........ 91

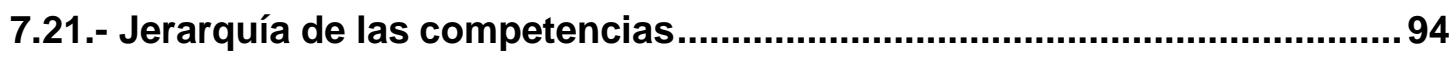

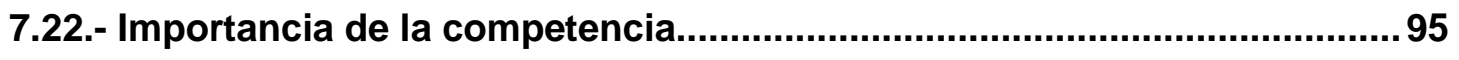

7.23.- Percepción del nivel de competencia de los empleados......................... 95

7.24.- Competencias de mayor problemática .................................................... 96

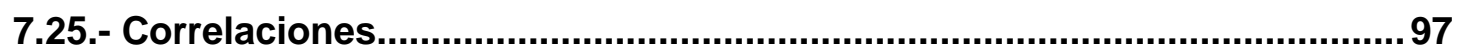

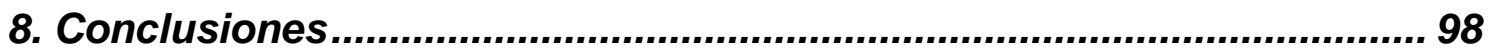

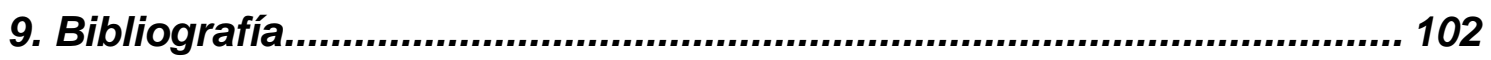

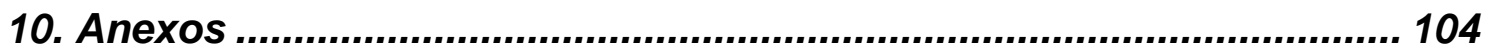

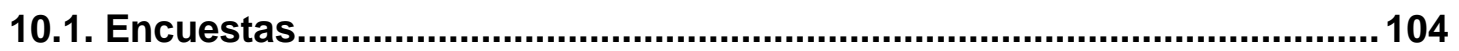

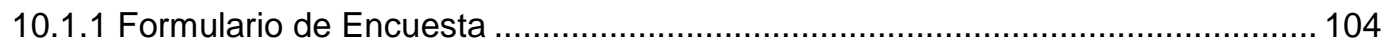




\section{Planteo del problema}

Existen en Argentina distintas y variadas experiencias en Gestión y Desarrollo de Centros Regionales de Educación Superior (CRES); que en todos los casos han intentado dar respuesta a una demanda de conocimiento cada vez más creciente en formación Universitaria.

El contexto social, económico y cultural de cada Región ha definido los rasgos característicos e identidad que impregnan el proceso, propios de la idiosincrasia del lugar y de su riqueza histórica. De tal forma se favorecieron los mecanismos de consolidación social de los proyectos y el empuje que lo sustenta.

Más allá de los factores característicos, existen elementos objetivos que se convierten en variables críticas, aportando sustentabilidad a los proyectos. Esos elementos se constituyen en requisitos sustanciales y determinantes en emprendimientos de esta envergadura. Conocerlos y desarrollarlos plenamente es hoy un proceso que se transita en soledad, haciendo cada uno su propia experiencia y descubriendo, muchas veces con cierto asombro, que se han acertado 0 equivocado los mismos caminos en los distintos CRES. Tal parece, ese conocimiento que se genera del "saber hacer" no se traduce ni tampoco está disponible, lo que produce una pérdida de eficiencia que impacta muy significativamente en términos de calidad y uso de los recursos, generalmente escasos.

Las pautas de calidad en un CRES poseen características distintivas de los estándares propios de cada disciplina fijados por la Comisión Nacional de Evaluación y Acreditación Universitaria (CONEAU), estos alcanzan solo a cada Institución Universitaria homogeneizando las evaluaciones desde la Sede Central. Esa acreditación de calidad que ostenta cada oferta hay que someterla y ajustarla a la logística que implica el desarrollo de la actividad académica en un lugar distante, con el enorme desafío de ampliar las acciones concentradas particularmente en la enseñanza y con pocas posibilidades de actividad de extensión e investigación.

Algunos académicos argumentaron que es necesario más y mejor educación, entonces la inversión en Capital Humano se convierte en un aspecto central del 
Desarrollo. También lo es federalizar ese conocimiento y fundamentalmente las oportunidades reales de acceso. La Universidad pública y gratuita, muchas veces es solo accesible para quienes residen en una ciudad Universitaria o tienen posibilidades económicas de trasladarse.

En las ciudades del Interior el éxodo - durante varias décadas - de sus jóvenes a las ciudades universitarias, las privó en gran parte de los talentos y capital humano necesarios para el desarrollo, toda vez que la mayoría suele no regresar.

También las despobló de liderazgos sólidos y formados, además del ámbito de competencia que invita a superarse. Muchas ciudades se han quedado quietas, con pocas motivaciones y una anomia que las paraliza y desespera. Esto impacta seriamente en las posibilidades de desarrollo social, económico y cultural.

¿Los CRES dan respuesta a las demandas de calidad académica que esperan los empleadores?

\section{Objetivos de la investigación}

Del problema planteado en el acápite anterior se desprenden del siguiente objetivo general del presente trabajo:

- Establecer la Calidad Académica de los CRES

Del mismo se desprenden los siguientes sub-objetivos:

- Identificar las expectativas de los empleadores de los graduados de los CRES, respecto de sus competencias.

- Identificar la percepción de los empleadores de los graduados de los CRES, respecto del desempeño en las distintas competencias.

- Determinar la brecha entre las competencias laborales de los graduados y las esperadas por los empleadores.

- Jerarquizar las problemáticas observadas. 


\section{Evaluación del problema}

Una oferta Universitaria de Calidad y Pertinente en las ciudades del Interior impacta positivamente en el desarrollo de las economías regionales, el examen más riguroso en términos de calidad se rinde frente a las empresas que representan el mercado laboral y que con sus decisiones opinan sobre los graduados.

Existe un consenso generalizado en la comunidad académica universitaria, que sugiere evitar la proliferación anárquica e improvisada de iniciativas Universitarias en pos de garantizar la calidad y excelencia de la formación. En primer lugar evaluando con parámetros objetivos la viabilidad de los proyectos; y luego fijando y acompañando procesos de desarrollo que integren a todos los actores.

El riesgo inherente, por falta de planificación y evaluaciones adecuadas de factibilidad, es convertir a los CRES en "enseñaderos". Donde el objetivo prioritario solo sea la formación curricular del graduado y se subordine la formación integral, humanística y en valores propia de la Cultura Universitaria.

El presente estudio aporto una identificación cabal de las variables necesarias para el desarrollo y la gestión de los Centros Universitarios. Estas variables asociadas a calidad, pertinencia y sustentabilidad de los factores; son necesarias para pensar un programa de Universalización de la Universidad.

\section{Limitaciones y alcance de la investigación}

Cabe aclarar que este trabajo no tuvo como pretensión realizar una evaluación acabada sobre la calidad de los CRES, ya que esto compete a la CONEAU y requiere un análisis y alcance mucho más profundo.

Se trata de un estudio exploratorio, que no pretende la definición de un "modelo" de CRES, sino una investigación exhaustiva del fenómeno de extensiones áulicas. 
Como se ha señalado en los objetivos específicos presentados precedentemente, el alcance del trabajo estuvo enmarcado en la opinión de los Empresarios locales, Representantes de Cámaras económicas, Organismos Estatales, ONG. Como una evaluación de calidad desde el mercado laboral.

Por otro lado, la investigación ha recogido la opinión de los actores que impulsan los CRES en términos de calidad, pertinencia de la oferta y sustentabilidad. Fueron relevados algunos CRES de la provincia de Buenos Aires definidos en el acápite de Población y Muestra.

\section{Marco teórico de referencia}

\subsection{Antecedentes de la investigación}

En Latinoamérica la expansión de la educación universitaria ocupa una de las acciones más significativas de las políticas de Estado, que sostenidas en el tiempo han alcanzado un desarrollo muy significativo.

En Cuba el Ministerio de Educación Superior sostiene y profundiza el programa de Universalización de la Universidad, en consonancia con la declaración final CRES, junio de 2008, Bogotá, Colombia : "El carácter de bien público social de la Educación Superior se reafirma en la medida que el acceso a ella sea un derecho real de todos los ciudadanos"

Las Sedes Universitarias Municipales (SUM), dependen de las Universidades Provinciales, sus carreras son dirigidas metodológicamente por sus facultades. En las mismas se desarrollan todos los procesos sustantivos, no solo la formación.

Los recursos humanos son en su mayoría profesionales de la localidad seleccionados y entrenados, contratados a tiempo parciales. La modalidad es presencial y semipresencial, atendiendo las distintas necesidades de los alumnos.

Para el periodo 2002-2009 la cantidad de Sedes creció de 390 a 3.150 alcanzando una matrícula, solo en las Sedes Universitarias, de 578.937 alumnos. 
El impacto más significativo logrado se traduce en términos de desarrollo local, especialmente referidas a:

- Democratización del ingreso a la Educación Superior;

- Mayores niveles de equidad social en el seno de la sociedad cubana;

- Efectos positivos en la cultura general integral de los estudiantes;

- Solución temporal a la desocupación de jóvenes, a los que la economía del país no permitía emplear y rescatarlos de su potencial marginalidad;

- Haber dado posibilidades de continuidad de estudios a los integrantes de los programas sociales;

- Contribución de las SUM a la solución de problemas municipales mediante la investigación científica y el desarrollo de proyectos comunitarios vinculados al Banco de Problemas;

- Impacto en el empleo mediante la incorporación de los estudiantes a diferentes plazas en el territorio;

- Impacto en la superación de profesionales y funcionarios municipales;

- Positivo impacto en las familias de los estudiantes de las SUM.

En Colombia, el Ministerio de Educación Nacional implemento un programa que denomina "revolución educativa" que tiene como objetivo central la ampliación de la cobertura y la desconcentración y pertinencia de la oferta.

Cinco acciones que transformaron la educación en Colombia:

- Educación durante toda la vida

- Educación para la innovación y la competitividad

- Fortalecimiento de la institución educativa

- Modernización permanente del sector

- Gestión participativa

En base a este paradigma, en términos de la educación Superior Universitaria se puso en marcha el programa Centros Regionales de Educación Superior (CERES) como estrategia que busca desconcentrar la oferta educativa y ampliar su cobertura. 
Este modelo parte del dialogo regional, se centra en la oferta de programas de educación superior pertinentes a la comunidad y acordes con la vocación productiva de la zona.

El esquema de funcionamiento se centra en la conformación y consolidación de alianzas regionales. Promueve la conformación de alianzas que posibilitan el uso compartido tanto de recursos humanos como financieros, de infraestructura y conectividad para facilitar el acceso a la educación superior. Los actores claves en las alianzas CERES que garantizan la operatividad y sostenibilidad son:

- Gobiernos departamental y local

- Sede adecuada para el CERES, que permita la oferta de Educación Superior con calidad

- Subsidios y becas de matrícula a los estudiantes de los CERES

- Apoyo en transporte y sostenimiento de estudiantes

- Sector productivo

- Laboratorios o espacios para prácticas y pasantías

- Brinda orientación a la Alianza sobre los programas académicos pertinentes al desarrollo productivo de la región

- Institución de Educación Superior operadora

- IES que ofrecen programas de Educación Superior con registro calificado del Ministerio de Educación Nacional (MEN)

- Aporta un coordinador al servicio del CERES

- Organizaciones sociales

El Ministerio de Educación Nacional entrega recursos para la instalación de aulas virtuales con tecnología de punta como equipos de cómputo, conectividad y equipos audiovisuales. Teniendo en cuenta la oferta educativa aporta recursos para la instalación de laboratorios y destinados al mejoramiento de Bibliotecas especializadas, como así también contenidos digitales como bases de datos y simuladores.

En el periodo 2003-2009 se crearon 141 CERES, en 31 departamentos con impacto en 480 municipios. Que generaron 20.560 nuevos cupos en 674 programas 
académicos ofrecidos (47\% T\&T). La inversión del MEN ascendió a \$22.066 millones para su dotación.

El MEN ha impulsado la autoevaluación como una cultura de mejoramiento permanente con el fin de incentivar en los CERES iniciativas que permitan lograr mayor efectividad en sus componentes académicos, administrativos, financieros y operativos.

Otra acción del MEN es el fortalecimiento en innovación educativa con el uso de tecnologías a través de la modalidad virtual; con el objetivo de incrementar la cobertura en zonas de difícil acceso a la Educación Superior. Algunas de las acciones que se materializaron son:

- Modelos financieros para educación a distancia.

- Transformación de programas a distancia a virtuales.

- Formación de formadores

- Gestión en comunidad virtual de aprendizaje

- Objetos virtuales de aprendizaje

- Herramientas web 2.0 para la docencia

- Tutoría en ambientes virtuales de aprendizaje

- Competencias básicas en el uso de TIC

\section{Pertinencia de la educación Superior desde una perspectiva de demanda Otras experiencias internacionales}

\section{Irlanda}

Entidades de fomento a la pertinencia

- Department of Education and Science

- Expert Group on Future Skills Needs

- Forfás - temas de competitividad, innovación y tecnología

- Higher Education Authority (HEA)

- Skills and Labour Market Research Unit (SLMRU)

Estrategias

- Definir sectores de clase mundial para el país.

- Definir apuestas productivas a nivel regional. 
- Identificar las tendencias y factores de cambio en cada sector y evaluar los requerimientos de competencias a futuro.

- Plantear recomendaciones sobre las acciones que se deben tomar para asegurar que el sector esté equipado con el nivel correcto de competencias y destrezas para garantizar un éxito continuo.

- Hacer estudios y análisis sobre las competencias requeridas a nivel regional.

- Instrumentos: encuestas y entrevistas a empleadores.

\section{Canadá}

El estudio de pertinencia por el lado de la demanda tuvo como objetivo evaluar la satisfacción de los empleadores con los recién graduados del sistema educativo canadiense (por provincia) en las áreas de competencias académicas y técnicas, así como conocer su nivel de satisfacción con la respuesta general del sistema a las necesidades de capital humano del sector productivo Las provincias involucradas fueron Alberta, Torontoy Ontario

\section{Estrategias}

Cada provincia tiene su propio mecanismo de recolección de información sobre la demanda de graduados. No existe un sistema de información que consolide esta información.

Encuesta de Satisfacción a Empleadores (definida por cada provincia)

Encuesta Nacional a Graduados (Nacional)

\section{Inglaterra}

La entidad de fomento a la pertinencia es Learning and Skills Council, Organización financiada con recursos públicos.

El Sistema ofrece a los recién graduados y empleadores el conocimiento y las competencias pertinentes para lograr el éxito económico y social del país

La encuesta Nacional de Competencias para Empleadores consolida información detallada sobre la incidencia, nivel y naturaleza de los problemas de competencias que encuentran los empleadores, con relación a capacitación y brechas en su fuerza 
laboral. También explora las actividades y costos de los empleadores en materia de capacitación para el trabajo.

\section{Australia}

La entidad de fomento a la pertinencia es Graduate Careers Australia, Organización conformada por el sector de Educación Superior, Gobierno y Empresas del sector privado. Permite una articulación entre oferta y demanda de recién graduados.

La encuesta de Competencias para Empleadores tiene como principal objetivo identificar las 10 competencias y atributos más requeridos por los empleadores de los recién graduados. Se solicita ordenar por prioridad las 24 competencias/atributos más requeridos en los últimos años.

\subsection{Bases teóricas}

\subsubsection{CRES}

En la Argentina, se está Institucionalizando la actividad académica desarrollada en Ios CRES, el tema está en discusión y ocupa el interés de los actores de mayor responsabilidad en términos del desarrollo de la Educación Superior.

Los documentos que abordan el tema bajo estudio son: La declaración de la CONEAU, "Creación de subsedes Universitarias", el "Duodécimo dictamen del Consejo de Universidades" y el Acuerdo Plenario de la CIN № 802/11; a continuación se hace un resumen de los aspectos más salientes y las conclusiones vertidas en estos trabajos:

\section{La declaración de la CONEAU, “Creación de Subsedes Universitarias”:}

Preocupa a la Comisión Nacional de Evaluación y Acreditación Universitaria una práctica creciente: la creación por parte de universidades, tanto estatales como privadas, de subsedes o carreras -denominadas a veces "extensiones áulicas"- en lugares alejados de su zona natural de actividad. 
Ello está dando lugar a un panorama anárquico que debilita la calidad del sistema de Educación Superior por la insuficiencia en dichas subsedes del plantel académico, de la infraestructura física y bibliográfica y de otros servicios esenciales para el aprendizaje. Esas extensiones áulicas conspiran también con frecuencia contra los objetivos fundacionales y la necesaria unidad de gestión y formación de las Instituciones Universitarias.

Lo expuesto no supone dejar de tener en cuenta la aspiración de las comunidades locales de contar con posibilidades de acceso a la formación universitaria, sino señalar que este tipo de creaciones no constituye el medio más idóneo para obtener el nivel de calidad educativa requerido. Dicha circunstancia atenta finalmente contra el logro de las legítimas expectativas de los estudiantes y de la sociedad.

No hay dudas que la atribución para tales creaciones surge de la autonomía que la Constitución Nacional otorga a las universidades nacionales y de las leyes que reglamentan el derecho constitucional de enseñar y aprender que rige a las instituciones privadas.

Es verdad que de acuerdo con la ley 24.521, la CONEAU tiene por único objetivo mejorar y garantizar la calidad de la educación superior. Para alcanzar dicha finalidad el mencionado ordenamiento legal concede a este organismo diversos mandatos, que se traducen en informes, recomendaciones y dictámenes de carácter técnico-académico, sin abarcar los controles de legalidad y legitimidad ni asumir el seguimiento de las instituciones y programas. No cabe duda, sin embargo, que la opinión de este cuerpo sobre el nivel académico y profesional de dichas subsedes se pondrá de manifiesto en el momento de realizar la evaluación de la institución principal a la acreditación de las carreras de grado correspondientes a las actividades reguladas por el Estado y de posgrado. Pero tal análisis puede resultar tardío y por lo tanto provocar dificultades y perjudicar a los estudiantes que cursen en ellas sus estudios.

Por tales razones, la CONEAU considera necesario llamar la atención acerca de las circunstancias reseñadas y promover consultas sobre este tema con el Consejo Interuniversitario Nacional, el Consejo de Rectores de Universidades Privadas, los 
Consejos Regionales de Planificación de la Educación Superior, la Secretaría de Políticas Universitarias del Ministerio de Educación y eventualmente el Consejo de Universidades.

\section{"Duodécimo dictamen del Consejo de Universidades":}

El Consejo introduce la problemática de las extensiones territoriales de Instituciones Universitarias Nacionales, en el marco del proceso que ha caracterizado a la educación Superior Universitaria Mundial desde la segunda mitad del siglo XIX, del cual Argentina no es ajena. De 3 Universidades con 8.600 alumnos en 1918, Argentina ha pasado a tener 89 Instituciones Universitarias con 1.493 .556 alumnos (dato de 2003). Mientras en el mismo lapso la población Argentina se multiplico por 5, las Instituciones Universitarias Públicas y Privadas lo hicieron por 33 y los alumnos por 173. Se agrega que si a la matrícula Universitaria se suma la de los establecimientos de educación superior no universitaria (de formación docente y formación técnica), los números indican que Argentina ocupa uno de los primeros lugares en el mundo por la cantidad relativa de alumnos.

El dictamen señala que, aunque estas cifras ponen de manifiesto la magnitud del esfuerzo del Estado y de la sociedad Argentina en orden a la expansión de la educación Superior, reflejan únicamente el aspecto cuantitativo de la cuestión. Con respecto al aspecto cualitativo, "no es aventurado pensar que un crecimiento tan pronunciado, en tan corto espacio de tiempo, constituye un problema delicado en materia de calidad". Por consiguiente, la prioridad de la política universitaria, según el dictamen, debe ser la preocupación por la calidad académica, presente en los reclamos de las autoridades, los docentes universitarios y los alumnos; también en el órgano legislador, que incorpora a la Ley de Educación Superior normas relativas a la evaluación Institucional y a la acreditación de carreras profesionales.

Es imposible juzgar aquellos emprendimientos que promueven la multiplicación indefinida de unidades académicas, ya sea mediante la creación de nuevas instituciones universitarias o la extensión territorial de las existentes como un beneficio objetivo, independiente de la calidad de la oferta educativa. El dictamen plantea que merece analizarse especialmente la multiplicación de subsedes y otras 
extensiones territoriales universitarias, una modalidad que en los últimos tiempos se ha acentuado notoriamente ya que una vez satisfecha la aspiración de crear una universidad en las capitales de Provincia y algunas otras ciudades grandes del interior, las comunidades locales más pequeñas aspiran a tener, al menos, alguna carrera universitaria. Para lograrlo se gestiona entonces una facultad dependiente de la Universidad Nacional más próxima o una subsede o delegación de ella. Si no se lo consigue, se recurre a una Universidad Nacional más lejana. Si tampoco eso se logra, se lleva el proyecto a una Universidad Privada. En todos los casos, las entidades representativas y las autoridades y políticos locales se movilizan para hacer realidad el proyecto, ofreciendo apoyo económico o infraestructura. El dictamen destaca que las primeras carreras en las que se piensa son las que requieren una infraestructura y un equipamiento mínimos, y que, no por casualidad, corresponden a profesiones sobresaturadas. Cuando se alcanza el objetivo, otras ciudades de similar dimensión se sienten motivadas a seguir el ejemplo. "En todo este proceso no hay límites de distancias; las extensiones pueden estar a centenares de kilómetros, en algunos casos, a más de mil".

El dictamen subraya que las extensiones territoriales plantean cuestiones académicas, jurídicas y socio-políticas.

\section{- El problema académico:}

En lo que concierne a las académicas, el problema se centra en la calidad del servicio educativo prestado en tales condiciones. "En esta materia, la evaluación institucional interna y externa y la acreditación de las carreras profesionales serán las pruebas de fuego". Se señala que la dispersión geográfica conspira contra la noción misma de universidad, "aunque el gigantismo de algunas haya debilitado el contacto y la intercomunicación entre las unidades académicas que las componen, la proximidad física sigue teniendo una importancia que la actual valorización de la interdisciplinariedad contribuye a destacar". Por otra parte, se observa que estas extensiones no pueden reproducir la calidad de la infraestructura y el equipamiento científico, técnico y bibliográfico de las Sedes principales, ni tampoco el nivel de los planteles docentes, "con lo cual la Institución Universitaria está cubriendo con su nombre calidades y títulos de muy distinto valor intrínseco". 


\section{- La cuestión jurídica:}

En el aspecto jurídico, el dictamen distingue entre Universidades Nacionales y Privadas.

En las primeras, de acuerdo con la legislación vigente, la cuestión está estrechamente vinculada a los alcances de la autonomía. Según el Consejo, en virtud de esa autonomía, algunas de ellas crean todo tipo de extensiones sin restricción alguna. Es importante destacar algunas salvedades que se hacen en este punto: en primer lugar la existencia de Universidades "Regionales", creadas y organizadas con facultades dispersas dentro de una región o las que no han sido concebidas como regionales pero tienen extensiones dentro de lo que se podría llamar su "región natural". En segundo término, un caso atípico: la Universidad Tecnológica Nacional, que hoy cuenta con 19 facultades y 10 unidades académicas regionales. Este tipo de Instituciones no genera problemas -sostiene el dictamenpero -aclara- hay otros casos en que las extensiones han creado situaciones conflictivas, no solo por estar ubicadas fuera de la natural zona de influencia de la propia Universidad, sino además por invadir las de otras Universidades Nacionales.

En cuanto a las Instituciones Universitarias privadas, el dictamen sostiene que todas las extensiones existentes fueron en su momento autorizadas o regularizadas a posteriori por el Ministerio. "Solo podrá autorizarse a las Instituciones Universitarias privadas a crear Sedes o unidades académicas equivalentes fuera de la jurisdicción que le es propia, cuando fundadas razones así lo justifiquen y se acredite además capacidad de gestión suficiente". Se establece también que la autorización para el funcionamiento de una nueva universidad debe indicar expresamente la jurisdicción territorial dentro de la que deberá concentrar sus actividades.

\section{- La cuestión socio-política}

El dictamen afirma que no puede soslayarse en el análisis el interés superior de la sociedad y el Estado. El sistema educativo, tal como es concebido en los países 
modernos "exige un mínimo de planeamiento estratégico, al menos para una asignación adecuada de los recursos siempre insuficientes".

Se destaca que las estadísticas indican que el promedio nacional de abandono o deserción de los alumnos ingresantes asciende al 50\% en el primer año de estudios y llega al $81 \%$ en los años siguientes. Solo se gradúa el $19 \%$ de los ingresantes. En las instituciones universitarias privadas la deserción es menor, pero igualmente considerable.

Según el dictamen, la multiplicación no planificada de subsedes universitarias, lejos de resolver el problema, lo extiende y agrava, embarcando a los jóvenes en carreras en las que se frustran y fracasan cuatro de cada cinco que lo intentan. "Desde otro punto de vista, tal política significa una asignación de recursos de muy difícil justificación, frente a tantas necesidades educativas insatisfechas”.

Queda claro que las reflexiones anteriores valen tanto para las Instituciones Universitarias públicas como para las privadas. Para evitar esto la ley ha establecido, además de la supervisión del Ministerio de Cultura y Educación, la evaluación institucional y la acreditación de carreras profesionales, común a universidades públicas y privadas. "La única diferencia es que, tratándose de las ultimas, los errores no gravitan sobre el presupuesto del Estado".

\section{“Acuerdo Plenario de la CIN № 802/11"}

\section{Programa de expansión de la educación superior}

\section{I.- Las Universidades y la expansión de la Educación Superior}

La Argentina como Nación tuvo en su complejo devenir, un aspecto que la ha caracterizado en el concierto de naciones latinoamericanas, que ha sido el desarrollo de la educación. Tiene en la Universidad Nacional de Córdoba, cercana a cumplir cuatrocientos años, su antecedente de más larga data y en su corta vida de Nación soberana, supo conformar el modelo más desarrollado e inclusivo de educación. Su sistema universitario fue formador de gran cantidad de profesionales, profesores, dirigentes e intelectuales latinoamericanos. Las crisis recurrentes del último sexenio 
y políticas de estado con continuidad, que aplicaron países latinoamericanos en el desarrollo universitario, llevaron a perder ese liderazgo hace una década, situación que ha comenzado a ser revertida en los últimos años.

La Reforma del 18 desarrolló varios ejes de política verdaderamente revolucionarios para su época, que hoy han sido satisfechos y en algunos casos superados totalmente. A saber: autonomía universitaria, cogobierno, libertad de cátedra, y extensión como tercera acción sustantiva (además de docencia e investigación).A estas políticas, el peronismo le agregó en la década del 50 la gratuidad de la educación universitaria y en esta etapa, la inclusión como eje sustantivo de su desarrollo.

Hay aspectos centrales de Política Pública que no están en la LES, como su valor de instrumento de política activa, tanto en el sentido reparador de permitir el acceso a la formación superior en áreas densamente pobladas y sin Universidad, como su potente capacidad de retención y atracción poblacional, es decir sensible propiciador de calidad de vida, elemento central de políticas de ordenamiento territorial $y$ poblamiento.

La comprensión de la función social que deben cumplir las Universidades, está consolidado en la Declaración de la Segunda Conferencia Regional de Educación Superior - CRES 2008 - convocada por IESALC-UNESCO, realizada en Cartagena de Indias, donde se afirma que la Universidad Latinoamericana tiene como misión principal el desarrollo social e integral de sus entornos poblacionales. La definición de la educación como "Bien público social, derecho humano y universal, y responsabilidad del estado" defendida con éxito por Latinoamérica, junto a Universidades africanas y algunas asiáticas, en la Segunda Conferencia Mundial de Educación Superior - UNESCO - de París en 2009, es un hito histórico. Se enfrentó a la postura de los países centrales que pretendían convertirla en servicio, pasible de ser comercializado, como otro bien transable.

Habiendo sido partícipes destacados de la elaboración de estos documentos, las Universidades Públicas Argentinas, tienen el compromiso político-institucional de formalizar un pensamiento estratégico universitario, alineado con la visión 
estratégica que el pueblo argentino va señalando al avalar las políticas públicas generadas en los últimos años y en especial a las referidas a la Educación Superior. Algunos de los componentes de ese Pensamiento Estratégico son: precisar prioridades de formación de graduados en carreras necesarias para el desarrollo nacional, regional y local, ofrecer las formaciones universitarias y las modalidades de cursado que mejoren la inclusión de los jóvenes en el ejercicio ciudadano, en el trabajo y el servicio social, responder a las prioridades nacionales y regionales de desarrollo integral, alentando la investigación, desarrollo, innovación y transferencia, en esa dirección.

Es posible inferir que aunque existan políticas activas en Argentina no hay sistema universitario consolidado. No se ha definido desde el Estado (en parte en consideración a la autonomía universitaria), ni tampoco desde las universidades en su conjunto construir un sistema articulado. Uno de los aspectos a considerar es que existen dos organizaciones que reúnen las Universidades a nivel nacional, según sean públicas (CIN) o privadas (CRUP). En las últimas décadas, producto de las recurrentes crisis, se ha consolidado una cultura organizacional de "coyuntura". El día a día, ha sido la impronta durante mucho tiempo y recién en los dos o tres últimos años comienza a escucharse sobre planes estratégicos, análisis de escenarios futuros y planificación.

En este contexto tiene gran importancia y cobra fuerza el requerimiento de Expansión de la Educación Superior (ES) y que, de no ser discutido y acordado previamente, puede generar grandes conflictos o producir un desequilibrio de serias consecuencias. Es que hay dos políticas legítimas y pertinentes, pero "aparentemente" encontradas: la de inclusión de sectores del conurbano, regiones y provincias desfavorecidos, para los que la herramienta ha sido la creación de nuevas universidades y la de una estrategia de poblamiento armónico y sostenible del territorio nacional, que entiende a la ES como un potente instrumento de retención y/o atracción poblacional, para paralizar y en lo posible revertir, los procesos emigratorios desde las pequeñas ciudades hacia los centros más densamente poblados, que atraen por su mayor calidad de vida, en que la educación es un componente principal. 
Uno de los temas más importantes en la concepción estratégica del Estado, es la educación y su impacto en la inclusión, en el desarrollo sostenible de la comunidad y en la realización de las personas. Prácticamente no hay discurso público que no haga referencia a la educación como herramienta principal de progreso y justicia social. Pero cuando, como en el caso argentino, la educación universitaria pública es financiada totalmente por el estado, con el aporte de todos los argentinos, aún de los excluidos, debiera considerarse imprescindible la planificación y la consolidación como política de estado. En las actuales condiciones, en la denominada sociedad global del conocimiento, que debe ser correctamente interpretada para la realidad argentina, se puede tener acceso a una mejor calidad de vida en pequeñas $y$ medianas ciudades que en las megalópolis. $Y$ esto favorece además un sistema socio productivo de mayor sostenibilidad ambiental y justicia social, con ciudades de escala humana. Tiene que quedar muy claro que la existencia de oferta universitaria es un elemento caracterizador de alto impacto, en lo que se agrega como "calidad de vida". Los dos movilizadores juveniles más importantes, son la posibilidad de estudio y trabajo.

La posibilidad de planificar la presencia de la Universidad en todo conglomerado poblacional que así lo requiera es un desafío a asumir. Tecnicaturas universitarias, Ciclos Básicos presenciales y algunas carreras de grado presenciales 0 semipresenciales, vinculadas a la formación de dirigentes y profesionales para el desarrollo local endógeno, son sólo algunos de los instrumentos que se tiene a disposición. Pero ello requiere un riguroso análisis de la pertinencia de la propuesta, la cual debe estar inducida por la pertinencia y la necesidad social.

\section{II.- Los ejes caracterizadores de la Universidad Argentina Pública y Gratuita:}

a) Compromiso a estar presente en todas las áreas disciplinarias de su modalidad estatutaria: La Universidad Argentina Pública y Gratuita (UAPG), no debe descartar dentro de su misión y visión ninguna de las posibles propuestas, que verifiquen pertinencia para el medio socio productivo en que se brindan, en un análisis fundado y riguroso, que debiera contener estándares mínimos acordados. Este análisis debe contemplar demandas y necesidades de la región de impacto, en una prospectiva de medio y largo plazo. No debiera haber a priori propuestas de primera y de segunda, ya que 
muchas de las descartadas por la tradición universitaria pública, son fuertemente inclusivas para sectores desfavorecidos, y actualmente ofrecidas por la educación privada. Aunque exista oferta privada en la región es importante la presencia pública, en carácter referencial para la inclusión.

b) Perfil de servicio público de la propuesta: La UAPG debe tender a contemplar en sus diversas formaciones, la acción de sus egresados en el desarrollo local, regional y nacional. El perfil de servicio público preferencial de sus carreras, debería contemplar la visión prospectiva, la planificación y la responsabilidad profesional en la convergencia de los conocimientos específicos hacia el bien común. Un campo a desarrollar es la visión del desafío de integración latinoamericana y las experiencias de intercambio estudiantil y docente.

c) Horizontalización de su estructura académica: Sin entrar en la historia institucional particular y la inercia de las estructuras académicas, a los efectos de la ampliación de las propuestas y de propiciar la mayor participación y compromiso de sus integrantes, es altamente conveniente horizontalizar la vieja estructura de cátedra, conformando equipos de trabajo docente inclusivos, más amplios, y con responsabilidades menos segmentadas y más solidarias entre todos, a fin de garantizar procesos educativos basados en la corresponsabilidad.

d) Cobertura territorial armónica, escalonada y articulada: Debe migrarse desde el paradigma de generar las propuestas desde el potencial (disponibilidad docente y de infraestructura) al de las necesidades de la región, en planes de transformación de las estructuras ordenándolas al objeto. Es necesario poner en valor todas las modalidades de estudio actuales para mejorar la cobertura territorial, especialmente dirigida a formar los profesionales que requiere el desarrollo endógeno de los pueblos y ciudades de la amplia geografía argentina. La territorialización de Tecnicaturas, Ciclos básicos por áreas del conocimiento, Ciclos de Licenciatura y Modalidades de Educación Semipresencial con tutorías, son algunas de ellas. Debería promoverse la creación de Centros Regionales de Educación Superior en todas las provincias o regiones con financiamiento asegurado, apoyado en sistemas de 
tutorías, con currículo flexible, y una propuesta educativa que no signifique replicar carreras, sino responder a las inquietudes y necesidades de la producción regional, con pertinencia y responsabilidad social.

e) Desarrollo de nuevas propuestas articuladas intra e inter institucionalmente: Es conveniente que las nuevas ofertas sean pensadas en forma articulada, desde los recursos docentes disponibles en las distintas unidades académicas de cada Universidad, como entre Universidades públicas que se complementen y compartan solidariamente las propuestas.

f) Formación integral y solidaria de sus integrantes: Es necesario avanzar concretamente en incorporar a la formación disciplinaria, contenidos y prácticas centradas en formación integral en valores, como la solidaridad y el compromiso social. Es importante recuperar las experiencias de cada Universidad en prácticas sociales preprofesionales y proponer esta formación integral como transversal y obligatoria dentro de modalidades flexibles de amplio espectro. Esto es, asumir con responsabilidad el compromiso social que significa ser parte de la Universidad Argentina Pública y Gratuita.

\section{III.- Primera etapa: Adquisición de capacidades de planificación en los CPRES para la Expansión del Sistema.}

La gran expansión del sistema de educación superior que ocurrió en Argentina en los últimos veinticinco años, se concretó a través de dos vertientes, el crecimiento de la matrícula y la expansión institucional. En cuanto a esta última, al crecimiento del número de instituciones, a la creación de universidades públicas y privadas, se suma la expansión territorial de las instituciones existentes, por medio de la creación de sedes, subsedes, extensiones áulicas y centros de apoyo para programas de educación a distancia.

Hasta los años noventa, el crecimiento por expansión de la matrícula fue neto: más alumnos en las carreras ya existentes, y también indirecto, por la creación de nuevas carreras a partir de la recuperación de la democracia. A partir de los años noventa, en cambio, el incremento de la matrícula empezó a estar más ligado a la creación de nuevas opciones para los estudios universitarios en localidades que tradicionalmente 
no contaban con esas ofertas, ya sea por creación de nuevas instituciones (esto especialmente en el caso de las nuevas universidades nacionales, ya que las privadas nuevas no se asientan en sitios sin oferta universitaria previa) o por extensiones de las preexistentes. El crecimiento de la matrícula empezó a ser la respuesta a una mayor distribución territorial de la oferta universitaria. Un ejemplo trasparente $y$ de importante dimensión se puede encontrar en las nuevas universidades del Conurbano Bonaerense creadas durante los años noventa; entre el 2002 y el 2008, cuando estas universidades ya tenían su oferta de formación estabilizada, tuvieron un crecimiento promedio interanual de la matrícula del $15,5 \%$ mientras que, para el mismo período, el de las universidades tradicionales de la región (UBA, UNLP y UNLZ) fue de apenas el 2,4\%; la matrícula de estas nuevas universidades llegó en 2008 a 79.037 alumnos sin que eso significara una disminución en la matrícula de las universidades tradicionales, que alcanzó 429.718. En todo caso la mínima perdida de matrícula de las universidades tradicionales se ha dado a favor de las nuevas universidades privadas de la Ciudad de Buenos Aires, y no por el desarrollo de las nuevas universidades nacionales del Conurbano. Pero también es destacable la creación de nuevas universidades públicas en regiones escasamente cubiertas de las provincias de Córdoba y Buenos Aires.

Se trata de un fenómeno generalizado y que también puede observarse en otros países de la región (Brasil, Venezuela, Colombia, Cuba) en los que existe una demanda de regionalización de la educación superior y, al mismo tiempo, políticas públicas que van al encuentro de esas demandas. La tendencia es hacia la vecinalización de la oferta universitaria ya sea con el objetivo de la desconcentración o de la universalización.

Expuestas así las cosas, en la situación actual de Argentina, con crecimiento sostenido y con políticas públicas que reivindican el rol promotor y planificador del Estado, la cuestión de la regionalización y desconcentración del sistema exige una planificación que, por un lado, sistematice y organice los esfuerzos del Estado, del sistema y los actores locales y, por otro, atienda la demanda de ampliar la cobertura geográfica de la educación superior contribuyendo al objetivo de ampliar los niveles de democratización y contribuir a la formación de más y mejores graduados de acuerdo con las necesidades del país, de su desarrollo integral y de las regiones. 
El Consejo Interuniversitario Nacional ha llamado la atención sobre la necesidad de buscar una alternativa que permita superar la atención de estas demandas únicamente por la vía de la creación de nuevas universidades, cuya consolidación implica mucho tiempo y un esfuerzo en el que, mientras se construye lo nuevo, se fragmenta a veces traumáticamente, siempre de manera menos eficiente, lo existente. En ese marco propuso "la generación de un Programa de Cooperación y Articulación Universitaria Nacional que utilice y optimice los recursos institucionales existentes, tanto para el sistema universitario público, como en las distintas regiones, a efectos de extender una oferta integral en los aspectos que así lo requieran en las zonas donde se revele la necesidad de atenderlo, a través de un política ordenada y cooperativa" (Acuerdo Plenario $N^{\circ} 629 / 07$ ).

Una política integral de cobertura territorial debe aprovechar las experiencias de las universidades, tomando lo mejor de la variedad de tipologías que produjeron las distintas estrategias de expansión geográfica instrumentadas por las instituciones:

a) Creación de sedes propias, extensiones áulicas, centros universitarios, así como de nuevos programas por parte de instituciones preexistentes con escasa cobertura en el territorio natural de desenvolvimiento.

b) Desarrollo de sistemas regionales o nacionales de educación a distancia, semipresencial o de cursado intensivo.

c) Articulación de carreras con Instituciones de Educación Superior (IES).

d) Radicación de carreras universitarias en IES, en instituciones educativas de otros niveles.

e) Asociación con otras universidades.

f) Asociación con organismos públicos.

g) Asociación con organizaciones no estatales (fuera del campo educativo)

Pero, por sobre todo, esta política de ocupación del territorio debe atender a las oportunidades que, a la hora de desconcentrar las propuestas de educación superior, ofrecen las Tecnologías de la Información y la Comunicación y su aplicación a la enseñanza. Se debe impulsar una política que promueva el diseño de espacios locales de formación superior bimodal, es decir, constituidos en una concepción en que la institucionalidad se constituya mediante una articulación estrecha entre la presencialidad y la utilización de las TICs. 
El Programa prevé la extensión de la cobertura territorial de la educación superior aprovechando las capacidades existentes en ambos subsistemas, Universidades e Instituciones de Educación Superior. Se propone transformar las experiencias dispersas y deficientes de expansión geográfica en un ciclo virtuoso en el que el sistema llegue a más personas pero con calidad y pertinencia, es decir, priorizando las áreas de formación más necesarias para desarrollo integral de la sociedad y en las que se verifican vacancias nacionales, regionales o locales.

El Programa pretende dar una respuesta a la creciente necesidad de educación superior superando las alternativas de fragmentación del sistema, de creación de universidades sin planificación o la proliferación de ofertas de acuerdo con una dinámica de mercado basada solamente en un seguidismo ciego de la demanda más obvia.

La modalidad que se proyecta para esto es la de implementar múltiples acciones, entre ellas la creación de Centros Regionales de Educación Superior (C.R.E.S.) desarrollados a partir de las más modernas estrategias pedagógicas y pensados desde la utilización plena de los recursos que ofrecen las TICs.

Los C.R.E.S. (cuyas características definitivas serán uno de los primeros productos cooperativos de este programa), se postulan como unidades institucionales para el desarrollo de actividad académica integral, la atención de necesidades locales y subregionales de formación en distintos niveles. Se los piensa localizados en puntos geográficos determinados de acuerdo con prioridades regionales para ampliar la cobertura del sistema de educación superior, gestionados cooperativamente por instituciones del sistema de educación superior según sea pertinente. La implantación y actividad de los Centros incluirá un plan de desarrollo para el despliegue progresivo y planificado de sus actividades y la formación de recursos humanos académicos necesarios para su funcionamiento y consolidación.

La propuesta apunta a que cada uno de estos Centros sea una herramienta en los distintos CPRES para atender las demandas y necesidades sociales de manera dinámica, y determinando prioridades, mediante el análisis de las demandas y 
necesidades sociales, y a través de consensos construidos con los actores regionales y locales.

En los últimos dos años se han creado siete nuevas universidades nacionales que ya están en distintas etapas de su implementación y puesta en marcha. Estas nuevas instituciones implican la solución de expectativas de formación universitaria a nivel local mediante una alternativa que exige un gran esfuerzo administrativo, académico y financiero concentrado en poco tiempo, frente a otras alternativas posibles y más graduales. El caso es que hay proyectos de creación de otras universidades públicas en distintas etapas de tratamiento. Seguramente una rápida respuesta por la vía del Programa de Expansión podrá dar satisfacción a las expectativas que impulsan esos proyectos en un marco de participación y planificación que involucre a los distintos autores.

\section{IV.- Fines y Propósitos del Programa de Expansión de la Educación Superior}

La finalidad es incrementar las oportunidades de acceso, permanencia y egreso a la educación superior extendiendo la cobertura territorial para la atención de necesidades y demandas de formación superior en orden al desarrollo integral de regiones y localidades.

Los propósitos estratégicos son:

- Garantizar que la expansión del sistema de educación superior responda a criterios de pertinencia y de función social, superando la lógica del mercado.

- Institucionalizar un instrumento de planificación para el desarrollo de la educación superior capaz de identificar, procesar y encauzar la demanda en función de las necesidades sociales, establecer prioridades y concertar la coordinación de capacidades y recursos de las instituciones del sistema, de las provincias, municipios y actores regionales y locales.

- Definir modelos de evaluación de la calidad para los centros regionales de educación superior y las subsedes, concertando criterios institucionales y pedagógicos mediante el ejercicio de la responsabilidad conjunta de las instituciones y actores regionales. 
- Articular el sistema de educación superior con los demás niveles del sistema educativo, a nivel regional y nacional.

Los objetivos son:

- Institucionalizar prácticas de planeamiento conjunto y cooperativo entre las universidades y las jurisdicciones a nivel regional y del sistema.

- Asegurar el acceso a la educación superior como reconocimiento de derechos a partir de la ampliación de la cobertura territorial y de una oferta educativa pertinente, esto es, fundada en la necesidad y demanda social.

- Mejorar la calidad de la formación superior, en general y especialmente en las áreas prioritarias.

- Atender a la formación académica y profesional en áreas de vacancia regional.

- Incrementar la efectividad de los procesos de entre carreras, instituciones y subsistemas de Educación Superior.

- Aumentar el impacto del Sistema de Educación Superior en el desarrollo regional y local.

- Mejorar la vinculación y asociación de las universidades con municipios y organizaciones locales.

\section{V.- Propuesta de Instrumentos de Expansión}

Son distintas variantes de un Programa que permita opciones de abordaje acordes a la diversidad institucional, que deben cumplir con el Protocolo de Pertinencia de la Propuesta en función de la demanda y necesidad social, por desarrollar en la SPU. Las puede haber de Expansión Territorial como de Respuesta a la demanda y necesidades sociales insatisfechas. Por ejemplo:

- Sedes Universitarias Públicas Asociadas (Sedes convenidas entre Universidades y Gobiernos Provinciales y/o Municipales). Los alumnos y los docentes tienen los mismos derechos que en las Universidades Públicas. 
- Expansión territorial de las instituciones universitarias preexistentes en sus territorios naturales.

- Creación de Centros Regionales de Educación Superior (CRES)

- Diversificación de la Oferta de ES Pública y Gratuita para la Inclusión (Nuevas Carreras articuladas, Nuevas Modalidades de cursado que permitan trabajar y estudiar, Ofertas Semipresenciales, Ciclos Básicos por Áreas de conocimiento, Tecnicaturas Superiores, etc.)

- Creación de nuevas instituciones universitarias

VI. Antecedentes para la construcción de una alternativa de Expansión de la Educación Superior

\section{a- Marco de Lineamientos y Objetivos Nacionales Estratégicos Ordenadores:}

Son los establecidos por las visiones del Plan del Ministerio de Educación; el Plan de Ciencia y Tecnología del Ministerio de Ciencia, Tecnología e Innovación Productiva; la Visión Estratégica del Ordenamiento Territorial del Ministerio de Planificación Federal, Inversión Pública y Servicios; y el Plan Estratégico Agroalimentario del Ministerio de Agricultura, Ganadería y Pesca, Plan Industrial 2020, etc.

b- Confección del Mapa de la Oferta de ES de la Argentina:

Georreferenciar la oferta de ES pública y privada oficializada en la DNGU en el territorio, en una versión agrupada en grandes áreas (en diferentes colores) y en otra por carreras afines (Tarea de la Dirección Nacional de Planeamiento y Coordinación Universitaria de la SPU y los CPRES, con la colaboración del CIN y del CRUP).

\section{c- Confección del Mapa de la Cobertura Institucional de ES Argentina:}

Georreferenciar la presencia física (sedes, subsedes, delegaciones, centros regionales, etc.) de las IES públicas y privadas (Tarea de la Dirección Nacional de Planeamiento y Coordinación Universitaria de la SPU y los CPRES, con la colaboración del CIN y del CRUP).

VII.- Radicación de Centros Regionales de Educación Superior y Fortalecimiento de los existentes

La primera etapa del Programa de Expansión de la Educación Superior la constituyó la instancia de diagnóstico y evaluación cuyos resultados permiten contar en los 
CPRES con capacidad de planificación y análisis de las propuestas y de las necesidades; en el sistema, con información más completa sobre la oferta real según su distribución geográfica y sobre las lógicas de la expansión institucional, mayormente regidas por el mercado.

En este contexto se destacan dos aspectos a tener en cuenta en la segunda etapa del programa: por un lado, superar la lógica de mercado logrando una oferta más equilibrada con las necesidades y las prioridades de la sociedad; por otra parte, se constató la existencia de iniciativas de cobertura regional integral de parte de algunas universidades nacionales, no aranceladas $y$ otras realizadas cooperativamente entre municipios, universidades nacionales $y$, en un caso, la Universidad Provincial del Sudoeste de la Provincia de Buenos Aires.

De estas consideraciones surgen las dos líneas que deben caracterizar esta segunda etapa: por un lado la determinación de localidades con condiciones prioritarias para la radicación de Centros Regionales de Educación Superior y, por otro, el fortalecimiento de las redes y centros existentes con el objetivo de mejorar las condiciones de calidad y generar nuevas carreras en áreas declaradas prioritarias que sin el aporte estatal no pudieron ser cubiertas.

\subsubsection{Competencias}

\subsubsection{Las competencias de los graduados}

Extraído de Stakeholders' satisfaction with Civil Engineering Graduates

La competencia de los egresados es la capacidad, las habilidades, las aptitudes logradas por los graduados como resultado de su educación. Durante el proceso educativo, estas características son evaluadas por exámenes y actividades prácticas de modo tal que los graduados generan expedientes académicos y certificados indicativos de sus competencias.

Después de completar su educación, los graduados deben utilizar sus competencias para aplicarlas en sus trabajos. El éxito de los egresados en los lugares de trabajo y en las comunidades resulta determinado por sus niveles de competencia. Los niveles de competencias son verificados por los empleadores, clientes y 
comunidades donde trabajan los graduados. Por lo tanto, la medición de las competencias de los graduados podría llevarse a cabo basándose en la información de los empleadores, los clientes de los graduados. Sin embargo, como no hay método uniforme alguno en orden a evaluar o medir la competencia de los egresados en los lugares de trabajo, deben establecerse los factores de competencia.

Aunque hay muchas clases de competencias a ser logradas por los graduados, estas pueden categorizarse en tres factores: conocimientos, habilidades y actitudes. Eunok y Janghyun (2005), afirmaron que la nueva currícula en la enseñanza debía concentrarse en fomentar habilidades prácticas para satisfacer las necesidades técnicas e industriales. Jordan et al (2005) mostraron que lo que era importante que se lograra entre los resultados de los cursos, se hallaban la mejora de los conocimientos y las actitudes. Massa, Masciadrelli y Mullett (2005) afirmaron que la educación debía preparar a sus estudiantes con conocimientos, habilidades y actitudes necesarias para tener éxito en un ambiente de trabajo. Pomales-García, Liu y Soto (2006) llegaron a la conclusión de que la literatura existente sobre excelencia en la enseñanza, debía subrayar la importancia de conocimientos, habilidades y actitudes esperadas por los interesados (clientes, empleadores).

El conocimiento es la comprensión teórica de un tema adquirido por los graduados a través de la educación con la capacidad de utilizarlo para un propósito específico (Conocimiento, 2008). Es útil para: analizar, aprender, asociar, razonar, comprender y comunicar problemas en los lugares de trabajo.

La habilidad es la capacidad de los egresados para llevar a cabo trabajos predeterminados con el mínimo gasto de tiempo o energía (Habilidades, 2008). Es útil para ejecutar tareas en el lugar de trabajo.

La actitud es un estado mental o juicio de los graduados que los conecta con los problemas de su trabajo (Actitud Propositiva, 2008). El juicio es el resultado del aprendizaje observacional de por parte de los graduados a partir de su entorno (Actitud en Psicología, 2008). La actitud es útil en tanto se erige como respaldo para que las tareas en los lugares de trabajo resulten exitosas. 
Las competencias de los graduados que incluyen esos tres factores deben ser una base de investigación tanto para la competencia existente de enseñanza como de la competencia esperada por parte de los interesados (clientes, empleadores).

\subsubsection{2 ¿Qué es lo que verdaderamente esperamos de nuestras escuelas?}

El planteo de esta cuestión lleva a diferentes preguntas, más importantes que la pregunta de calificar. El punto es, ¿cómo debe definir una escuela su propósito y luego llevarlo a cabo? Se ofrecerá una solución a esta pregunta, pero debe enfatizarse que depende de cada escuela responder esto por sí misma.

Se sostiene que verdaderamente se espera de las escuelas que proporcionen educación en cuatro categorías:

1. CONOCIMIENTO: permite entender lo que se aprende en relación con lo que ya se sabe. El conocimiento proporciona la habilidad para generalizar desde las experiencias. Con conocimiento es posible acumular 30 años de experiencias en lugar de sólo un año repetido 30 veces.

2. CONOCIMIENTO PRÁCTICO: permite hacer. El conocimiento práctico utiliza la historia meramente para comprensión. Permite poner el conocimiento a trabajar.

3. BUEN JUICIO: es la habilidad para decidir lo que es importante y lo que no lo es. El buen juicio le permite a las personas establecer prioridades por sí mismas.

4. CARACTER: es una combinación de Conocimiento, Habilidad y Buen Juicio, acoplada con motivación. Se reconoce el desarrollo del carácter por ciertos rasgos entre los que se pueden citar:

$\begin{array}{lll}\text { Honestidad } & \text { Iniciativa } & \text { Curiosidad } \\ \text { Veracidad } & \text { Integridad } & \text { Cooperatividad } \\ \text { Habilidad de trabajar solo } & \text { Habilidad de trabajar en grupo } & \text { Iniciativa } \\ & & \text { Autoestima }\end{array}$

Para la mayoría de las escuelas, la lista de conocimientos que se espera que los estudiantes adquieran, está compuesta por las directivas provenientes de la autoridad central (la fuente de fondos o acreditaciones) y lo que la escuela decide hacer por sí misma. La lista de conocimientos prácticos normalmente es menos específica, salvo en las escuelas de profesiones u oficios. En general, las autoridades no prestan atención al buen juicio o al carácter. Por otra parte, cuando la Secretaria de Trabajo de EE.UU. designó una comisión de Industria para determinar 
lo que se requiere de los graduados de las escuelas, propusieron su propia lista. Identificaron cinco competencias y tres destrezas y cualidades personales básicas necesarias para un desempeño de trabajo sólido.

En general, sólo las escuelas de nivel primario parecen ser las que más atención prestan al desarrollo del carácter. A cada uno de los siguientes niveles los docentes parecen querer que algún otro se preocupe por esta característica. En una Universidad, sólo los entrenadores deportivos parecen preocuparse por el desarrollo del carácter.

En cuanto al desarrollo del buen juicio, muchos educadores no lo han desarrollado para sí mismos, y otros han renunciado a la idea de enseñarlo a los educandos.

El desarrollo del buen juicio y el carácter es manejado mejor si se tienen estudiantes que participan en actividades creativas y de equipo. En tal situación, aprenden a establecer prioridades, a trabajar juntos y a desarrollar las habilidades sociales requeridas en una sociedad donde el trabajo en equipo es esencial para el éxito. Bajo estas circunstancias los estudiantes necesitan a un entrenador -o maestro particular- más que a un docente.

\subsubsection{Conocimiento práctico para el puesto de trabajo}

Los conocimientos prácticos identificados por la CSTLDN ${ }^{1}$. Se compone de cinco competencias y tres destrezas y cualidades personales básicas que se necesitan para un desempeño de trabajo sólido. Estos incluyen:

COMPETENCIAS -que los trabajadores eficientes pueden usar productivamente-:

- Recursos - asignación de tiempo, dinero, materiales, espacio y personal-;

- Destrezas interpersonales -trabajo en equipos, enseñanza a otros, servicio a clientes, liderazgo, negociación, y lograr un buen ambiente de trabajo con personas de entornos culturales diversos-;

- Información -adquisición y evaluación de datos, organización y mantenimiento de archivos, interpretación, comunicación y uso de computadoras para procesar información-;

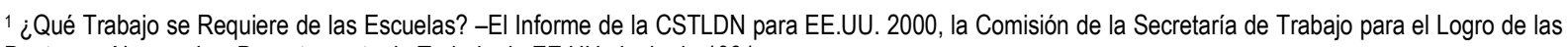
Destrezas Necesarias, Departamento de Trabajo de EE.UU., junio de 1991. 
- Sistemas -comprensión de sistemas sociales, organizacionales y tecnológicos, seguimiento y corrección del desempeño, y diseño o mejora de sistemas-;

- Tecnología -selección de equipo y herramientas, aplicación de tecnología a tareas específicas y mantenimiento y reparación de tecnologías-.

DESTREZAS Y CUALIDADES PERSONALES BASICAS -competencias requeridas-:

- Destrezas básicas -lectura, escritura, aritmética y matemática, expresión y saber escuchar / prestar atención-.

- Destrezas del pensamiento -pensamiento creativo, toma de decisiones, resolución de problemas, ver cosas con la imaginación, saber cómo aprender autónomamente, y razonamiento-.

- Cualidades personales -responsabilidad individual, autoestima, sociabilidad, autogestión e integridad-.

En Connecticut, donde hay varios consejos de administración de calidad que están activamente adaptando administración de calidad a las escuelas, se ha hecho un esfuerzo bastante completo para identificar los elementos del conocimiento que todos los estudiantes deben adquirir. Las metas están expresadas sin una clara distinción entre el conocimiento propiamente dicho y el conocimiento práctico, pero todo parece indicar que han hecho un buen comienzo ${ }^{2}$. El listado está en un proceso de revisión y mejora por los representantes de una amplia gama de sectores de la comunidad.

Hay una dificultad en establecer las metas y objetivos de las escuelas debido a la rapidez con la que los cambios han estado ocurriendo en la sociedad. El profesor Ron J. McBeath, del Colegio Estatal San José ha diseñado el siguiente cuadro que resulta de suma utilidad para entender el motivo por el cual las personas de diferentes edades y en diferentes posiciones en la sociedad tienen ideas tan diferentes sobre lo que las escuelas deben hacer.

${ }^{2}$ Centro de Aprendizajes Elementales de Connecticut, adoptado por el Consejo Estatal de Educación de Connecticut, enero de 1987. 


\section{Cuadro 1. Tres Etapas}

En Producción

\begin{tabular}{|l|l|l|}
\hline \multicolumn{1}{|c|}{ Agrícola } & \multicolumn{1}{c|}{ Industrial } & \multicolumn{1}{c|}{ Información } \\
\hline Rueda & Motor & Motor de propulsión a reacción \\
\hline Mano de obra & Máquinas & Mecatrónica (máquinas electrónicas) \\
\hline "Industria" aldeana & Mecanización & Automatización \\
\hline Exploración & Explotación & Conservación \\
\hline Pueblo & Ciudad & Mercado global \\
\hline
\end{tabular}

En Ciencia

\begin{tabular}{|l|l|l|}
\hline \multicolumn{1}{|c|}{ Clásica } & Relativismo Cuántico & \multicolumn{1}{c|}{ Información } \\
\hline Certezas & Confusión & Probabilidades \\
\hline Absolutos & Absolutos Relativos & Relativos \\
\hline Sistemas cerrados & Sistemas abiertos & Sistemas orgánicos \\
\hline
\end{tabular}

En Educación

\begin{tabular}{|l|l|l|}
\hline \multicolumn{1}{|c|}{ Hacer Cosas Para } & \multicolumn{1}{c|}{ Hacer Cosas Por } & \multicolumn{1}{c|}{ Hacer Cosas Con } \\
\hline Autocracia & Dejar hacer & Democracia \\
\hline Dominación Docente & Permisividad & Cuestionamientos \\
\hline Énfasis en el sujeto & Énfasis en el método & Interdisciplinariedad \\
\hline Respuesta única & Respuesta variada & Destreza en la respuesta \\
\hline Memoria repetitiva & Expresión libre & Creatividad \\
\hline Orientado al producto & Orientado al proceso & Desempeño \\
\hline Mente activa & Mente reactiva & Mente Transactiva \\
\hline Motivo extrínseco & Motivo extrínseco & Motivación intrínseca \\
\hline Agrupamiento por edad & Agrupamiento por normas & Agrupamiento por habilidades \\
\hline Enseñanza de la clase & Enseñanza del grupo & Estudio independiente \\
\hline Acceso limitado & Acceso aleatorio & Acceso sistemático \\
\hline Ayudas en la instrucción & Audiovisuales & Tecnología educativa \\
\hline Pensamiento convergente & Pensamiento divergente & Ambos hemisferios cerebrales \\
\hline Competitivo & Cooperativa & Aventura \\
\hline Dirigido a lo interno & Dirigido a otros & Auto Realización \\
\hline Dependiente & Independiente & Interdependiente \\
\hline
\end{tabular}

En general las personas en posiciones con responsabilidades en la sociedad, que significa que son normalmente los mayores, tienden a pensar en la educación en términos de la columna izquierda. Los docentes jóvenes muy probablemente se ubicarán en la columna correcta del cuadro del Profesor McBeath. Por consiguiente, si se llega a un consenso entre los que pagan por la educación pública, es necesario desarrollar una declaración de propósitos para las escuelas, de la cual pueden fluir soluciones a problemas, que sean aceptables para el mayor número de clientes. La administración de calidad da una mayor confianza en lograr esto, debido a que mediante la administración de calidad es más fácil llevar "la voz del cliente" al diseño de la experiencia educativa. 
En la medida en que los docentes y los estudiantes se familiarizan con la administración de calidad, ellos serán capaces de moverse a la cuarta columna que está a la derecha de las tres columnas desarrolladas por el Profesor McBeath.

Los estudiantes de la escuela secundaria de la Montaña Edgecumbe, después de considerar sus propias motivaciones y la manera en que ellos quieren actuar recíprocamente con sus docentes, han desarrollado el siguiente cuadro:

Posibles Roles de Docentes y Estudiantes

$\begin{array}{lllll}\text { Docentes } & \text { Hacen Para } & \text { Hacen Por } & \text { Hacen Con } & \text { Hacen Posible } \\ \text { Estudiantes } & \text { Sin opción } & \text { Cautivo } & \text { Dependiente } & \text { Independiente } \\ & \text { Cautivo } & \text { Pasivo } & \text { Aceptación } & \text { Investigador } \\ & \text { Antagonista } & \text { Dependiente } & \text { Seguidor } & \text { Buscador de Conocimiento } \\ & \text { ¡Déjenme Salir! } & \text { Estoy Bien } & \text { Está Bien } & \text { Alegría en el Aprendizaje }\end{array}$

Una característica importante del proceso educativo, en la medida en que se produce un movimiento de izquierda a derecha en el cuadro anterior, es el desarrollo de una autonomía creciente por parte del estudiante. Esta es una de las cualidades requeridas en el informe de la CSTLDN y que tiende a ser destruida por la aplicación rigurosa de pruebas normalizadas.

\subsubsection{Competencias proyecto Tuning-Europa, Tuning-America Latina}

El Proyecto Tuning, como se le conoce actualmente, tuvo sus comienzos y empezó a desarrollarse dentro del amplio contexto de reflexión sobre educación superior que se ha impuesto como consecuencia del acelerado ritmo de cambio de la sociedad. El proyecto está especialmente en el proceso de La Sorbona-Bolonia-Praga-Berlín, a través del cual los políticos aspiran a crear un área de educación superior integrada en Europa en el trasfondo de un área económica europea. La necesidad de compatibilidad, comparabilidad y competitividad de la educación superior en Europa ha surgido de las necesidades de los estudiantes, cuya creciente movilidad requiere información fiable y objetiva sobre la oferta de programas educativos. Además de esto, los (futuros) empleadores dentro (y fuera) de Europa exigirán información confiable sobre lo que significan en la práctica una capacitación o un título determinado. Un área social y económica europea tiene que ir paralela a un área de educación superior. 
Una de las razones fundamentales para la creación del proyecto Tuning fue la necesidad de implementar a nivel de las instituciones universitarias el proceso que siguió a la Declaración de Bolonia de 1999, utilizando las experiencias acumuladas en los programas ERASMUS y SOCRATES desde 1987. A este respecto, reviste especial importancia el Sistema Europeo de Transferencia y Acumulación de Créditos (ECTS). El proyecto se orienta hacia competencias genéricas y específicas a cada área temática de los graduados de primero y segundo ciclo. Aún más, el proyecto tiene un impacto directo en el reconocimiento académico, garantía y control de calidad, compatibilidad de los programas de estudio a nivel europeo, aprendizaje a distancia y aprendizaje permanente. En otras palabras, Tuning aborda todos los temas mencionados en el Comunicado de Praga (Prague Communiqué) de Junio del 2001 y los enlaza como partes de un todo unificado. Se espera que a mediano y largo plazo los resultados del proyecto tengan su impacto en la mayoría, y de ser posible en todos, las instituciones y programas de educación superior europeas en general y en las estructuras y programas educativos en particular.

\subsubsection{Calidad}

Dado que el trabajo ha evaluado las condiciones de calidad de los CRES, especialmente la de sus graduados, es adecuado comenzar con una conceptualización del término calidad.

Es habitual escuchar a las empresas e Instituciones hacer una referencia distintiva de su producto o servicio, asociándola a calidad. De esta forma se pretende diferenciar el producto o servicio que se ofrece, distinguiéndolo del resto.

La identificación de los elementos que componen la identidad característica de un producto o servicio es bastante subjetiva, cada vez que se lo analiza desde la aproximación de la percepción que el individuo tiene de la calidad; sin embargo existen en orden académico ciertos elementos objetivos que permiten su medición.

Tradicionalmente el control de la calidad ha sido considerado en el ámbito de producción como una medida para anticiparse a los errores o defectos de 
fabricación. En los 80 se consideraba como interpretaciones de calidad los atributos del producto, los fines utilitarios que se persiguen con él, la satisfacción de las necesidades, su relación de costo, la existencia del mercado y la oportunidad del servicio.

De esta manera, el valor para el cliente estaba determinado por la relación entre los resultados obtenidos y la calidad del proceso para obtenerlos en relación al precio el costo de acceder al servicio:

\section{Valor \\ Resultados + Calidad del proceso \\ Precio + Costo de acceder al servicio}

Fuente: Cottle, D. (1991). El servicio centrado en el cliente. Editorial Díaz de Santos. Madrid. España

No obstante, hoy en día la alta competitividad y la cada vez más dificultosa diferenciación de los productos y servicios han transformado a la gestión de la calidad en una herramienta estratégica para competir.

Se considera como elemento determinante la satisfacción del cliente, así la calidad tiene que ver con el hecho que los usuarios o consumidores queden satisfechos con el producto o servicio, por lo tanto, el concepto de calidad va más allá que el simple cumplimiento de ciertas especificaciones, puesto que esto no asegura que el cliente esté satisfecho. La calidad no es un status, sino un proceso de mejora continua.

Es decir, la calidad desde el punto de vista del cliente está relacionada con el grado en que sus expectativas son satisfechas teniendo en cuenta el precio que está dispuesto a pagar o pagó. 


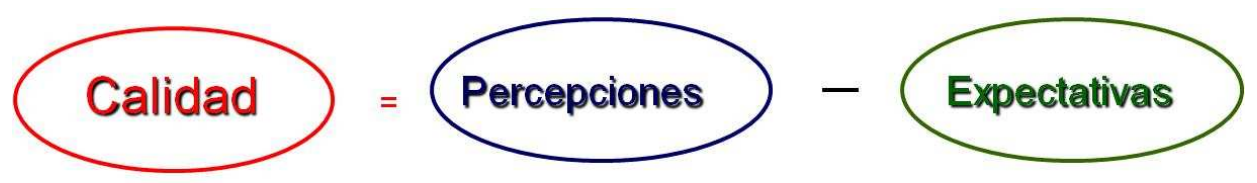

Satisfacción del cliente

\section{Suministros}

al cliente

Expectativas

del cliente

Fuente: Cottle, D. (1991). El servicio centrado en el cliente. Editorial Díaz de Santos. Madrid. España

\subsubsection{1 Índice Estadounidense de Satisfacción del Cliente (IESC)}

Un marco que provee un análisis de la satisfacción del cliente es el Índice Estadounidense de Satisfacción del Cliente (IESC), el cual sirve como un indicador económico de la calidad del rendimiento económico y a la vez brinda información para aplicaciones de negocios. Es una herramienta comercial estratégica para ganar ventaja competitiva y crear valor para el accionista a través de las inversiones en calidad y satisfacción del cliente

El modelo del IESC consiste de un conjunto de ecuaciones causales que vinculan las expectativas del cliente, la calidad percibida, y el valor percibido que determinan la satisfacción del cliente (IESC). A su vez, la satisfacción se vincula con las consecuencias determinadas por las quejas y la lealtad del cliente -medido por la tolerancia del precio y la retención del cliente-. Para la mayoría de las empresas, los clientes que regresan son los mayores contribuyentes para las ganancias. 


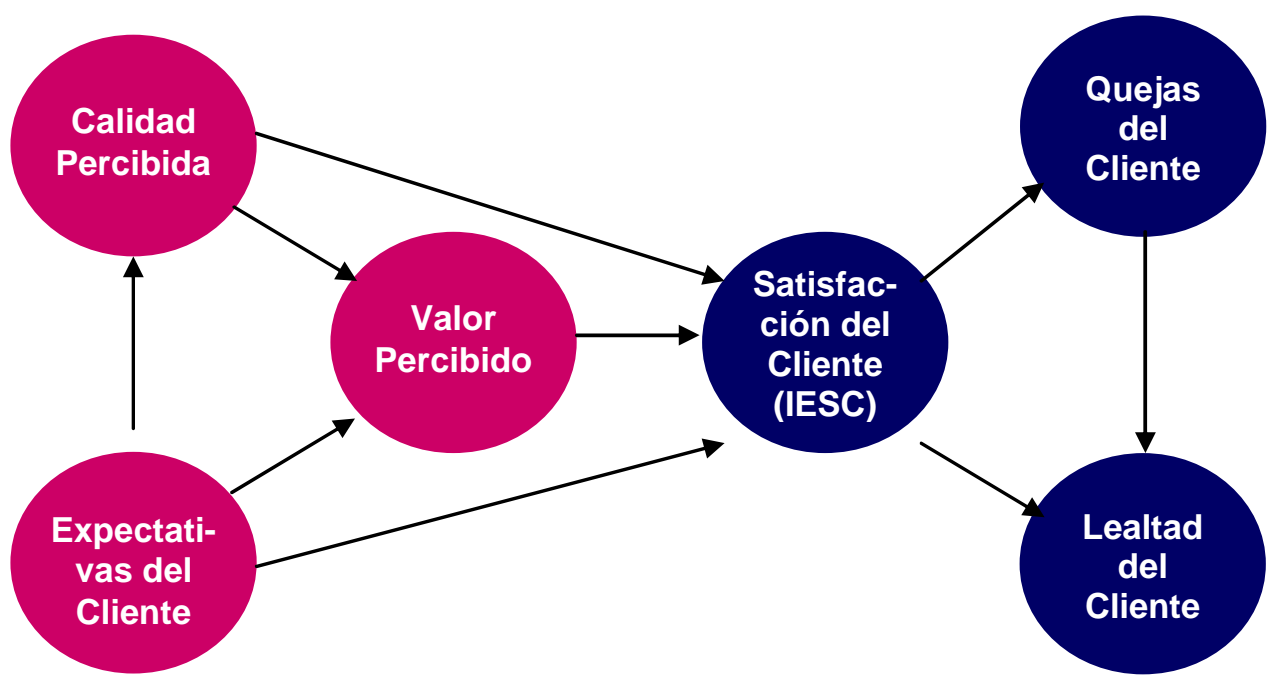

A continuación se detallan los principales conceptos incluidos para el análisis del IESC:

\section{Expectativas del Cliente}

Las expectativas combinan las experiencias del cliente con un producto o servicio y la información sobre éste a través de los medios de comunicación, publicidad, vendedores, y por recomendaciones de otros clientes. Las expectativas del cliente influyen en la evaluación de la calidad y predicen (desde la perspectiva de precompra de cliente) de qué modo el producto o el servicio se desempeñará.

\section{Calidad percibida}

La calidad percibida es medida a través de tres puntos:

- calidad global,

- confiabilidad

- hasta que punto un producto o el servicio satisface las necesidades del cliente.

En base a las mediciones realizadas por el IESC, se puede concluir que la calidad percibida demuestra tener el mayor impacto en la satisfacción del cliente.

\section{Valor percibido}

El valor percibido es medido a través de dos puntos:

- precio total en función de la calidad

- calidad global en función del precio 
En el modelo del IESC, el valor percibido influye directamente en el IESC, y es afectado por las expectativas y la calidad percibida. Aunque el valor percibido es de gran importancia para la (primera) decisión de compra, usualmente tiene un poco menos de impacto en la satisfacción y la repetición de la compra.

\section{Quejas del Cliente}

Las quejas de los clientes son medidas como el porcentaje de consultados que informaron un problema con el producto o servicio de la empresa objeto de la medición, dentro de un período especificado. La satisfacción tiene una relación inversa con las quejas del cliente.

\section{Retención del Cliente}

La retención del cliente es medida a través de preguntas sobre la probabilidad de comprar los productos o servicios de una empresa a cada uno de los distintos precios. La satisfacción del cliente tiene un efecto positivo en la retención, pero la magnitud de ese efecto varía grandemente entre las empresas y sectores.

Otro modelo que permite analizar cuáles son los requerimientos mínimos de un segmento de clientes y qué cosas superan las expectativas del mismo es el modelo de dimensiones del producto o servicio.

La dimensión de producto básico o genérico es el satisfactor. El producto esperado es lo que mínimamente espera un cliente del producto o servicio. El producto aumentado es todo lo que el consumidor no espera y aumenta el valor para él. Y el producto potencial es todo lo que la empresa u organización puede desarrollar en el futuro con el objetivo de superar las expectativas del consumidor, diferenciarse y fidelizarlo. 
Dimensiones del producto

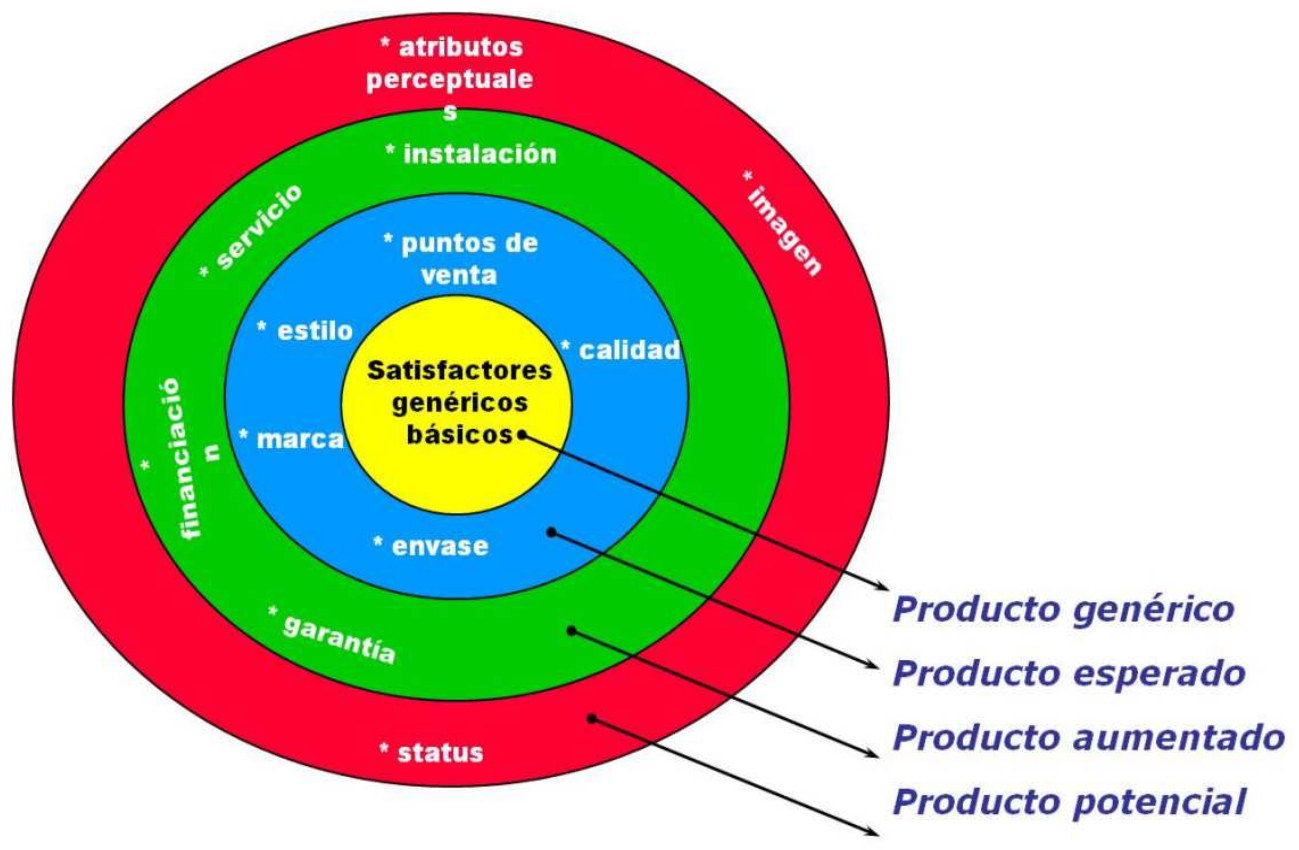

Fuente: Kotler, P. (1993). Dirección de la Mercadotecnia. Prentice Hall. México. Capítulo 16.

El modelo es una "foto" para un producto o servicio en un momento dado, pero lo que pasa con el consumidor es dinámico. Lo que en un momento sorprende al cliente pasado el tiempo puede convertirse en una expectativa mínima. Es por ello que el análisis debe actualizarse. Además están los competidores que con sus ofertas impactan en las expectativas del potencial consumidor.

También hay que considerar desarrollar en la dimensión de producto aumentado cosas que para el cliente sean valiosas, es importante tener en cuenta esto para no gastar tiempo y dinero en desarrollar atributos que el cliente no aprecia.

La satisfacción del cliente es relativa, quien juzga el nivel de satisfacción es el cliente. Queda claro analizando el modelo que es clave cumplir con los requisitos mínimos del cliente. Entendido esto surge otra cuestión: ¿cómo se va a cumplir con los requerimientos del cliente si no se conoce lo que el cliente espera?

La comprensión completa de los requisitos es un paso esencial para comenzar a mejorar la calidad. Identificar los requisitos es la clave para saber cómo trabajar en la mejora de la calidad. 


\subsubsection{Calidad en educación desde la óptica de la Institución y el alumno}

La OCDE”3(Organización para la Cooperación y el Desarrollo Económicos) en 1995 definió la educación de calidad como aquella que "asegura a todos los jóvenes la adquisición de los conocimientos, capacidades, destrezas y actitudes necesarias para equiparlos para la vida adulta".

Otra definición sería: "La educación de calidad es la que promueve el progreso de sus estudiantes en una amplia gama de logros intelectuales, sociales, morales y emocionales, teniendo en cuenta su nivel socioeconómico, su medio familiar y su aprendizaje previo. Un sistema educativo eficaz es el que maximiza la capacidad de las escuelas para alcanzar esos resultados". (J. Mortimore)

La calidad de las Instituciones educativas se debe definir y visualizar en un sentido integral, adoptando un enfoque de totalidad y globalidad de las mismas; en donde todos y cada uno de los elementos que conforman un centro educativo son considerados como susceptibles de estudio y análisis bajo criterios definidos de calidad.

En el análisis de la calidad deben considerarse, por lo tanto, todos los componentes que intervienen en el proceso educativo y sus mutuas relaciones y abarcar tanto los procesos como los resultados de la educación.

La calidad está determinada por la conjunción de los elementos que participan en la educación de un modo dinámico y por entender que el todo es más que la suma de las partes. En este orden de ideas, la calidad es la búsqueda de un equilibrio dinámico entre dos vertientes. Por un lado, las necesidades de los sectores sociales y exigencias de los actores individualmente involucrados con las Instituciones de Educación Superior, y por otro, los objetivos y funciones de éstas. Es decir, la calidad se refiere no sólo a la mejora en la eficiencia y/o la eficacia en el logro de los productos deseados, sino también a la definición cualitativa de éstos.

${ }^{3}$ Fundada en 1961, la Organización para la Cooperación y el Desarrollo Económicos (OCDE) agrupa a 34 países miembros y su misión es promover políticas que mejoren el bienestar económico y social de las personas alrededor del mundo. 


\subsubsection{La calidad desde la esfera de los valores}

Un sistema educativo de calidad se caracteriza por su capacidad para:

- Ser accesible a todos.

- Facilitar los recursos personales, organizativos y materiales, ajustados a las necesidades de cada alumno para que todos puedan tener las oportunidades que promoverán lo más posible su progreso académico y personal.

- Promover cambio e innovación en la Institución educativa y en las aulas.

- Promover la participación activa del alumnado, tanto en el aprendizaje como en la vida de la institución, en un marco de valores donde todos se sientan respetados y valorados como personas.

- Estimular y facilitar el desarrollo y el bienestar del profesorado y de los demás profesionales de la institución educativa.

Características de las instituciones educativas eficaces

- Compromiso con normas y metas compartidas y claras. Los fines generales de la educación deben considerar las tres categorías básicas:

- la competencia académica y personal,

- la socialización de los estudiantes, y

- la formación integral.

- Búsqueda y reconocimiento de valores propios.

- Liderazgo profesional de la dirección. La actividad directiva se centra en el desarrollo de actividades de información, organización, gestión, coordinación y control. Supone una continua toma de decisiones en aspectos: administrativos y burocráticos, jefatura del personal, disciplina de los alumnos, relaciones externas, asignación de recursos, resolución de problemas.

- Estabilidad laboral y estrategias para el desarrollo del personal, acorde con las necesidades pedagógicas. Procurar el aprendizaje continuo del profesorado y la actualización de los contenidos, recursos y métodos.

- Clima de aprendizaje. La enseñanza y el aprendizaje deben constituir el centro de la organización y la actividad educativa. Se debe cuidar el 
ambiente de aprendizaje buscando el aprovechamiento del estudiante y el empleo eficiente de los tiempos de aprendizaje.

- Profesionalidad de la docencia: organización eficiente del profesorado, conocimiento claro de los propósitos por los alumnos, actividades docentes estructuradas, tratamiento de la diversidad, seguimiento de los avances de los estudiantes, uso de refuerzos positivos, claras normas de disciplina. Eficacia docente

- Expectativas elevadas sobre los alumnos y sus posibilidades, comunicación de estas expectativas, proponer desafíos intelectuales a los estudiantes

- Atención a los derechos y responsabilidades de los estudiantes, darles una cierta responsabilidad en actividades del centro, control de su trabajo, atender a su autoestima.

- Elevado nivel de implicación y apoyo del entorno familiar. Participación de la comunidad educativa.

- Apoyo activo y sustancial de la administración educativa.

\subsubsection{Definición de cliente}

En primer término cabe discutir las distintas acepciones de la palabra "cliente" para luego especificar la que se utilizará en el presente informe de investigación.

Del latín cliens, el término cliente es un término que puede tener diferentes significados, de acuerdo con la perspectiva en la que se lo analice.

En economía el concepto permite referirse a la persona que accede a un producto o servicio a partir de un pago. Existen clientes constantes, que acceden a dicho bien de forma asidua, u ocasionales, aquellos que lo hacen en un determinado momento, por una necesidad puntual.

En este contexto, el término es utilizado como sinónimo de comprador (la persona que compra el producto), usuario (la persona que usa el servicio) o consumidor (quien consume un producto o servicio). 
Cabe mencionar que los especialistas en comercialización y ventas suelen distinguir entre distintas clases de clientes. Los clientes activos son los que, en la actualidad, concretan compras de manera frecuente. Los clientes inactivos, en cambio, hace tiempo que no realizan una compra por lo que es probable que estén satisfaciendo sus necesidades con la competencia.

Por otro lado, existen los clientes satisfechos o clientes insatisfechos, de acuerdo con el tipo de resultado que haya tenido el intercambio comercial. Los clientes tienen necesidades que la empresa o el vendedor debe satisfacer. Estas necesidades generan en el individuo una serie de expectativas con respecto al producto 0 servicio. Si dichas expectativas son frustradas, es decir si las necesidades no son satisfechas, es muy probable que el cliente deje de comprar en aquel sitio o, más específicamente, el producto en cuestión.

En el ámbito del derecho, el cliente es una persona que está bajo la tutela, representación o protección de otra (como un abogado): "Mi cliente se niega a declarar". En estos casos, el abogado es el portavoz del individuo, quien dirigirá el guión de lo que el mismo deba expresar al subir al estrado y se encargará de estudiar el caso de forma que pueda conseguir, a través del uso de sus propios recursos, que la persona obtenga un resultado favorable en el veredicto del jurado.

En la Antigua Roma se conocía como cliente a esa persona que dependía de un mecenas o benefactor. De este modo, un individuo que no podía alcanzar la ciudadanía de forma legal tenía una especie de protección.

En el ámbito de la informática se conoce como cliente el equipo que utiliza los recursos que le brinda otro, que recibe el nombre de servidor; esto se realiza de forma remota.

En política, a su vez, el término hace referencia a aquel que recibe recompensas a cambio de votos o cualquier tipo de favor político. 
En el sector del arte existen diversas formas de entender el concepto. Puede ser el que encarga una obra de arte a un determinado artista y que le ofrece una suma de dinero a cambio de su trabajo (también puede recibir el nombre de comitente o mecenas); también puede referirse a aquel que compra una obra (en algunos lugares recibe el nombre de coleccionista). También puede llamarse de este modo a quien trabaja como promotor de obras de arte (a su vez, se lo puede nominar también como marchante o galerista).

En psicología, existe un tipo de terapia que se conoce como "centrada en el cliente" que sirve para tratar a una persona teniendo en cuenta sus relaciones, es decir su forma de establecer contacto con su entorno. Se trata de un tipo de terapia no directiva.

La acepción que se le da el término "cliente" en el campo de la informática es el más cercano a la intención con que se lo ha usado en el presente trabajo de investigación, complementado con la noción de satisfacción o insatisfacción respecto del recurso recibido, que proviene del área de economía.

En definitiva en el presente trabajo de investigación se denomina "cliente" al interesado (empleador), que es el receptor del producto final (el graduado) y que paga por ello a quien lo produce (la universidad) no directamente sino por vía indirecta a través de impuestos, así como lo hace el resto de la comunidad, en diferentes proporciones, y por ello resulta de suma importancia que los recursos de los contribuyentes satisfagan las necesidades de la sociedad.

Es decir, que la referencia para el diseño y definición de especificaciones que caracterizan los programas de la Educación en el nivel superior debe estar dada por las necesidades de empresas, organizaciones y la sociedad en general que conforman una demanda indirecta de los servicios educativos. Esta es una referencia obligada para la Universidad luego del Acuerdo de Bolonia, donde se explicitó la necesidad del vínculo entre la Universidad y el Mercado de Trabajo. 
La competitividad de las empresas, por caso, demanda la mejor calidad y excelencia de la educación formal a cargo de las instituciones universitarias, lo que no puede confundirse con la cantidad de títulos emitidos.

De tal manera se hace imprescindible la observación y análisis de la medida en la que el egresado está dando satisfacción al requerimiento de tales atributos, para lo cual resulta pertinente la consulta al demandante de sus servicios. En ese proceso este demandante aparece siendo cliente de la oferta universitaria, un demandante indirecto de la misma.

Los CRES, como ampliación o extensión de la Universidad, pueden coadyuvar significativamente a la optimización de la satisfacción de esa demanda aportando los frutos que posibilita una mayor proximidad con necesidades locales o regionales. Muchas veces vinculadas al desarrollo local, a la trasferencia tecnológica, a la demanda de innovaciones en la formación y desarrollo de competencias específicas, a la adecuación de las programaciones y sus cronogramas en virtud de una menor dimensión y complejidad organizativa y funcional.

\subsubsection{Calidad en educación desde el punto de vista del cliente}

A lo largo del tiempo ha ido variando la consideración de lo que resulta fundamental en la calidad. Primero fue el "producto", más tarde el "proceso", luego los "trabajadores". Actualmente la calidad total se fundamenta en la idea de la satisfacción del cliente.

Lo más importante es la satisfacción del cliente, con el costo más bajo posible. La empresa de éxito será la que identifique y satisfaga las expectativas de sus clientes. El proceso de calidad total se inicia con la detección de problemas y deficiencias y la propuesta de determinadas soluciones.

La gestión de la calidad se fundamenta en el desarrollo continuo de planes integrales, no en la ejecución de simples acciones aisladas o puntuales. La toma de decisiones se debe realizar como consecuencia de datos y evidencias, no a partir de suposiciones y opiniones. Por lo tanto es preciso evaluar. 
La calidad depende básicamente de las personas, por ello resulta fundamental atender a aspectos como:

- La participación

- El compromiso

- La implicación voluntaria

- La colaboración

- El trabajo en equipo

- La formación de las personas

- Propiciar el desarrollo/crecimiento personal de cada individuo como clave del crecimiento y enriquecimiento de la organización

- La calidad total implica a toda la organización

Hay que tener en cuenta que el círculo de un sistema de calidad es recursivo: planear, ejecutar, evaluar, ajustar

\subsubsection{Los sistemas de calidad según las normas ISO 9000}

Las normas ISO 8402-86 definen el sistema de calidad de una organización como el conjunto de la estructura de la organización, las responsabilidades, los procedimientos, los procesos y los recursos que se establecen para llevar a cabo la gestión de la calidad en ella. Los objetivos que persigue la implantación de un sistema de calidad de acuerdo con las normas ISO-9000 pueden ser diversos:

- Asegurar que permanentemente y sistemáticamente los alumnos alcancen los conocimientos previstos y pactados con los clientes y alumnos

- Producir el cambio de mentalidad que supone sustituir la buena voluntad por el método que se quiera implantar.

El proceso de implantación de un sistema de calidad en una institución educativa considera las siguientes fases:

- Toma de conciencia de la situación actual de la Institución, de los problemas, de la necesidad de cambio.

- Decisión de empezar que se concreta en dos momentos: ¿qué se va a hacer? (se formará a la dirección y parte del personal sobre el tema de 
la calidad y los instrumentos que se utilizan en los sistemas de calidad), ¿dónde se está? (se hará un diagnóstico de la situación actual del centro).

- Declaración de un plan para la mejora de la Institución y aceptación por todo el colectivo.

- Actuación de todo el personal según los acuerdos.

- Seguimiento y control del proceso, con el fin de comprobar el logro de los objetivos, analizar las desviaciones y sus posibles causas; establecer mecanismos de corrección.

- Establecimiento de un sistema de mejora continua de la calidad.

Comprenderá: una estructura organizativa y el empleo de herramientas adecuadas.

\section{Metodología}

\subsection{Población y muestra}

Teniendo en cuenta que el enfoque de evaluación de calidad propuesto en este trabajo se basó en la opinión de los demandantes finales de graduados de los CRES, se optó por anteponer la calidad ante la cantidad de los datos, procurando obtener la opinión de referentes Institucionales y Empresariales. Para este trabajo se obtuvieron los datos de Asociaciones gremiales, Federación Agraria, Sociedad Rural, Cámaras Económicas, referentes de Cooperativas y representantes de los CRES. Atendiendo la representatividad de las Instituciones propias de la localidad en cada CRES.

Se tuvieron en cuenta algunas características esenciales al seleccionar la población bajo estudio. Entre éstas se pueden contar los siguientes:

Homogeneidad: Todos los consultados fueron representativos de las Instituciones y Cámaras Empresariales, contaron con similares conocimientos del mercado laboral, y se encontraron en plena vigencia en el desarrollo de sus actividades. Intervinieron distintos integrantes con el objeto de restringir una visión parcializada. 
Espacio: La población de CRES de la provincia de Buenos Aires, considerando como muestra los siguientes Centros universitarios:

CRUB, Centro Regional Universitario Bolívar.

CURS, Centro Regional Universitario Saladillo

Centro Universitario municipal San Fernando

CUCH Centro Universitario Chivilcoy

Centro Universitario 9 de julio

Centro Universitario Regional San Miguel del Monte

CRUO Centro Regional Universitario del Oeste Bragado

Centro Universitario 25 de Mayo

Centro Universitario Quequén

CRESTA Centro Regional de Estudios Superiores de Tres Arroyos

Cantidad: El tamaño de la población de los especialistas consultados se limitó a diez por cada CRES.

\subsection{Tipo de estudio}

La investigación realizada tiene el carácter de exploratoria.

\subsection{Técnicas de Recolección de Datos}

Se recurrió como técnica de investigación a un Panel de Expertos o Especialistas profesionales ${ }^{4}$, el cual está formado por un grupo de personas expertas en una materia determinada, con un gran bagaje y experiencia en el tema en cuestión.

Con el objeto de contar con información confiable a un costo mucho menor que el de herramientas de investigación de mercados tradicionales, se recurrió a diez referentes que brindaron sus respuestas.

\footnotetext{
${ }^{4}$ Los estudios que se realizan utilizando un "Panel de Expertos" tienen por finalidad obtener ideas o confirmar planteamientos por la experiencia de las personas seleccionadas representando más bien una consulta o una técnica proyectiva que una investigación cuantitativa de mercados propiamente dicha.
} 
Las principales ventajas de recurrir a un Panel de Especialistas sobre los métodos de investigación de mercados tradicionales son:

- Ahorro de costos,

- Superación de barreras geográficas, pudiendo reunir en una visita a todas las personas de esa ciudad,

- Lograr una mayor desinhibición de los participantes, lo que provoca que las opiniones vertidas sean más sinceras y arriesgadas,

- Posibilidad de recopilación inmediata de las opiniones nada más finalizar la misma, y

- Mayor individualidad en las respuestas frente a técnicas alternativas como el FocusGroup, en el que la presión del grupo puede llevar a ciertos participantes a cambiar de opinión y por ende "contaminar" los resultados

Para la medición de las expectativas de los empleadores, se aplicó un Cuestionario ${ }^{5}$ orientado a indagar sobre la satisfacción del usuario del servicio con respecto al desempeño profesional de los graduados.

Los aspectos investigados giraron en torno a las competencias de los graduados:

1. Información personal del empleador encuestado. Referido a datos personales e Institución por la que responde

2. Las expectativas del empleador con respecto a las competencias del graduado

3. Las percepciones del empleador con respecto a las competencias del graduado

Para recolectar la opinión del encuestado en relación a las expectativas y percepción de las competencias (inciso " $A$ " de la encuesta) se definieron veinte competencias, donde el encuestado eligió en qué medida los graduados del CRES poseen las competencias presentadas y cuál es el nivel de importancia asignado a cada una de ellas, calificando de 1 a 4, siendo uno la menor importancia y cuatro la mayor.

\footnotetext{
${ }^{5}$ Los datos se vuelcan en Anexos como: "Cuestionario de Evaluación de los empleadores, sobre los graduados".Se aplica un cuestionario tomado del trabajo de AlbaniMusyafa. Stakeholders Satisfactions with Civil Engineering Graduates. Curtin University of Technology.2009.
} 
Para cada competencia la calificación debía hacerse con respecto a:

1. Percepción de la importancia de la competencia

2. Percepción del nivel de competencia de los empleados

Para recolectar la opinión del encuestado en relación al orden de valoración de las cinco competencias planteadas (inciso "B" del cuestionario) éste otorga un orden jerárquico del 1 al 5 a cada atributo sobre conocimientos, habilidades y actitudes que graduado debería tener. El número 1 (uno) se asigna como la más sobresaliente y el 5 (cinco) como la menos sobresaliente.

\subsection{Técnicas de análisis}

El análisis de los datos se llevó a cabo luego de la confección de una base de datos. Los datos obtenidos en las encuestas fueron cargados a una matriz, donde cada campo representó cada pregunta de la encuesta. Las respuestas fueron codificadas numéricamente, para facilitar la carga. A su vez, se llevó a cabo un análisis univariado.

Luego se calculó el "Saldo de respuesta"6 de cada pregunta realizada, en función de la fórmula siguiente:

$$
\text { Saldode Re spuesta }=\frac{\sum_{i=1}^{n} F_{i} \cdot i}{\sum_{i=1}^{n} F_{i}}
$$

Donde:

$\mathrm{Fi}$ = Es la cantidad de respuestas (frecuencias) de cada ítem para cada valor de las opciones de respuesta

\footnotetext{
${ }^{6}$ El cálculo de ese promedio sigue idéntica metodología que la del Global CompetitivenessIndex del World Economic Forum para el procesamiento de la Executive Opinion Survey en que se pregunta sobre una serie de cuestiones y se solicita que se califique en un rango que va de 1 a 7 en que 1 es lo peor y 7 lo mejor y que luego se sintetiza a través de un promedio. Xavier Sala-i-Martin (Cabrera de Mar, Barcelona, España, 1963), es un economista de origen español y de nacionalidad estadounidense, articulista, catedrático de economía en la Universidad de Columbia y Asesor Jefe ("Chief Advisor") del World Economic Forum donde, además, es coautor del Global Competitiveness Report y el padre intelectual del Global Competitiveness Index que ordena a más de 140 países del mundo según su competitividad.
} 
$\mathrm{i}=$ Es el valor de cada uno de las opciones de respuesta

El cálculo consiste en multiplicar los componentes de las cantidades de respuestas (frecuencias) por el tipo de respuesta dado y luego sumar esos productos. Posteriormente a ese número se lo divide por la sumatoria de la cantidad de respuestas.

Luego se calculó la frecuencia de la brecha de satisfacción de la calidad del graduado, como la diferencia entre las percepciones y las expectativas que tienen los empleadores.

La brecha de satisfacción de los empleadores es la resultante de la resta entre la calificación otorgada a la expectativa que un empleador tiene sobre un aspecto del graduado y la percepción respecto de la calidad ofrecida por el graduado. El "árbol de posibilidades" está conformado por la tabla siguiente. 


\begin{tabular}{|c|c|c|}
\hline Expectativa & Percepción & Brecha \\
\hline 1,0 & 4,0 & $-3,0$ \\
\hline 1,0 & 3,0 & $-2,0$ \\
\hline 1,0 & 2,0 & $-1,0$ \\
\hline 1,0 & 1,0 & 0,0 \\
\hline 2,0 & 4,0 & $-2,0$ \\
\hline 2,0 & 3,0 & $-1,0$ \\
\hline 2,0 & 2,0 & 0,0 \\
\hline 2,0 & 1,0 & 1,0 \\
\hline 3,0 & 4,0 & $-1,0$ \\
\hline 3,0 & 3,0 & 0,0 \\
\hline 3,0 & 2,0 & 1,0 \\
\hline 3,0 & 1,0 & 2,0 \\
\hline 4,0 & 4,0 & 0,0 \\
\hline 4,0 & 3,0 & 1,0 \\
\hline 4,0 & 2,0 & 2,0 \\
\hline 4,0 & 1,0 & 3,0 \\
\hline
\end{tabular}

Fuente: Elaboración propia.

Y resumiendo sólo los casos únicos:

\begin{tabular}{|c|l|}
\hline Brechas & \multicolumn{1}{|c|}{$\begin{array}{c}\text { Estados posibles de } \\
\text { satisfacción }\end{array}$} \\
\hline$-3,0$ & Muy insatisfecho \\
\hline$-2,0$ & Bastante insatisfecho \\
\hline$-1,0$ & Algo insatisfecho \\
\hline 0,0 & Satisfecho \\
\hline 1,0 & Algo más que satisfecho \\
\hline 2,0 & Bastante más que satisfecho \\
\hline 3,0 & Muy satisfecho \\
\hline
\end{tabular}

Fuente: Elaboración propia. 
Para poder establecer un orden jerárquico de cada una de las competencias de los graduados respecto de las problemáticas detectadas, se procedió del siguiente modo.

1.- Se ordenaron de mayor a menor las Competencias en función de la calificación promedio de la Importancia asignada por los empleadores, lo que generó una posición jerárquica.

2.- Se determinó la Discrepancia de cada una de las Competencias como sustracción entre las calificaciones promedio del Desempeño percibido y de la Importancia asignada.

3.- Se estableció la Ponderación de la Discrepancia de cada una de las Competencias como el producto entre la Discrepancia y la calificación de la Importancia asignada.

4.- Finalmente se ordenaron de mayor a menor las Competencias en función de la Ponderación calculada, lo que generó la posición jerárquica de las problemáticas detectadas. 


\section{Resultados de la Investigación}

Los resultados de la investigación se presentaran a continuación mediante tabla de datos y gráficos que sintetizan la respuesta de cada una de las competencias evaluadas, identificadas en la encuesta como inciso "A".

Las respuestas obtenidas se presentan en primer lugar sobre las expectativas y luego por la percepción observada.

Identificando para cada competencia:

Saldo de Respuesta

Desvío Estándar

Coeficiente de variación

En tercer lugar se presenta un gráfico con el análisis de las brechas entre las expectativas y la percepción.

Finalmente se observa una tabla jerárquica ordenadas en función de la problemática de las características.

7.1.- Capacidad para planificar y utilizar el tiempo de manera efectiva (de tal forma que se logren los objetivos planteados)

Expectativas

Grafico 1

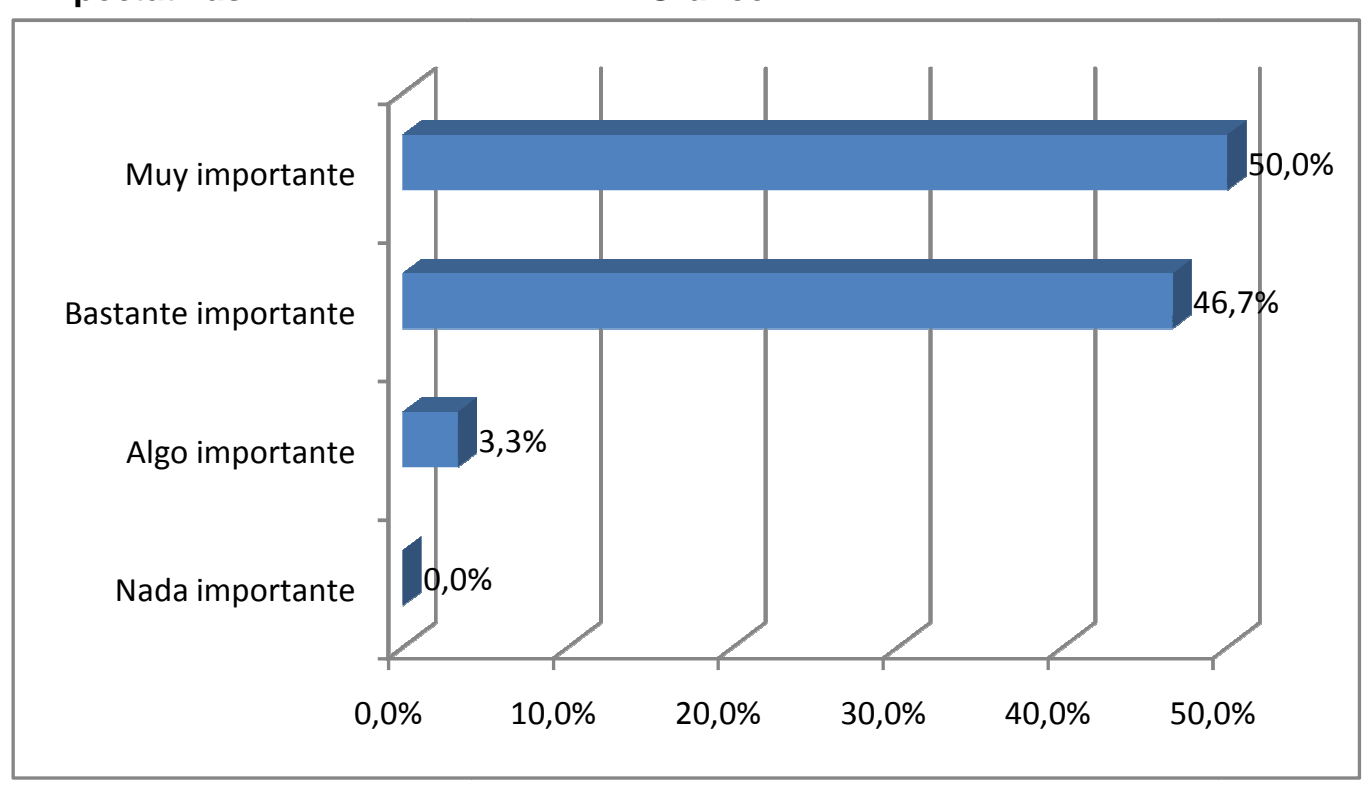




\begin{tabular}{|l|r|}
\hline Tabla 1 \\
\hline Saldo de respuesta & 3,47 \\
\hline D.S. & 0,60 \\
\hline C.V. & $17,3 \%$ \\
\hline
\end{tabular}

Fuente: elaboración propia

Con un "Saldo de respuesta" de 3,47 la situación se presenta intermedia entre "Bastante importante" a "Muy importante". Un Desvío Estándar de 0,6 y un Coeficiente de Variabilidad del 17,3\% permiten afirmar que los datos están muy concentrados y que el promedio es representativo.

\section{Percepción}

\section{Grafico 2}

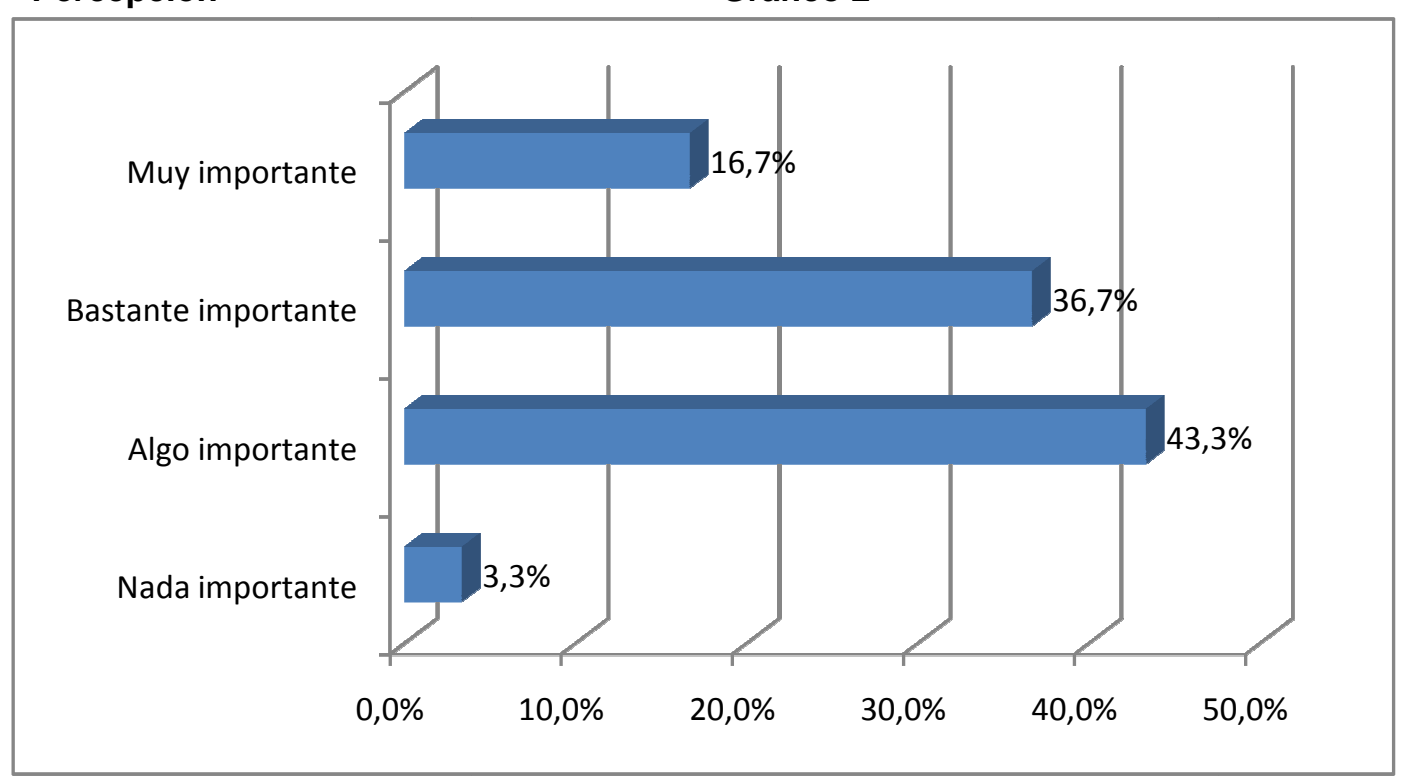

\section{Tabla 2}

\begin{tabular}{|l|r|}
\hline Saldo de respuesta & 2,67 \\
\hline D.S. & 0,8 \\
\hline C.V. & $30,0 \%$ \\
\hline
\end{tabular}

Fuente: elaboración propia

Con un "Saldo de respuesta" de 2,67 la situación se presenta intermedia entre "Muy importante" a "Algo importante". Un Desvío Estándar de 0,8 y un Coeficiente de Variabilidad del $30 \%$ permiten afirmar que los datos están muy concentrados y que el promedio es representativo. 


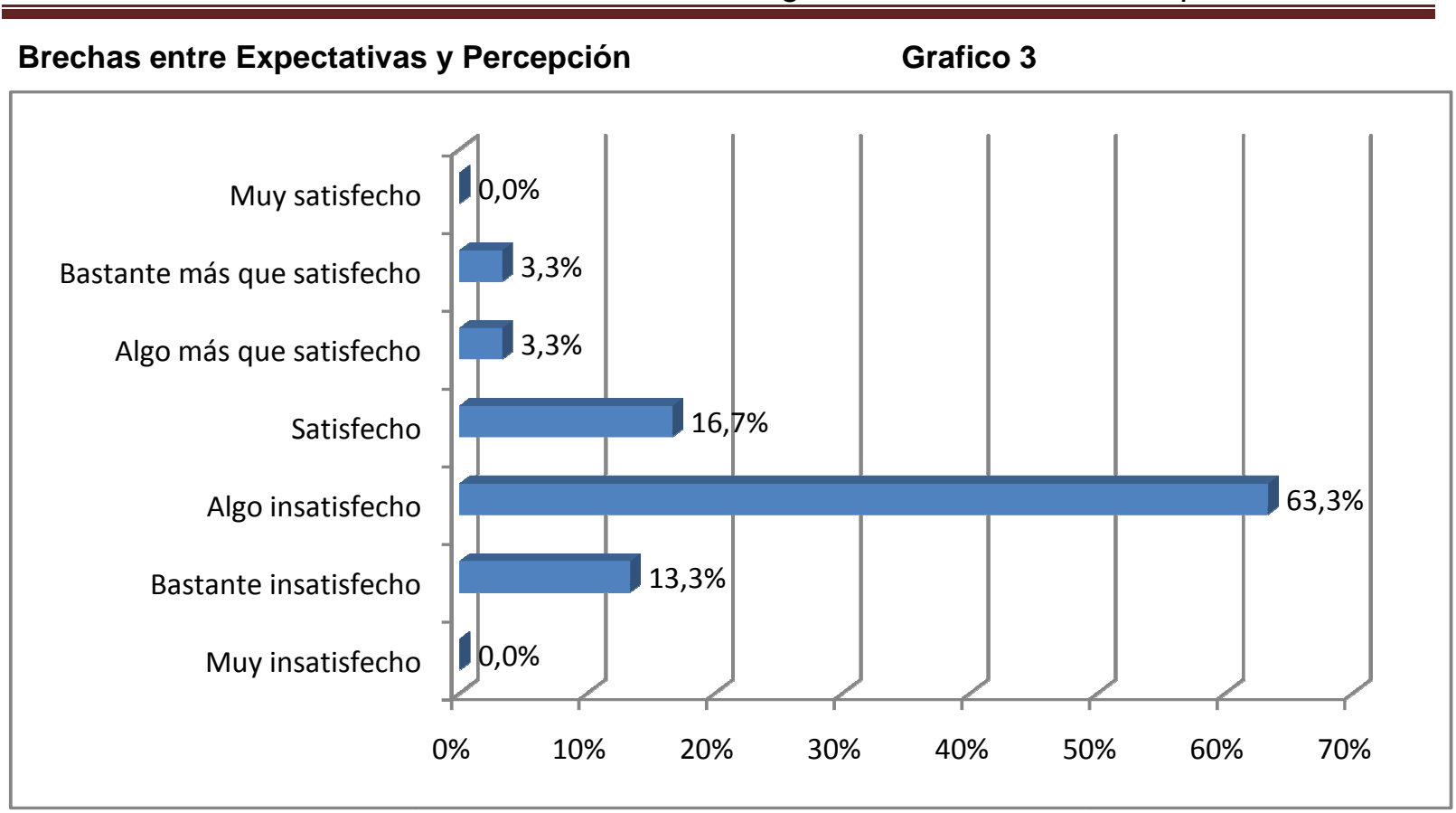

Fuente: elaboración propia

La brecha arroja un 16,7\% "Satisfecho", un 63,3\% "Algo Insatisfecho" y un 13,3\% "Bastante Insatisfecho", lo cual significa que se observa un déficit entre la expectativa y la percepción.

\section{2.- Capacidad para comunicar por escrito}

\section{Expectativas}

Grafico 4

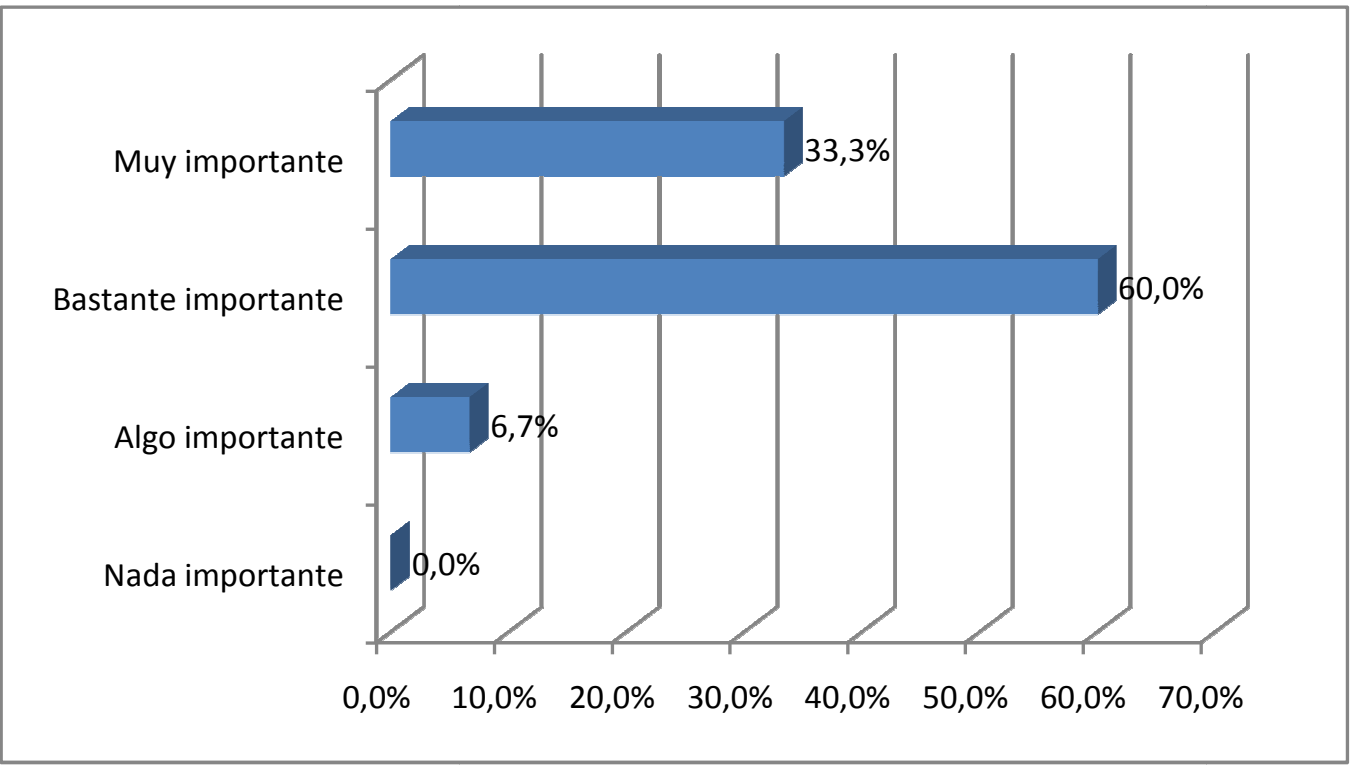




\begin{tabular}{|c|c|}
\hline Saldo de respuesta & 3,27 \\
\hline D.S. & 0,6 \\
\hline C.V. & $18,4 \%$ \\
\hline
\end{tabular}

Fuente: elaboración propia

Con un "Saldo de respuesta" de 3,27 la situación se presenta como "Bastante importante". Un Desvío Estándar de 0,6 y un Coeficiente de Variabilidad del 18,4\% permiten afirmar que los datos están muy concentrados y que el promedio es representativo.

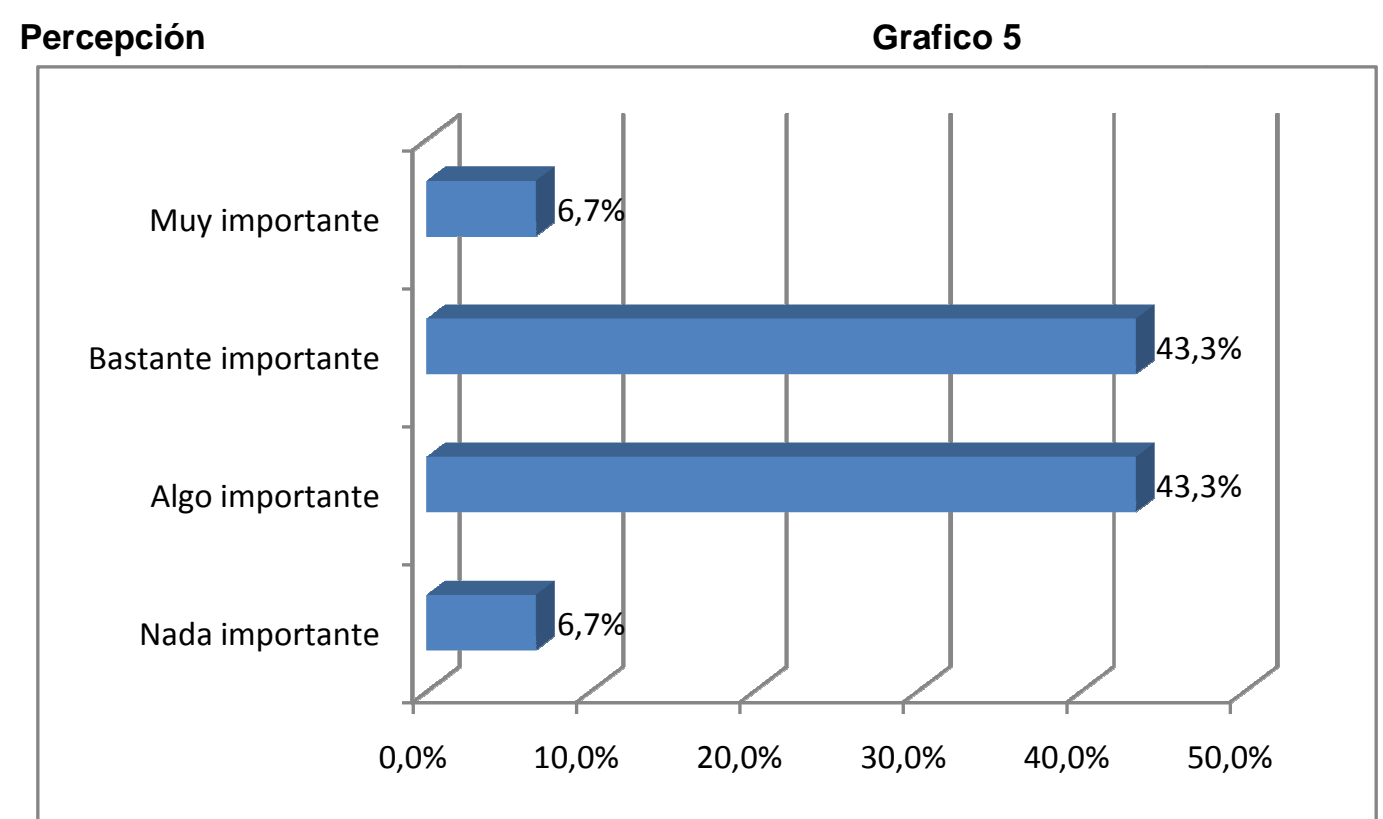

\section{Tabla 4}

\begin{tabular}{|l|r|}
\hline Saldo de respuesta & 2,50 \\
\hline D.S. & 0,7 \\
\hline C.V. & $28,0 \%$ \\
\hline
\end{tabular}

Fuente: elaboración propia

Con un "Saldo de respuesta" de 2,50 la situación se presenta equilibrada entre "Bastante importante" a "Algo importante". Un Desvío Estándar de 0,7 y un Coeficiente de Variabilidad del $28 \%$ permiten afirmar que los datos están muy concentrados y que el promedio es representativo. 


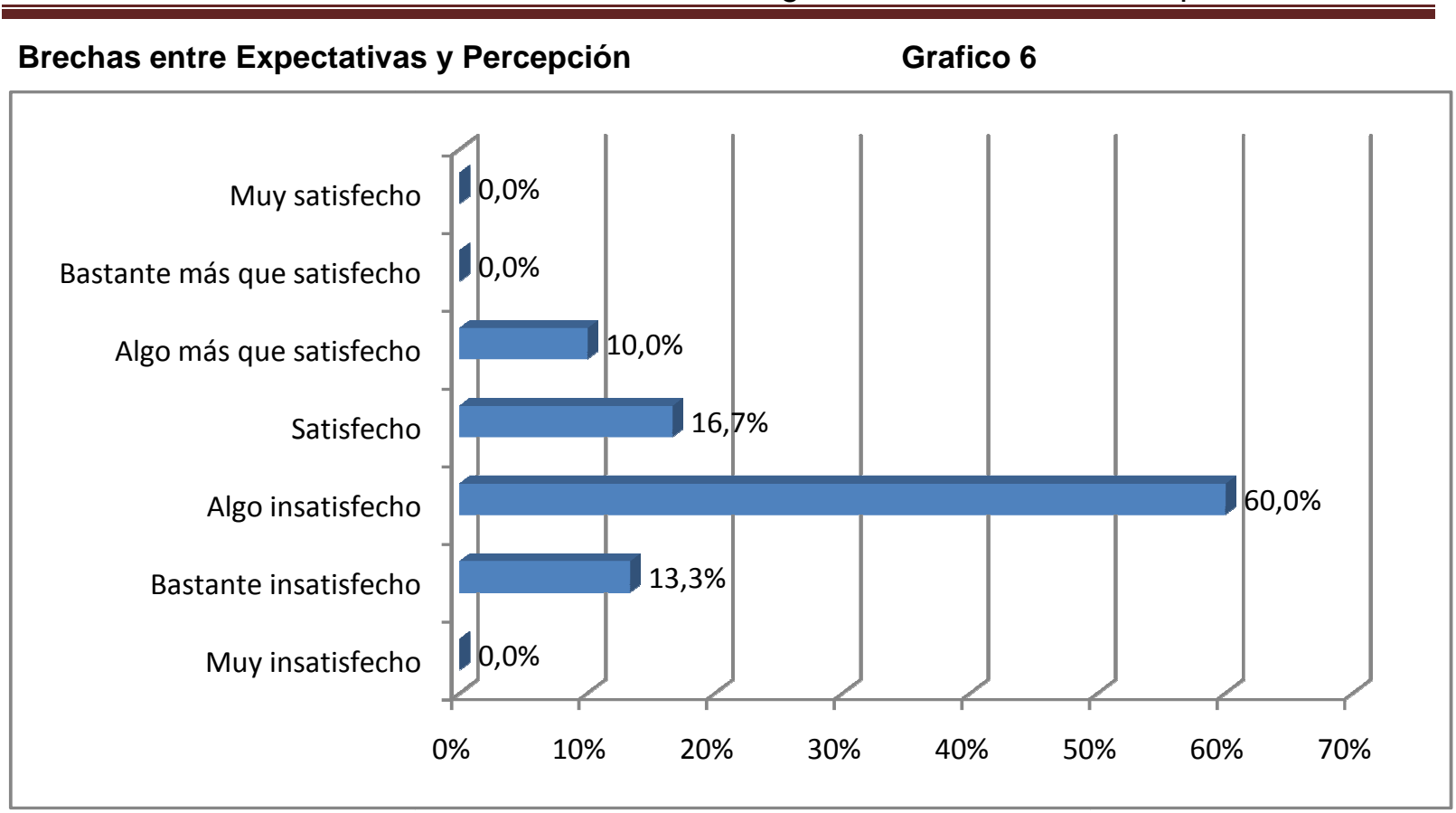

Fuente: elaboración propia

La brecha arroja un 16,7\% "Satisfecho", un 60\% "Algo Insatisfecho" y un 13,3\% "Bastante Insatisfecho", lo cual significa que se observa un déficit entre la expectativa y la percepción.

\section{3.- Capacidad para comunicarse oralmente de tal forma que los demás entiendan}

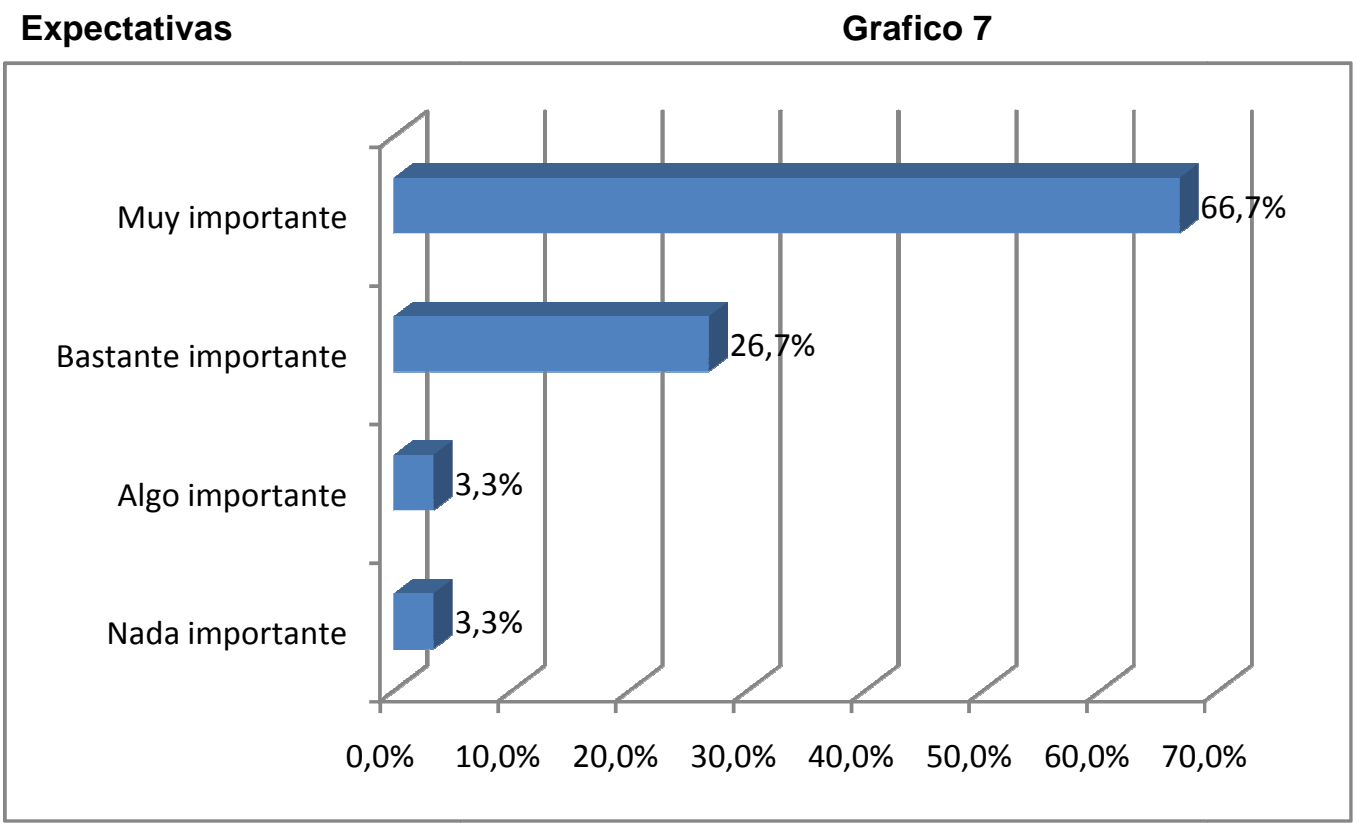




\begin{tabular}{l|r|}
\hline Tabla 5 \\
\hline Saldo de respuesta \\
\hline D.S. & 3,57 \\
\hline C.V. & 0,7 \\
\hline Fuen & $19,6 \%$ \\
\hline
\end{tabular}

Fuente: elaboración propia

Con un "Saldo de respuesta" de 3,57 la situación se presenta como "Muy importante". Un Desvío Estándar de 0,7 y un Coeficiente de Variabilidad del 19,6\% permiten afirmar que los datos están muy concentrados y que el promedio es representativo.

\section{Percepción}

Grafico 8

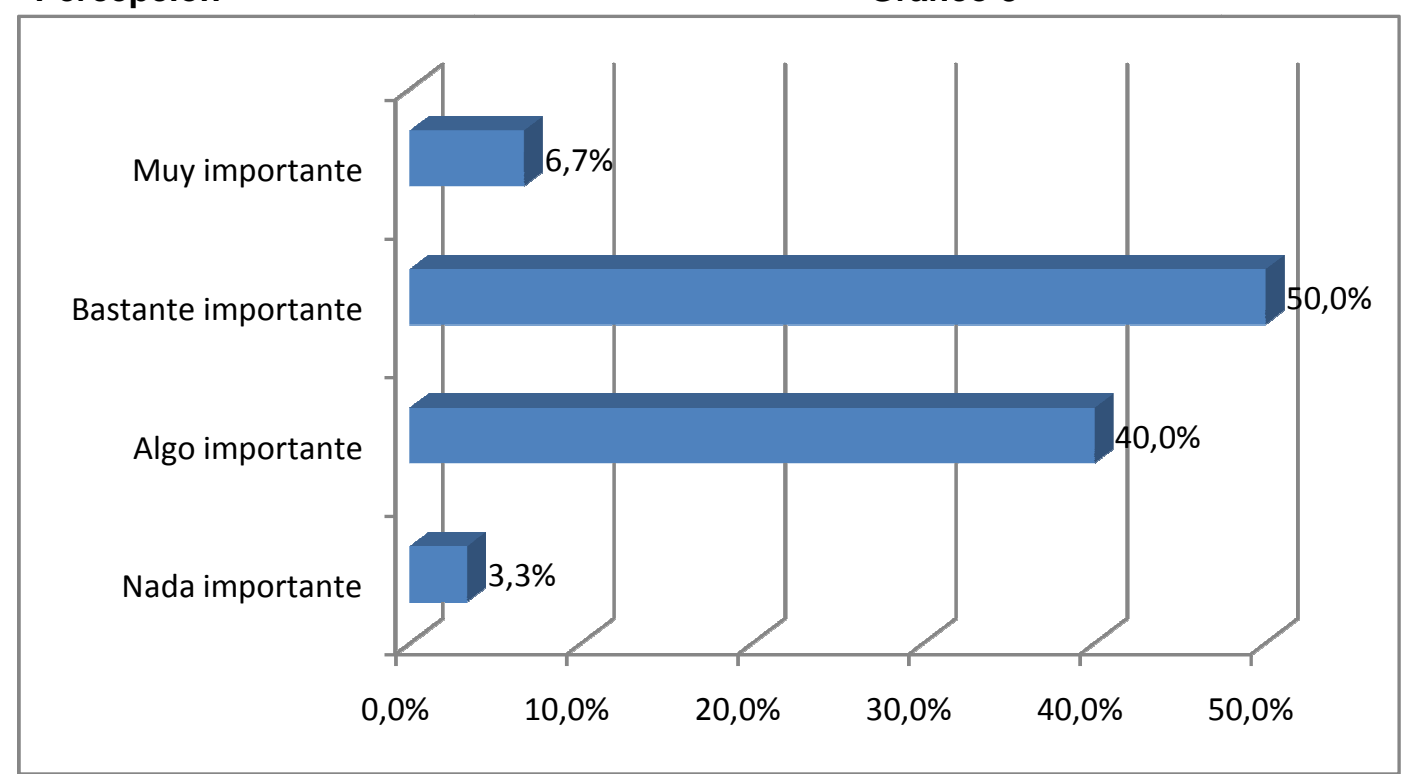

\section{Tabla 6}

\begin{tabular}{|l|r|}
\hline Saldo de respuesta & 2,60 \\
\hline D.S. & 0,7 \\
\hline C.V. & $26,9 \%$ \\
\hline
\end{tabular}

Fuente: elaboración propia

Con un "Saldo de respuesta" de 2,60 la situación se presenta intermedia entre "Bastante importante" a "Algo importante". Un Desvío Estándar de 0,7 y un Coeficiente de Variabilidad del 26,9\% permiten afirmar que los datos están muy concentrados y que el promedio es representativo. 


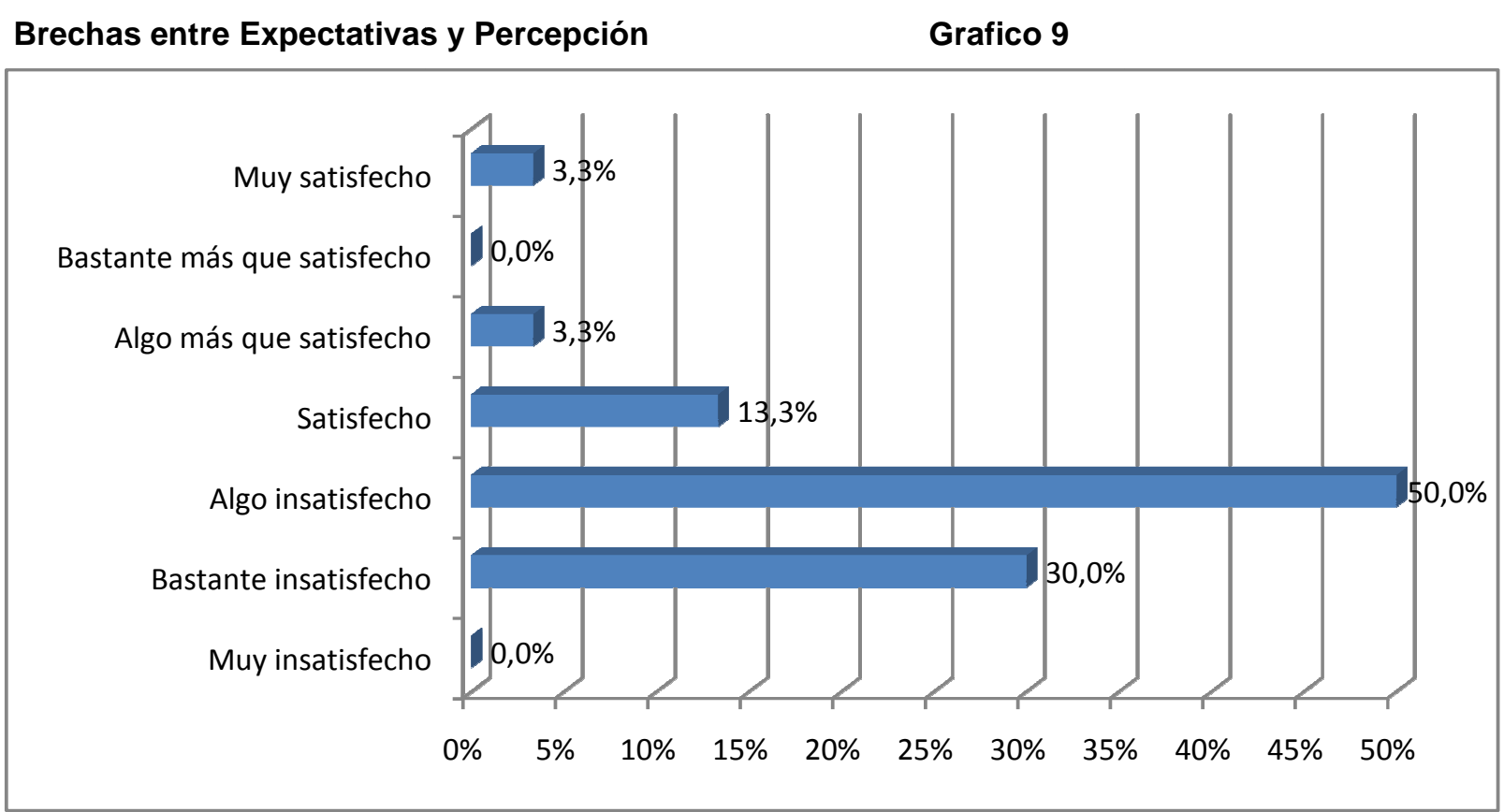

Fuente: elaboración propia

La brecha arroja un 13,3\% "Satisfecho", un 50\% "Algo Insatisfecho" y un 30\% "Bastante Insatisfecho", lo cual significa que se observa un déficit entre la expectativa y la percepción.

\section{4.- Capacidad para hablar y escribir en un idioma extranjero}

\section{Expectativas}

\section{Grafico 10}

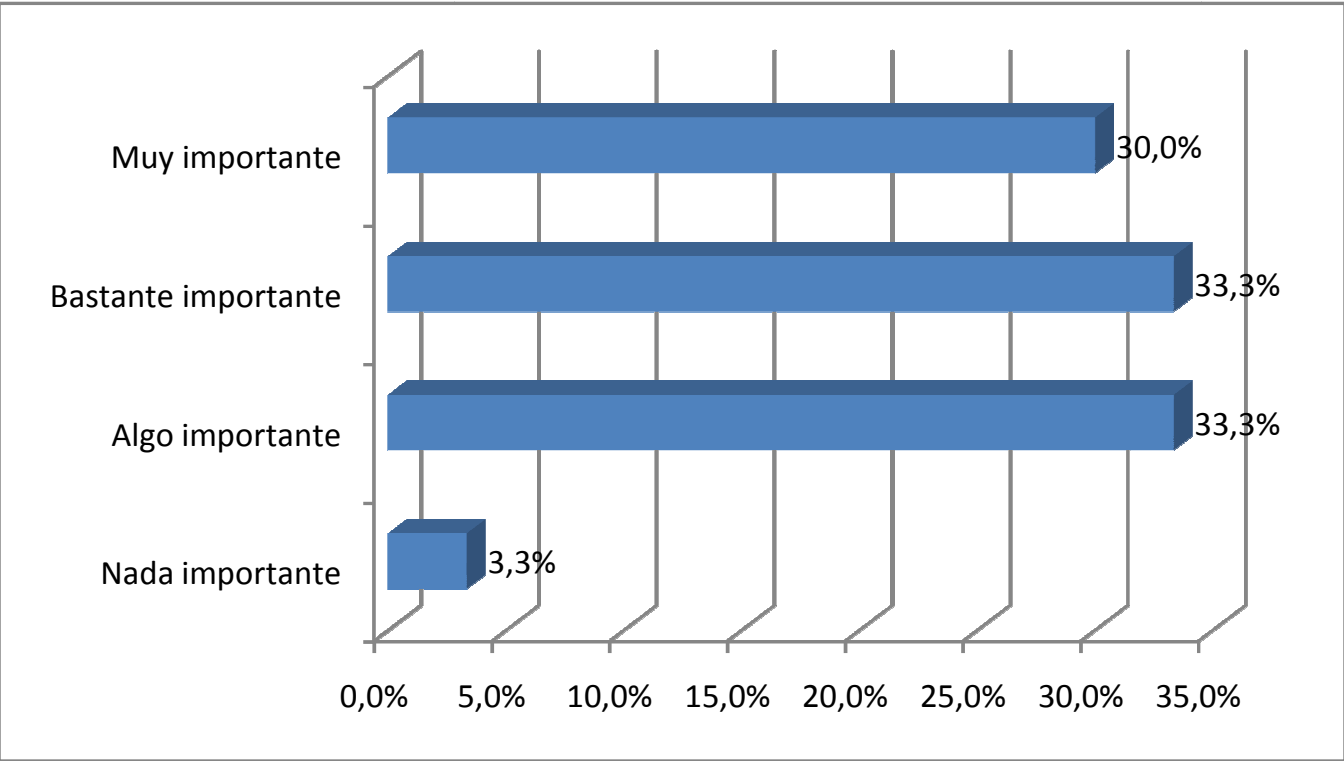




\begin{tabular}{l} 
Tabla 7 \\
\begin{tabular}{|l|r|}
\hline Saldo de respuesta & 2,90 \\
\hline D.S. & 0,9 \\
\hline C.V. & $31,0 \%$ \\
\hline
\end{tabular} \\
\hline
\end{tabular}

Fuente: elaboración propia

Con un "Saldo de respuesta" de 2,90 la situación se presenta intermedia entre "Algo importante" a "Muy importante". Un Desvío Estándar de 0,9 y un Coeficiente de Variabilidad del $31 \%$ permiten afirmar que los datos están muy concentrados y que el promedio es representativo.

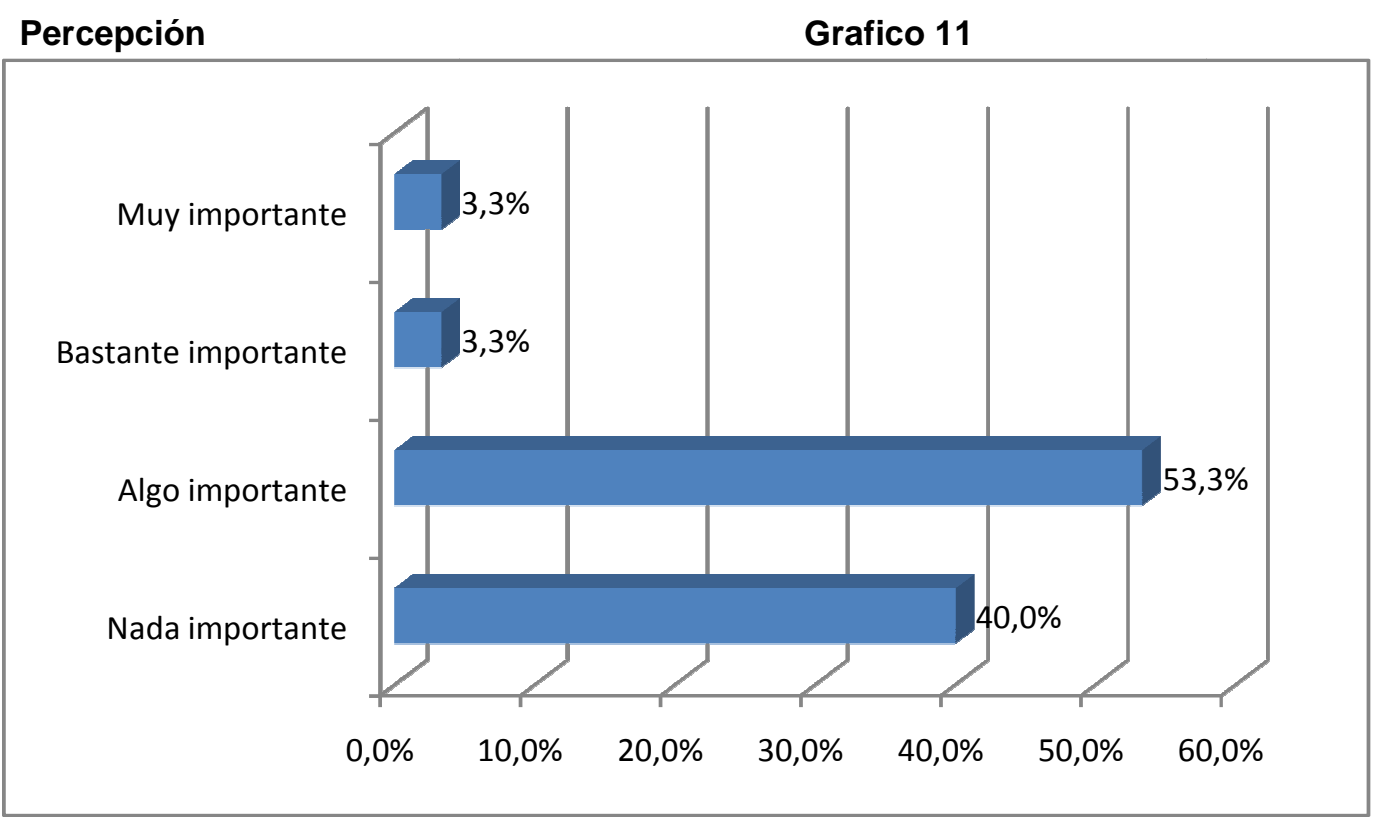

\section{Tabla 8}

\begin{tabular}{|l|r|}
\hline Saldo de respuesta & 1,70 \\
\hline D.S. & 0,7 \\
\hline C.V. & $41,2 \%$ \\
\hline
\end{tabular}

Fuente: elaboración propia

Con un "Saldo de respuesta" de 1,70 la situación se presenta intermedia entre "Algo importante" a "Nada importante". Un Desvío Estándar de 0,7 y un Coeficiente de Variabilidad del $41,2 \%$ permiten afirmar que los datos están concentrados y que el promedio es representativo. 


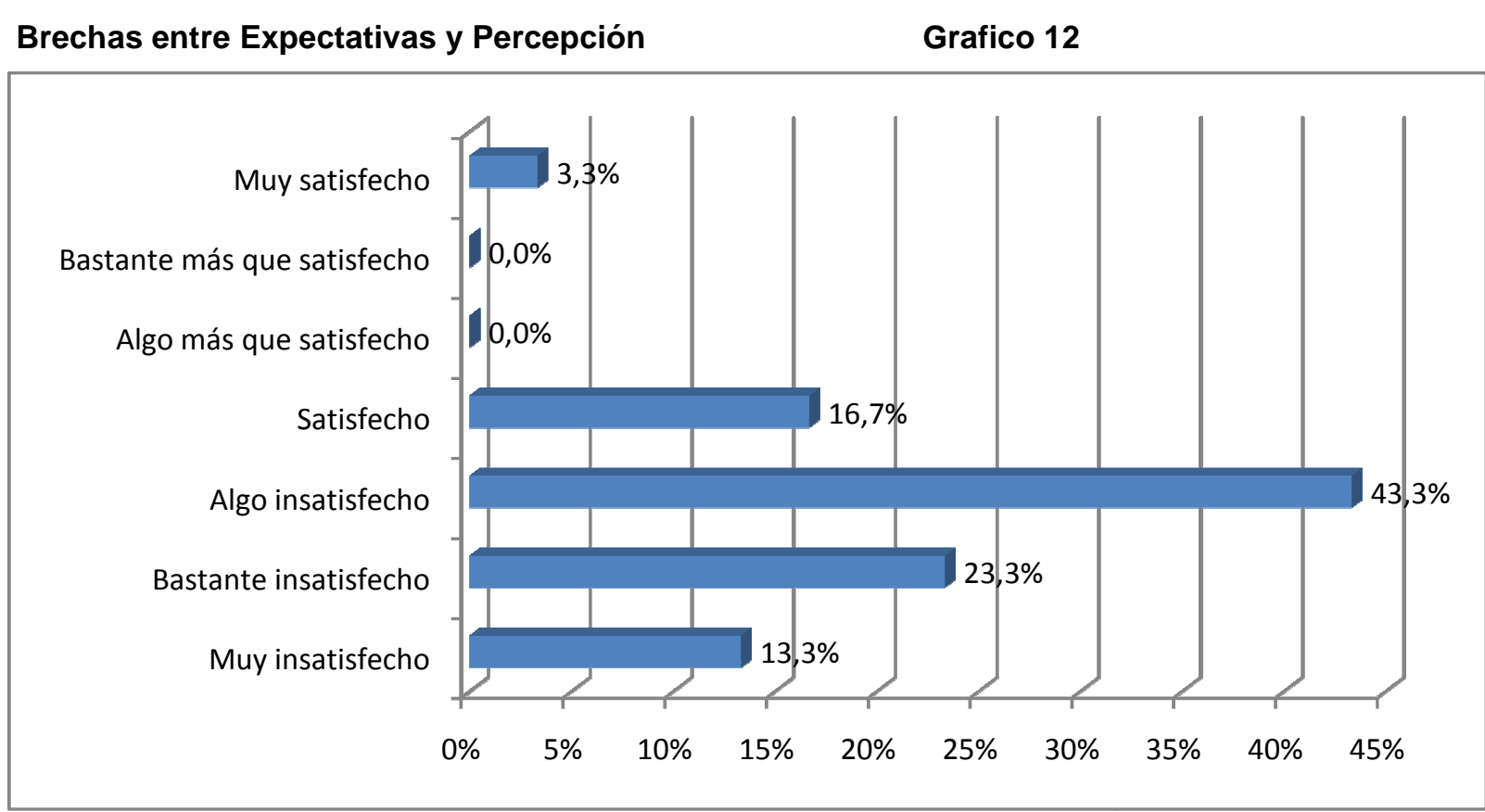

Fuente: elaboración propia

La brecha arroja un 16,7\% "Satisfecho", un 43,3\% "Algo Insatisfecho", un 23,3\% "Bastante Insatisfecho" y un 13,3\% "Muy Insatisfecho", lo cual significa que se observa un déficit entre la expectativa y la percepción.

\section{5.- Capacidad para utilizar herramientas informáticas básicas (procesador de palabra, hojas de cálculo, etc.)}

Expectativas

Grafico 13

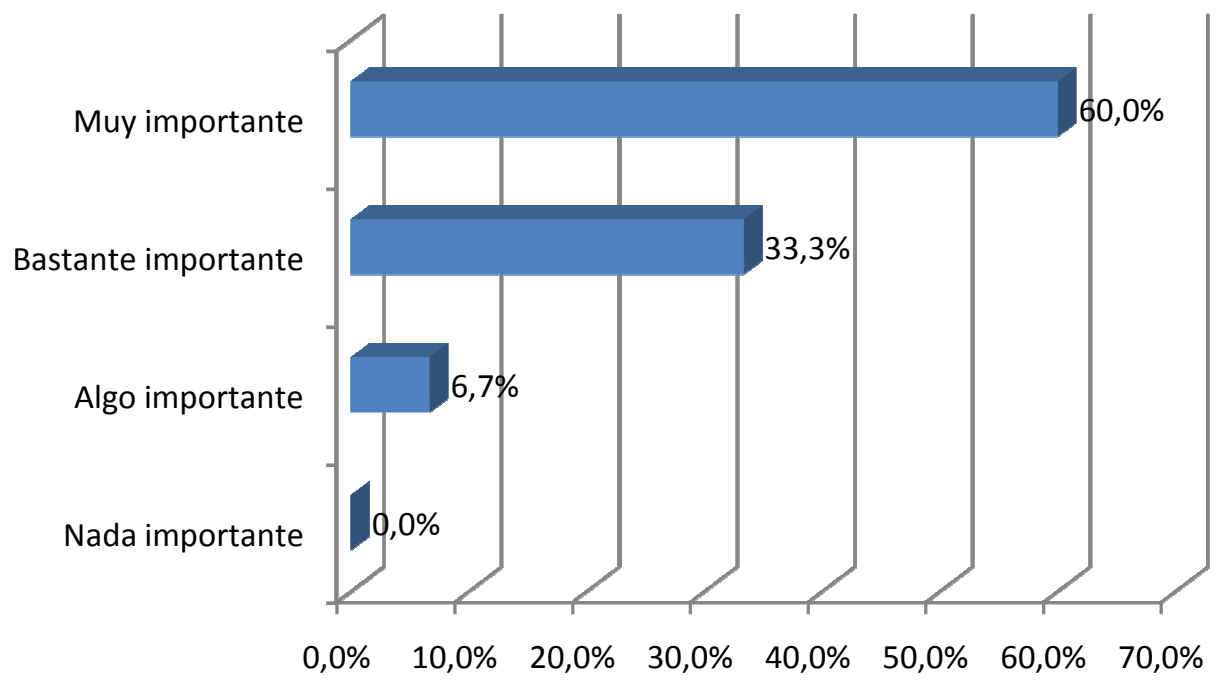




\begin{tabular}{|c|c|}
\hline Saldo de respuesta & 3,53 \\
\hline D.S. & 0,6 \\
\hline C.V. & $17,0 \%$ \\
\hline
\end{tabular}

Fuente: elaboración propia

Con un "Saldo de respuesta" de 3,53 la situación se presenta como "Muy importante". Un Desvío Estándar de 0,6 y un Coeficiente de Variabilidad del 17\% permiten afirmar que los datos están muy concentrados y que el promedio es representativo.

\section{Percepción}

\section{Grafico 14}

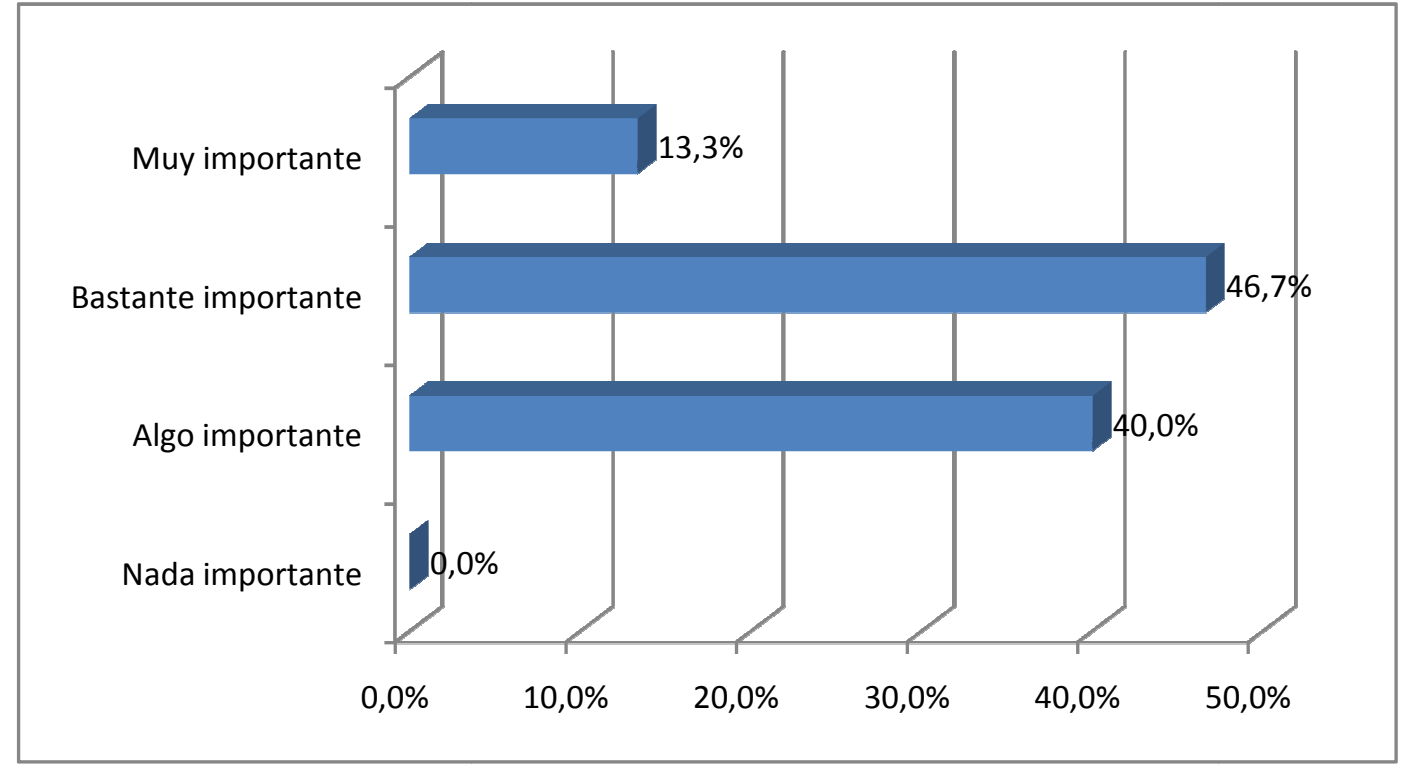

Tabla 10

\begin{tabular}{|l|r|}
\hline Saldo de respuesta & 2,73 \\
\hline D.S. & 0,7 \\
\hline C.V. & $25,6 \%$ \\
\hline
\end{tabular}

Fuente: elaboración propia

Con un "Saldo de respuesta" de 2,73 la situación se presenta intermedia entre "Bastante importante" a "Algo importante". Un Desvío Estándar de 0,7 y un Coeficiente de Variabilidad del 25,6\% permiten afirmar que los datos están muy concentrados y que el promedio es representativo. 


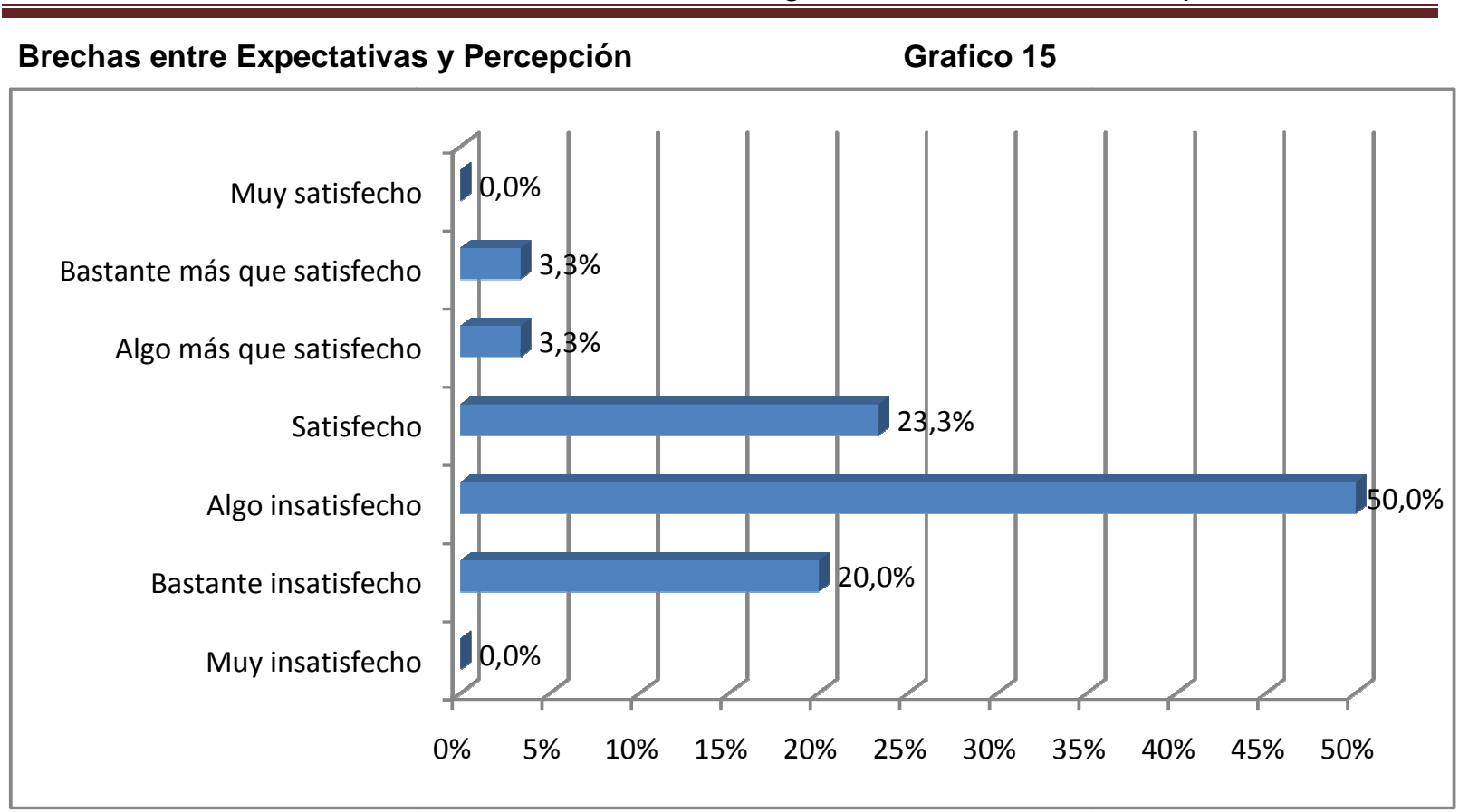

Fuente: elaboración propia

La brecha arroja un 23,3\% "Satisfecho", un 50\% "Algo Insatisfecho" y un 20\% "Bastante Insatisfecho", lo cual significa que se observa un déficit entre la expectativa y la percepción.

\section{6.- Capacidad para utilizar herramientas informáticas especializadas (paquetes estadísticos, programas de diseño, etc.)}

\section{Expectativas}

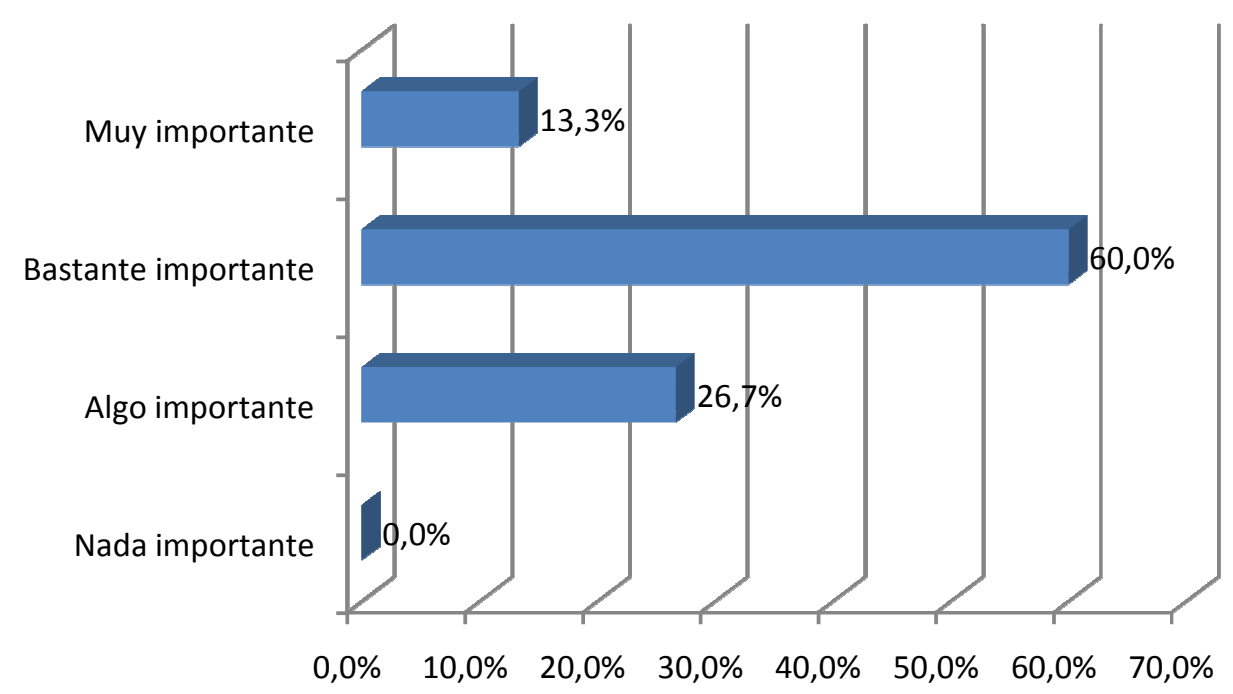




Tabla 11
\begin{tabular}{|l|r|}
\hline Saldo de respuesta & 2,87 \\
\hline D.S. & 0,6 \\
\hline C.V. & $20,9 \%$ \\
\hline
\end{tabular}

Fuente: elaboración propia

Con un "Saldo de respuesta" de 2,87 la situación se presenta como "Bastante importante". Un Desvío Estándar de 0,6 y un Coeficiente de Variabilidad del 20,9\% permiten afirmar que los datos están muy concentrados y que el promedio es representativo.

\section{Percepción}

\section{Grafico 17}

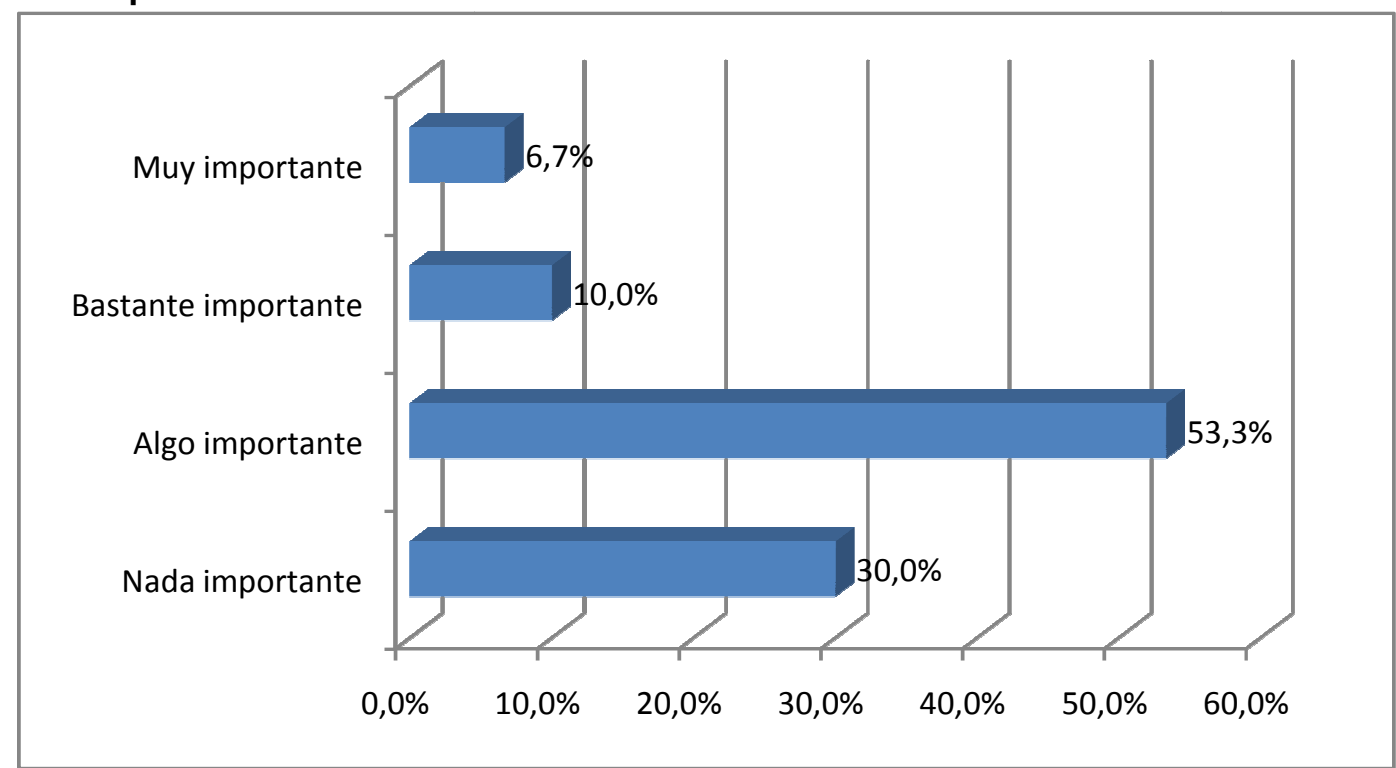

Tabla 12

\begin{tabular}{|l|r|}
\hline Saldo de respuesta & 1,93 \\
\hline D.S. & 0,8 \\
\hline C.V. & $41,4 \%$ \\
\hline
\end{tabular}

Fuente: elaboración propia

Con un "Saldo de respuesta" de 1,93 la situación se presenta como "Algo importante". Un Desvío Estándar de 0,8 y un Coeficiente de Variabilidad del 41,4\% permiten afirmar que los datos están concentrados y que el promedio es representativo. 


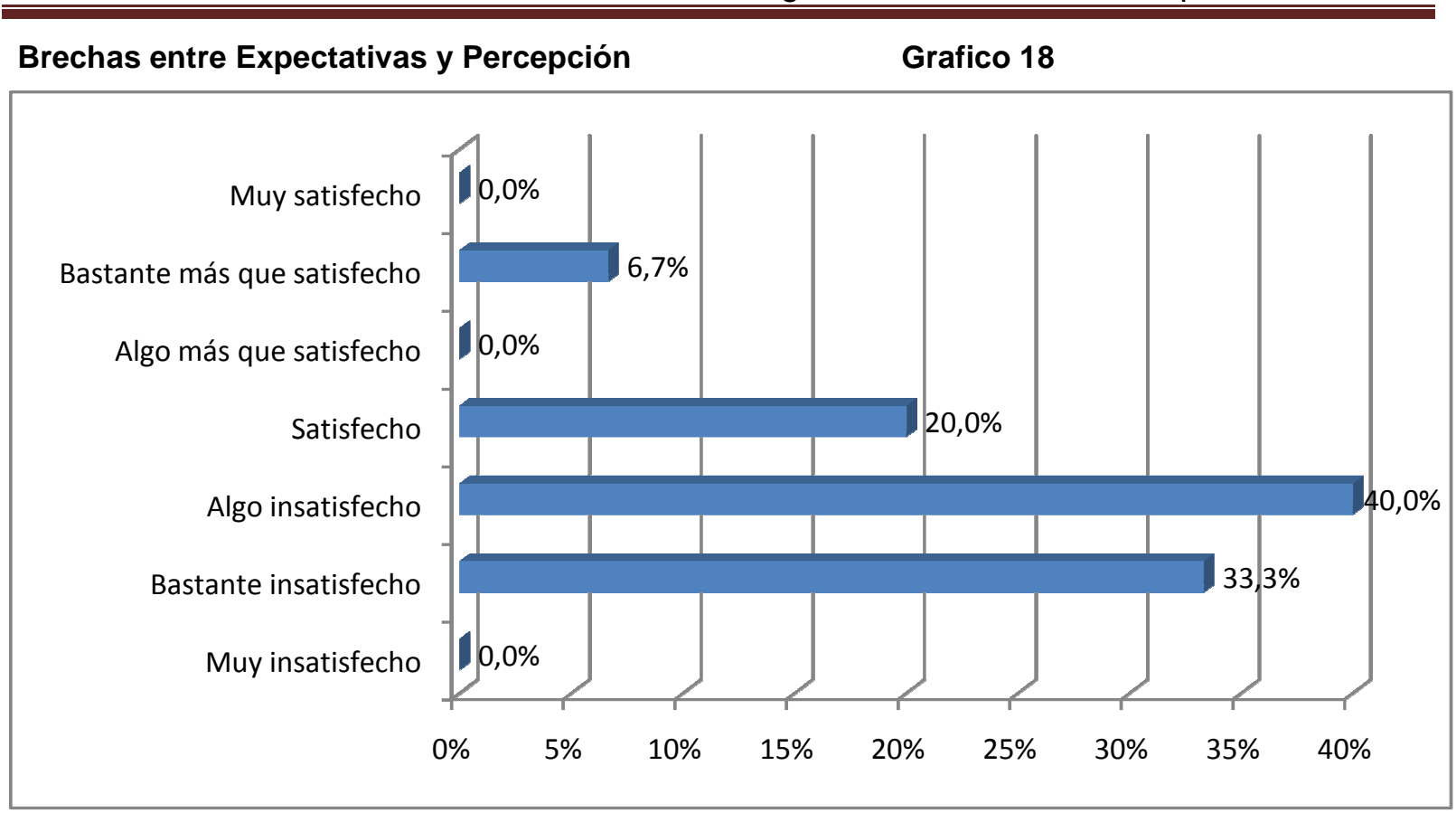

Fuente: elaboración propia

La brecha arroja un 20\% "Satisfecho", un 40\% "Algo Insatisfecho" y un 33,3\% "Bastante Insatisfecho", lo cual significa que se observa un déficit entre la expectativa y la percepción.

\section{7.- Capacidad para asumir responsabilidades y tomar decisiones} (establecer metas, identificar limitaciones y riesgos, y generar, evaluar y elegir las mejores alternativas)

Expectativas

Grafico 19

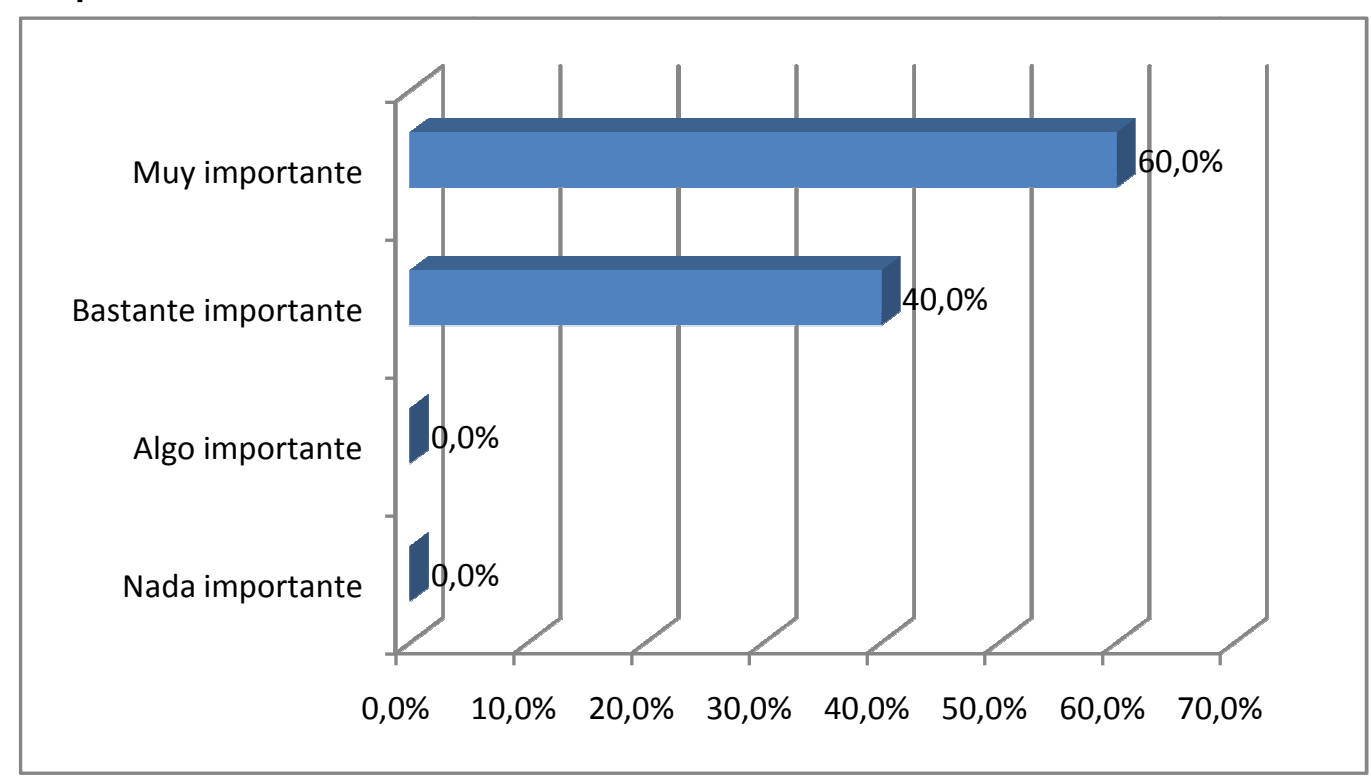




\begin{tabular}{|l|r|}
\hline \multicolumn{2}{|l|}{ Tabla 13 } \\
\hline Saldo de respuesta & 3,60 \\
\hline D.S. & 0,5 \\
\hline C.V. & $13,9 \%$ \\
\hline
\end{tabular}

Fuente: elaboración propia

Con un "Saldo de respuesta" de 3,60 la situación se presenta intermedia entre "Bastante importante" a "Muy importante". Un Desvío Estándar de 0,5 y un Coeficiente de Variabilidad del 13,9\% permiten afirmar que los datos están muy concentrados y que el promedio es representativo.

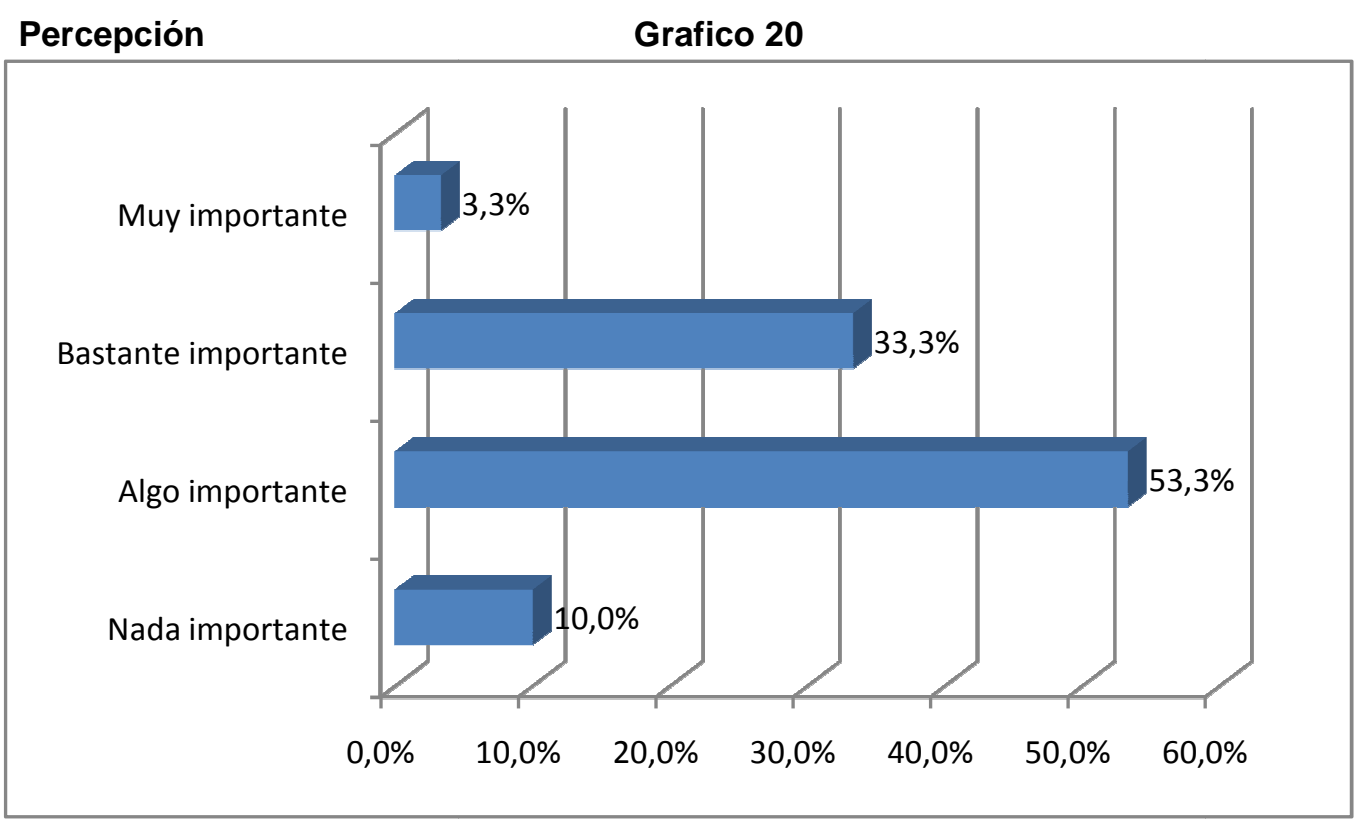

Tabla 14
\begin{tabular}{|l|r|}
\hline Saldo de respuesta & 2,30 \\
\hline D.S. & 0,7 \\
\hline C.V. & $30,4 \%$ \\
\hline
\end{tabular}

Fuente: elaboración propia

Con un "Saldo de respuesta" de 2,30 la situación se presenta intermedia entre "Bastante importante" a "Algo importante". Un Desvío Estándar de 0,7 y un Coeficiente de Variabilidad del $30,4 \%$ permiten afirmar que los datos están muy concentrados y que el promedio es representativo. 


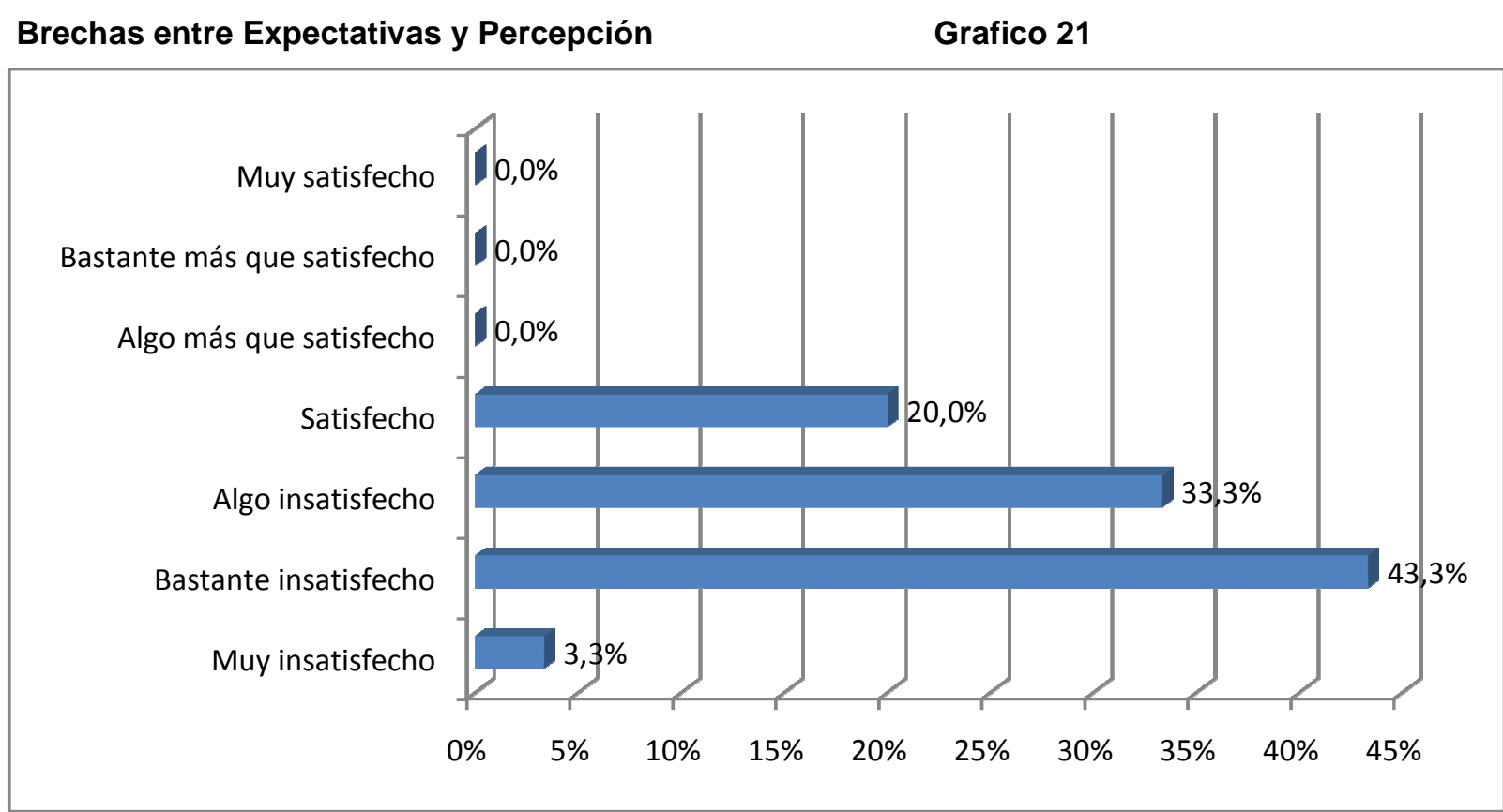

Fuente: elaboración propia

La brecha arroja un 20\% "Satisfecho", un 33,3\% "Algo Insatisfecho" y un 43,3\% "Bastante Insatisfecho", lo cual significa que se observa un déficit entre la expectativa y la percepción.

\section{8.- Capacidad para trabajar en equipo para alcanzar una meta común}

\section{Expectativas}

Grafico 22

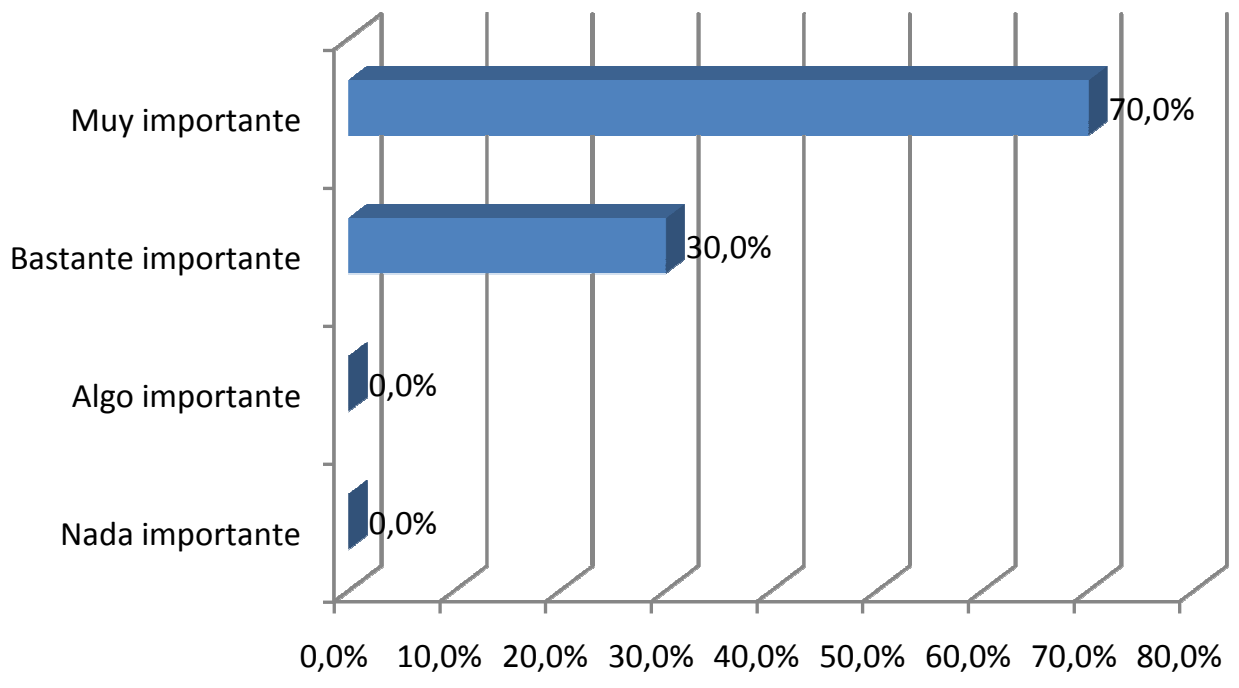




\begin{tabular}{|c|c|}
\hline Saldo de respuesta & 3,70 \\
\hline D.S. & 0,5 \\
\hline C.V. & $13,5 \%$ \\
\hline
\end{tabular}

Fuente: elaboración propia

Con un "Saldo de respuesta" de 3,70 la situación se presenta como "Muy importante". Un Desvío Estándar de 0,5 y un Coeficiente de Variabilidad del 13,5\% permiten afirmar que los datos están muy concentrados y que el promedio es representativo.

\section{Percepción}

Grafico 23

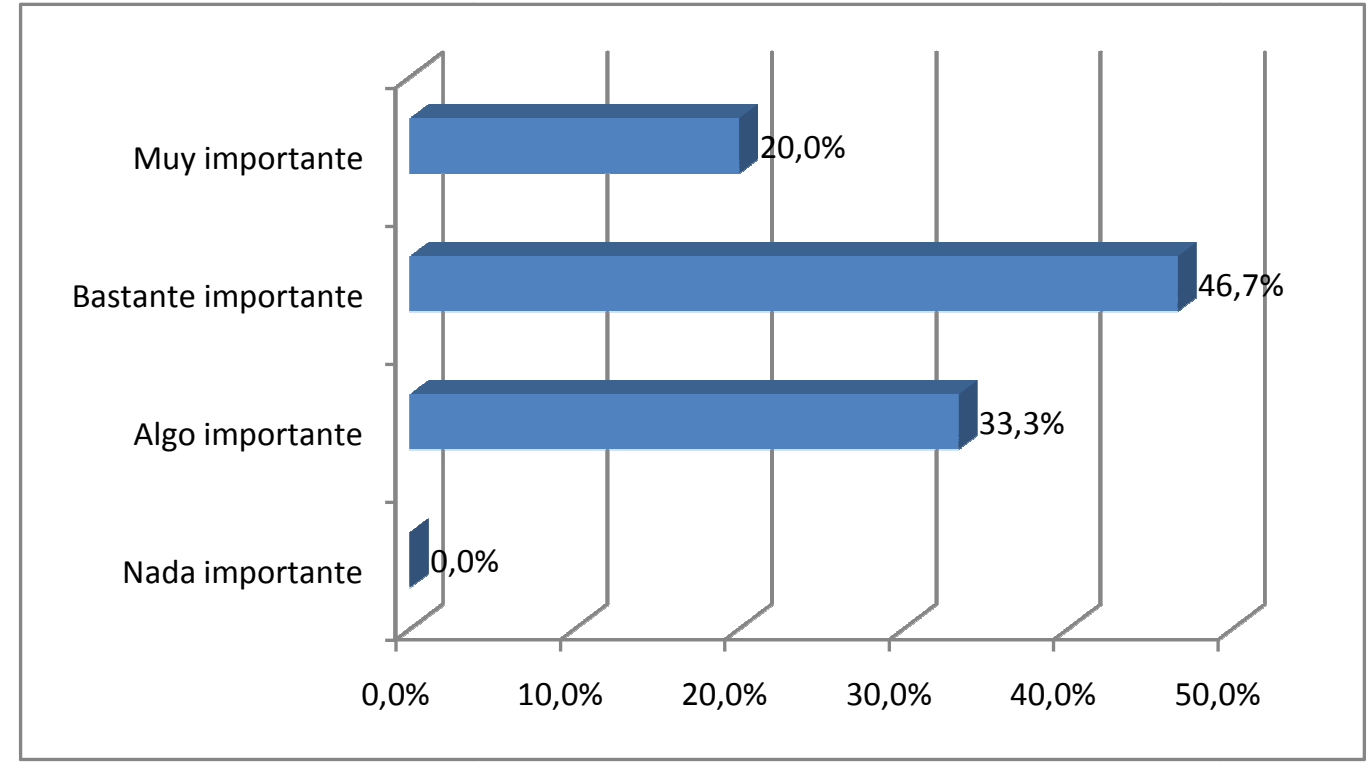

Tabla 16

\begin{tabular}{|l|r|}
\hline Saldo de respuesta & 2,87 \\
\hline D.S. & 0,7 \\
\hline C.V. & $24,4 \%$ \\
\hline
\end{tabular}

Fuente: elaboración propia

Con un "Saldo de respuesta" de 2,87 la situación se presenta como "Bastante importante". Un Desvío Estándar de 0,7 y un Coeficiente de Variabilidad del 24,4\% permiten afirmar que los datos están muy concentrados y que el promedio es representativo. 


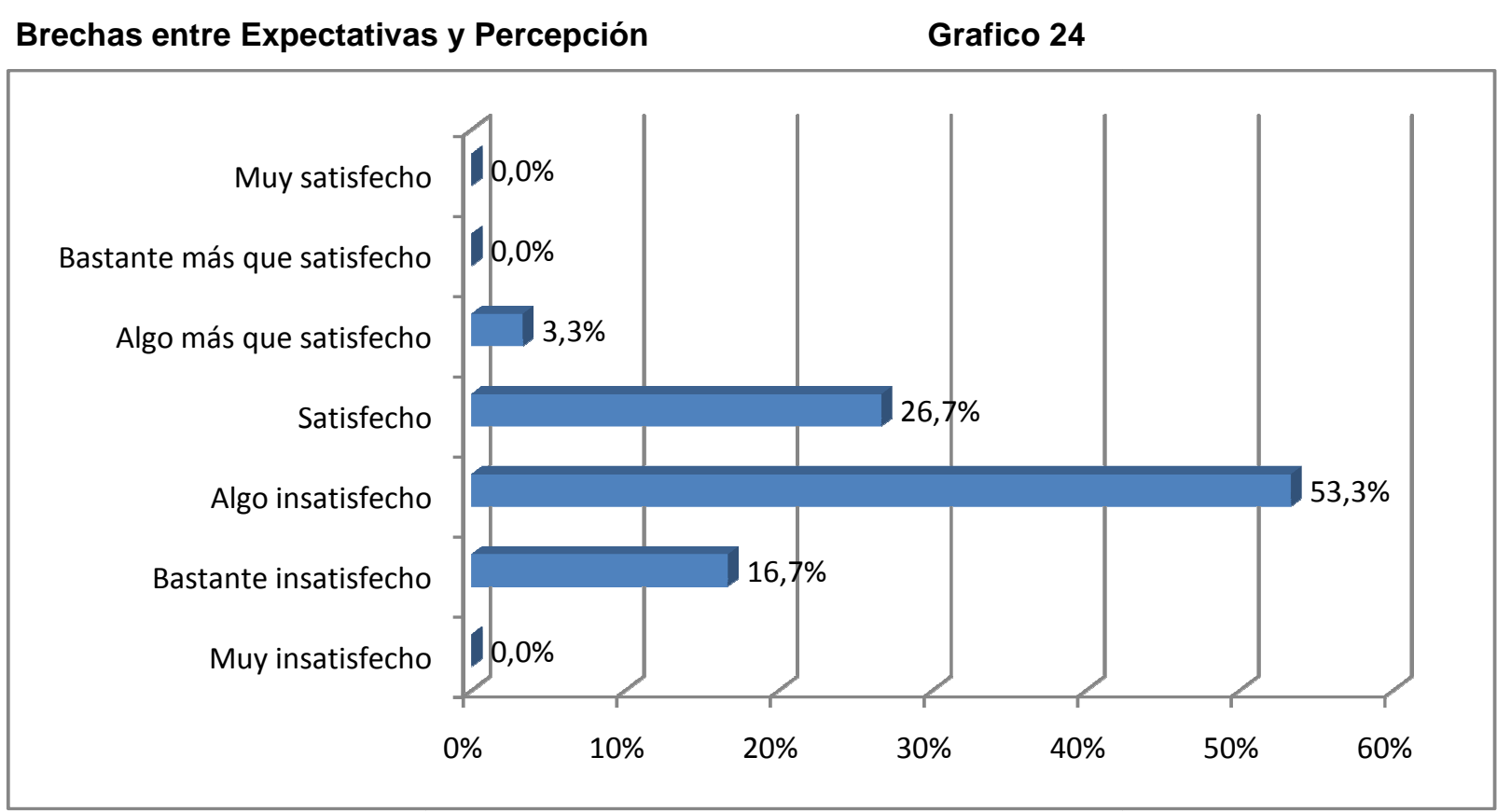

Fuente: elaboración propia

La brecha arroja un 26,7\% "Satisfecho", un 53,3\% "Algo Insatisfecho" y un 16,7\% "Bastante Insatisfecho", lo cual significa que se observa un déficit entre la expectativa y la percepción.

\section{9.- Capacidad para trabajar de forma independiente (sin necesidad de supervisión permanente)}

\section{Expectativas}

\section{Grafico 25}

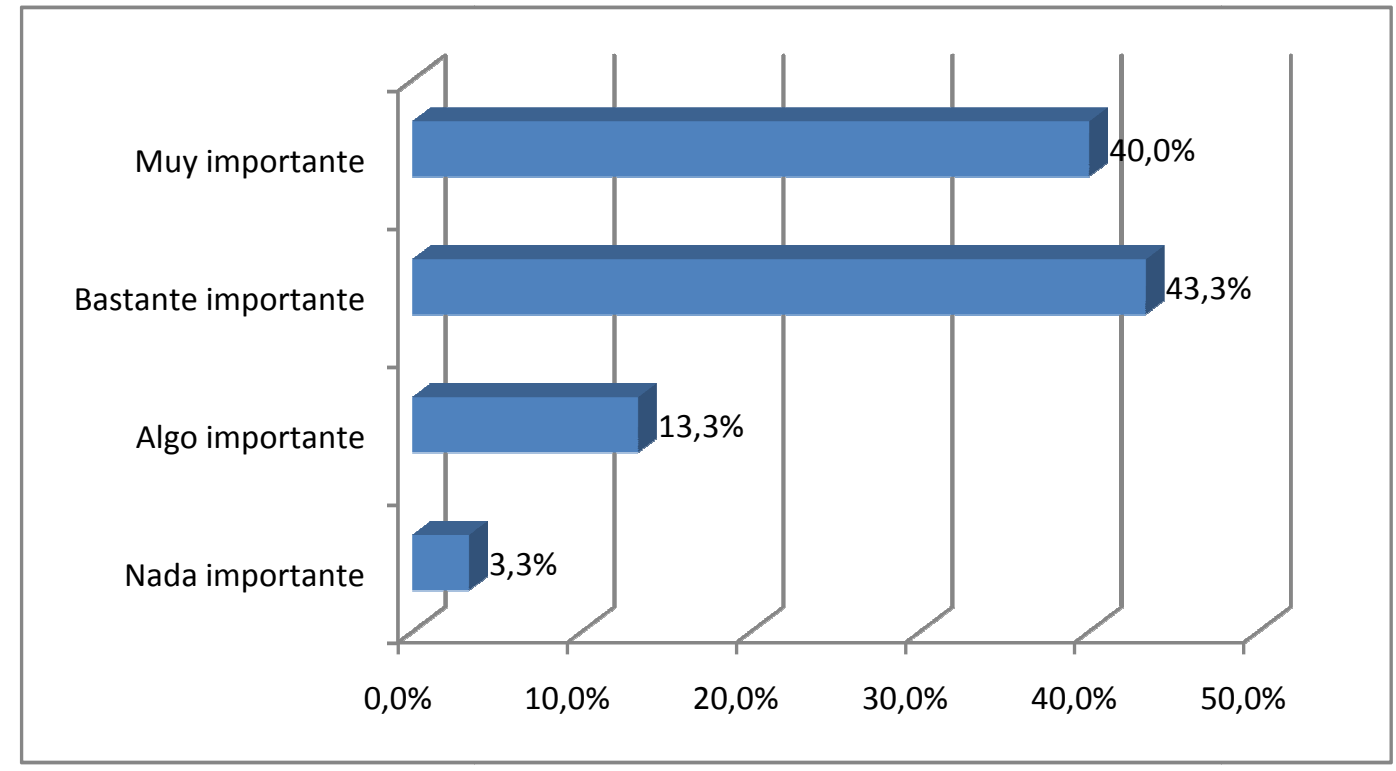

Tabla 17

\begin{tabular}{|l|r|}
\hline Saldo de respuesta & 3,20 \\
\hline D.S. & 0,8 \\
\hline C.V. & $25,0 \%$ \\
\hline
\end{tabular}

Fuente: elaboración propia 
Con un "Saldo de respuesta" de 3,20 la situación se presenta intermedia entre "Bastante importante" a "Muy importante". Un Desvío Estándar de 0,8 y un Coeficiente de Variabilidad del $25 \%$ permiten afirmar que los datos están muy concentrados y que el promedio es representativo.

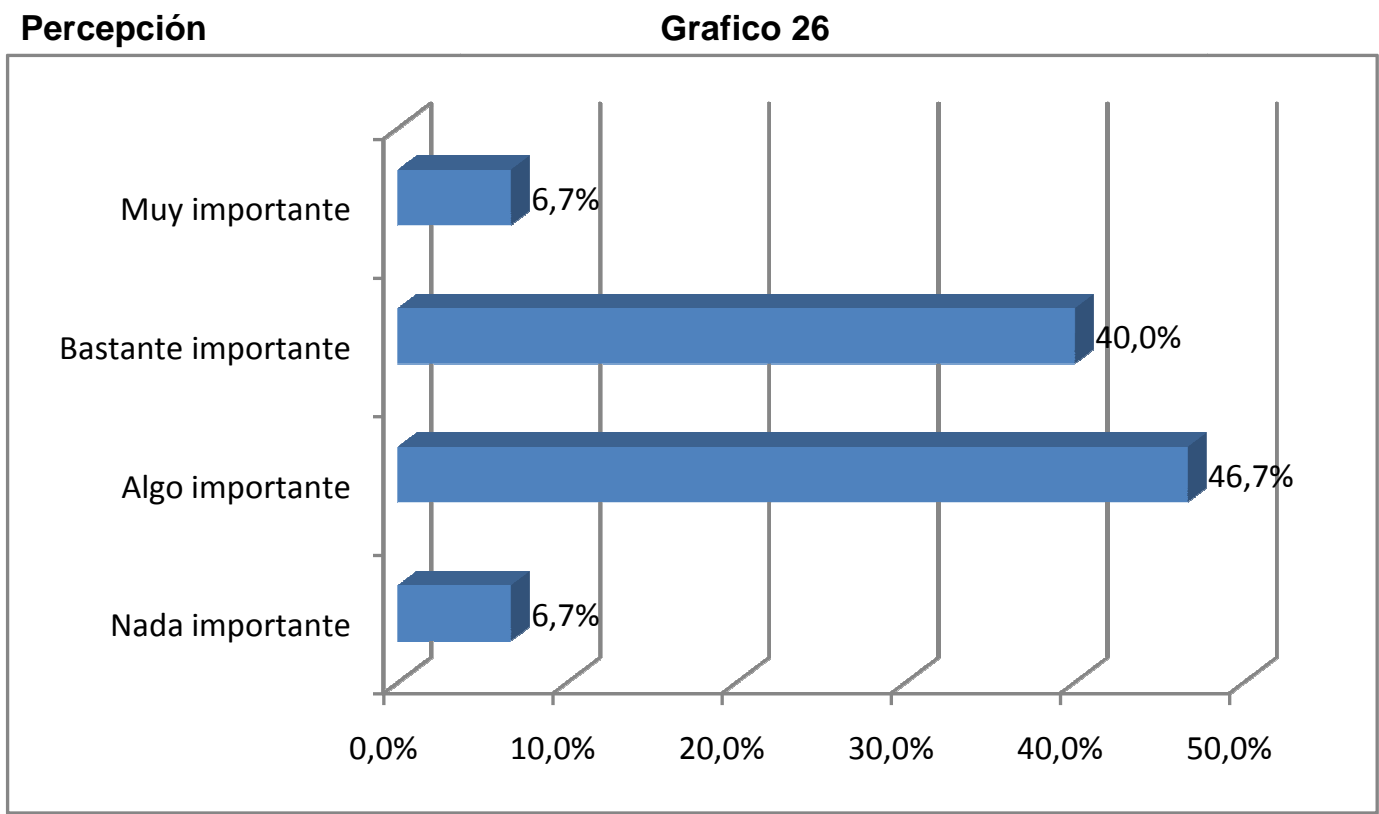

Tabla 18

\begin{tabular}{|l|r|}
\hline Saldo de respuesta & 2,47 \\
\hline D.S. & 0,7 \\
\hline C.V. & $28,4 \%$ \\
\hline
\end{tabular}

Fuente: elaboración propia

Con un "Saldo de respuesta" de 2,47 la situación se presenta intermedia entre "Bastante importante" a "Algo importante". Un Desvío Estándar de 0,7 y un Coeficiente de Variabilidad del 28,4\% permiten afirmar que los datos están muy concentrados y que el promedio es representativo. 


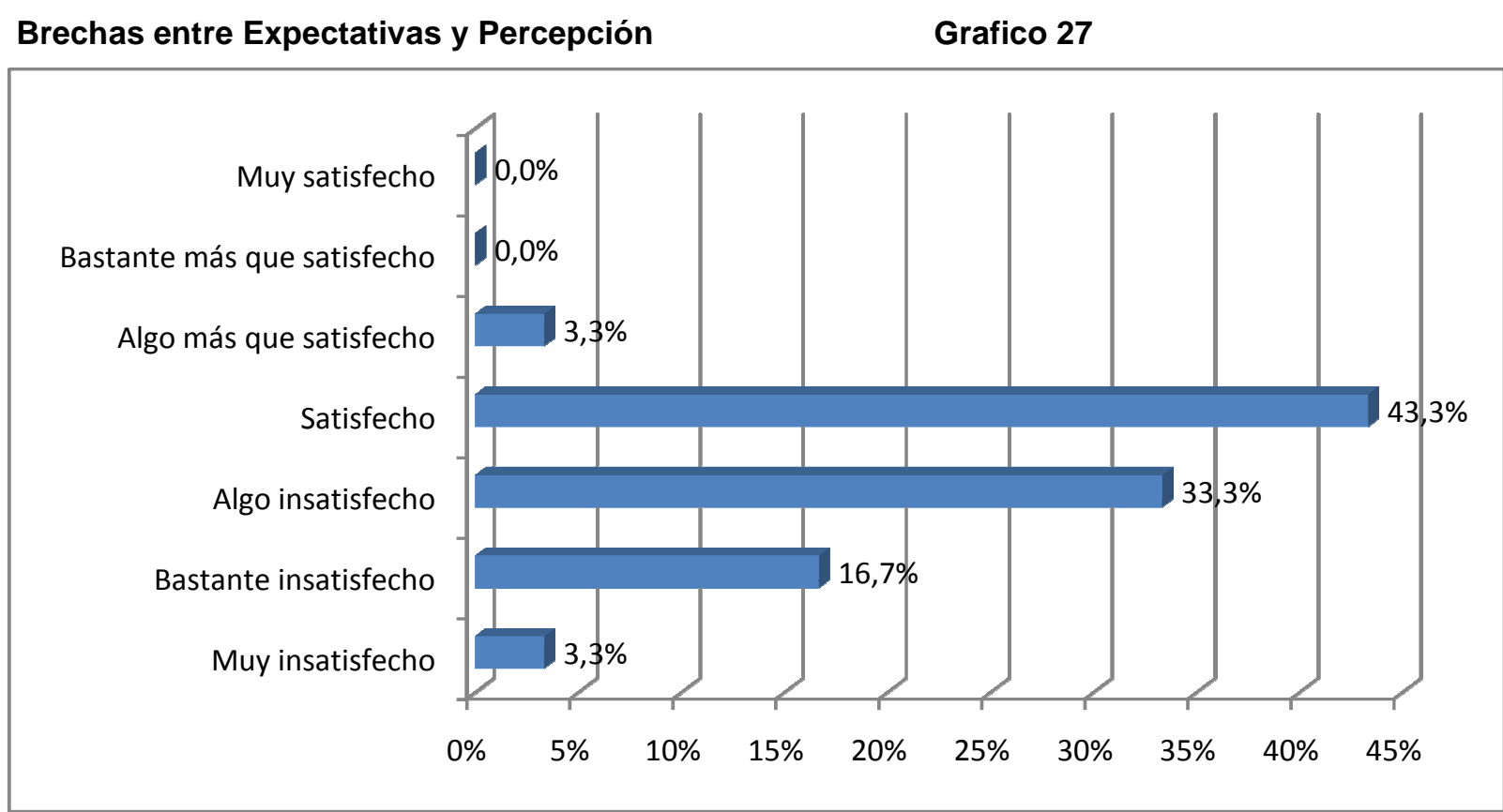

Fuente: elaboración propia

La brecha arroja un 43,3\% "Satisfecho", un 33,3\% "Algo Insatisfecho" y un 16,7\% "Bastante Insatisfecho", lo cual significa que se observa un déficit entre la expectativa y la percepción.

\subsection{0.- Formación en valores y principios éticos}

\section{Expectativas}

Grafico 28

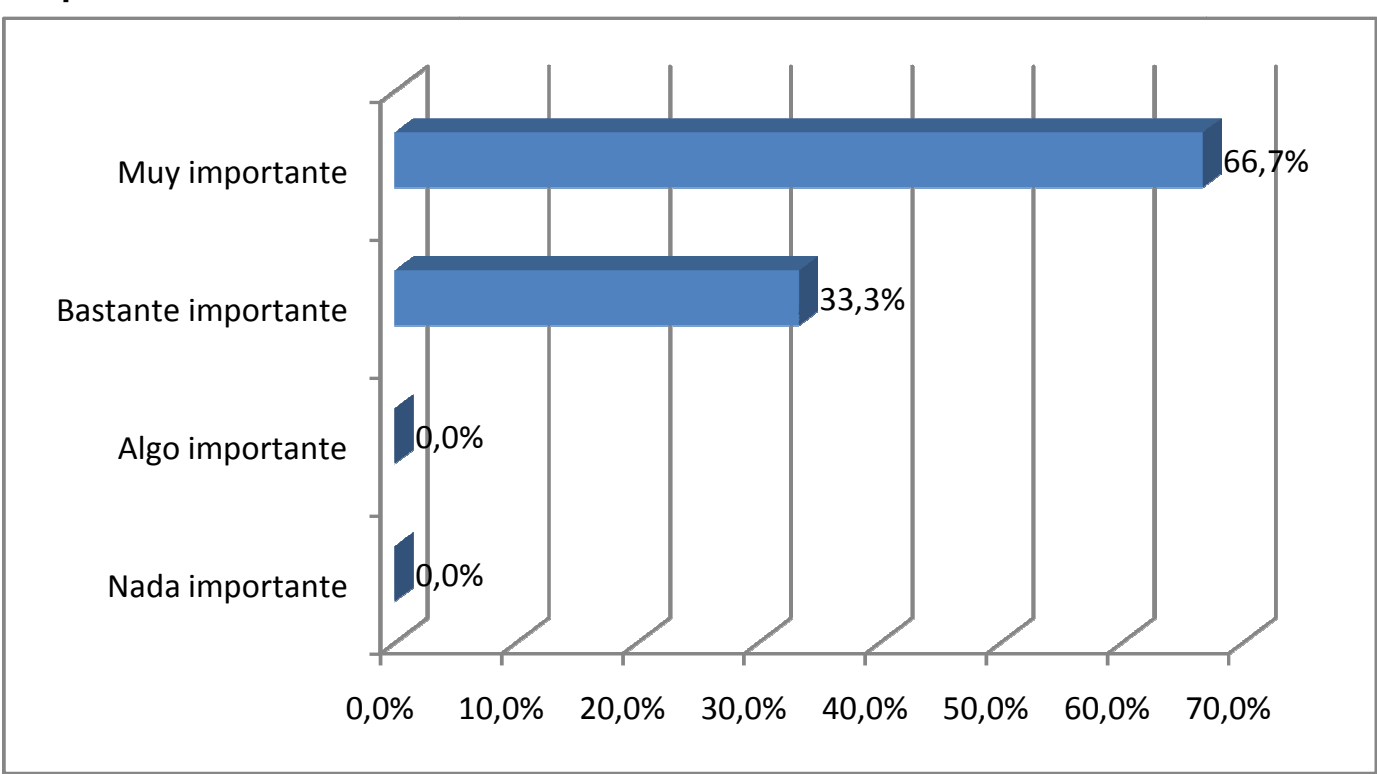

Tabla 19
\begin{tabular}{|l|r|}
\hline Saldo de respuesta & 3,67 \\
\hline D.S. & 0,5 \\
\hline C.V. & $13,6 \%$ \\
\hline
\end{tabular}

Fuente: elaboración propia 
Con un "Saldo de respuesta" de 3,67 la situación se presenta como "Muy importante". Un Desvío Estándar de 0,5 y un Coeficiente de Variabilidad del 13,6\% permiten afirmar que los datos están muy concentrados y que el promedio es representativo.

\section{Percepción Grafico 29}

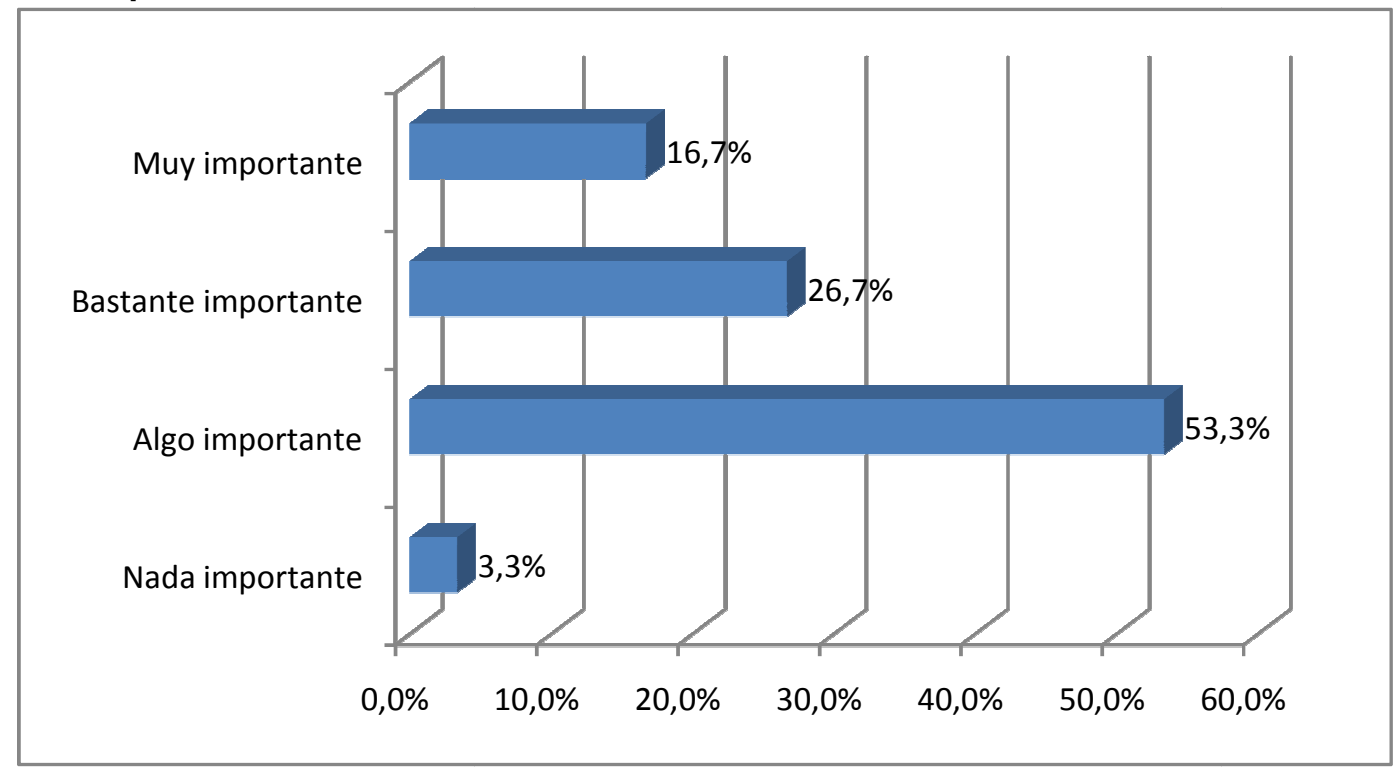

\section{Tabla 20}

\begin{tabular}{|l|r|}
\hline Saldo de respuesta & 2,57 \\
\hline D.S. & 0,8 \\
\hline C.V. & $31,2 \%$ \\
\hline
\end{tabular}

Fuente: elaboración propia

Con un "Saldo de respuesta" de 2,57 la situación se presenta como "Algo importante". Un Desvío Estándar de 0,8 y un Coeficiente de Variabilidad del 31,2\% permiten afirmar que los datos están muy concentrados y que el promedio es representativo. 


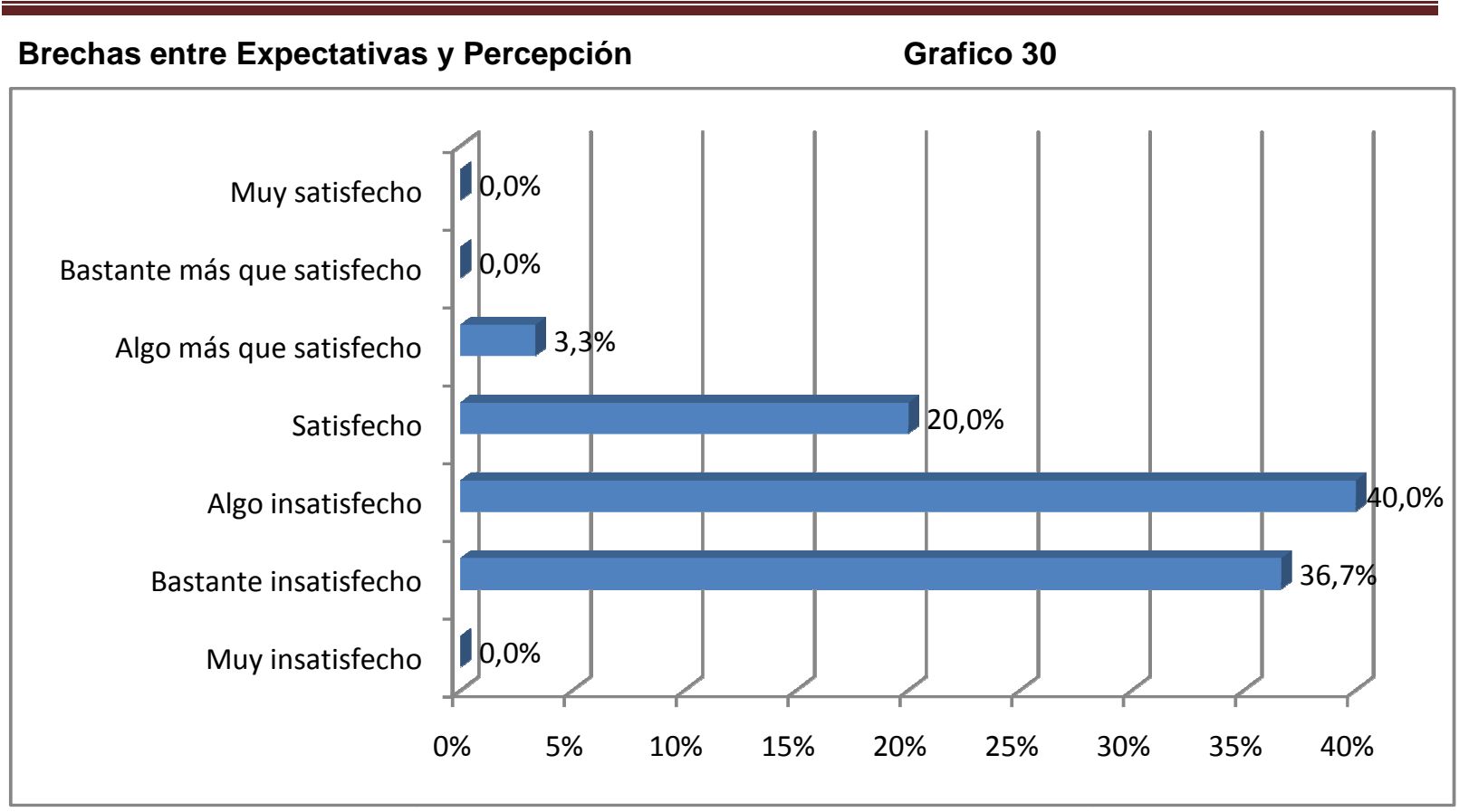

Fuente: elaboración propia

La brecha arroja un 20\% "Satisfecho", un 40\% "Algo Insatisfecho" y un 36,7\% "Bastante Insatisfecho", lo cual significa que se observa un gran déficit entre la expectativa y la percepción.

\subsection{1.- Capacidad para identificar, plantear y resolver problemas}

Expectativas

Grafico 31

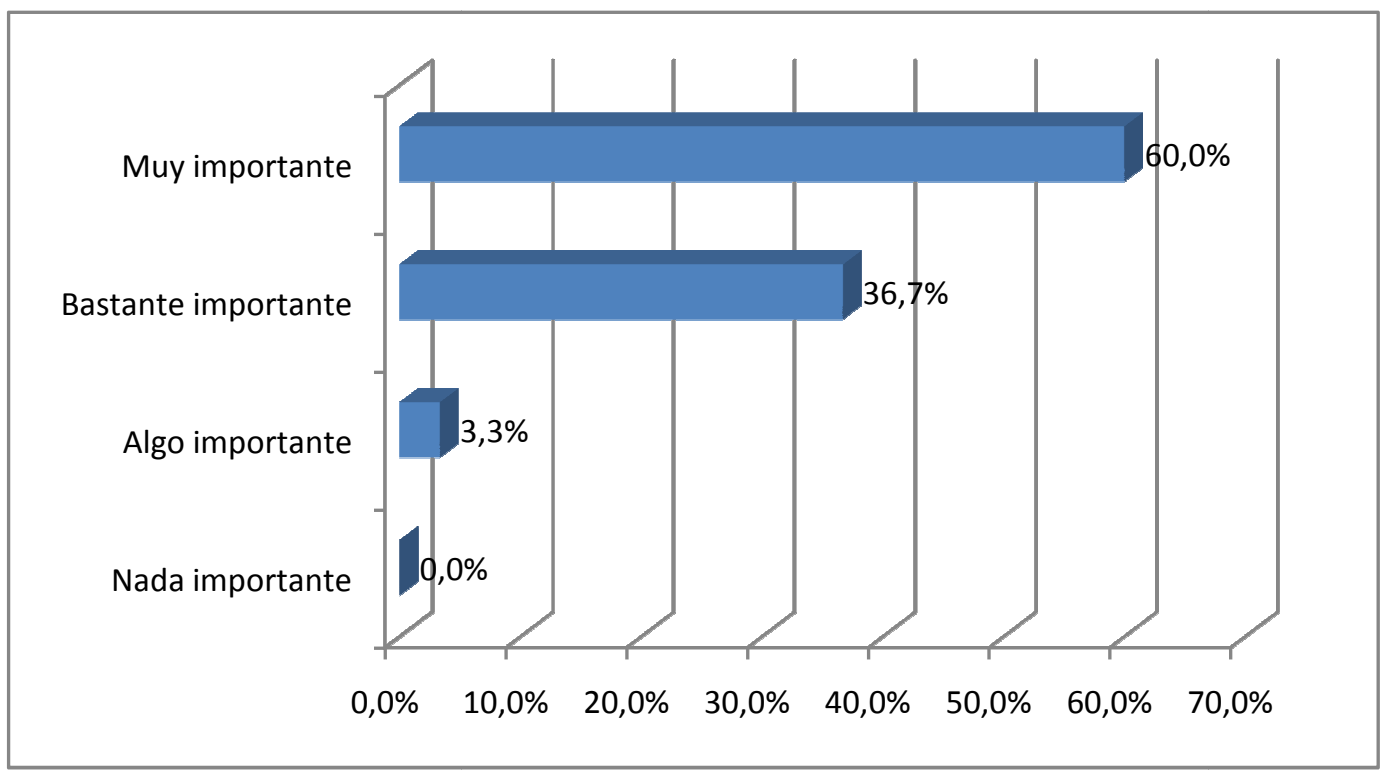

\section{Tabla 21}

\begin{tabular}{|l|r|}
\hline Saldo de respuesta & 3,57 \\
\hline D.S. & 0,6 \\
\hline C.V. & $16,8 \%$ \\
\hline
\end{tabular}

Fuente: elaboración propia 
Con un "Saldo de respuesta" de 3,57 la situación se presenta como "Muy importante". Un Desvío Estándar de 0,6 y un Coeficiente de Variabilidad del 16,8\% permiten afirmar que los datos están muy concentrados y que el promedio es representativo.

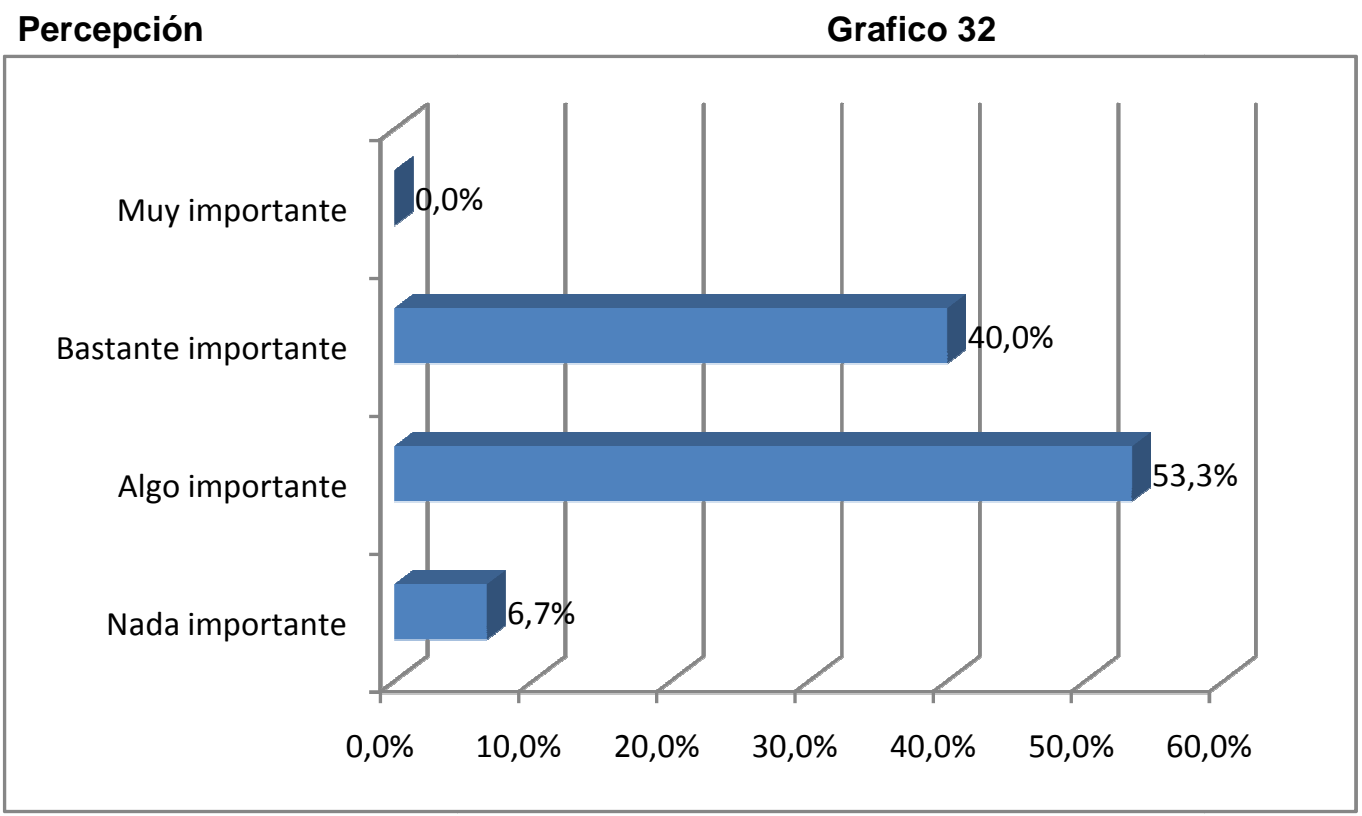

Tabla 22

\begin{tabular}{|l|r|}
\hline Saldo de respuesta & 2,33 \\
\hline D.S. & 0,6 \\
\hline C.V. & $25,7 \%$ \\
\hline
\end{tabular}

Fuente: elaboración propia

Con un "Saldo de respuesta" de 2,33 la situación se presenta intermedia entre "Bastante importante" a "Algo importante". Un Desvío Estándar de 0,6 y un Coeficiente de Variabilidad del 25,7\% permiten afirmar que los datos están muy concentrados y que el promedio es representativo. 


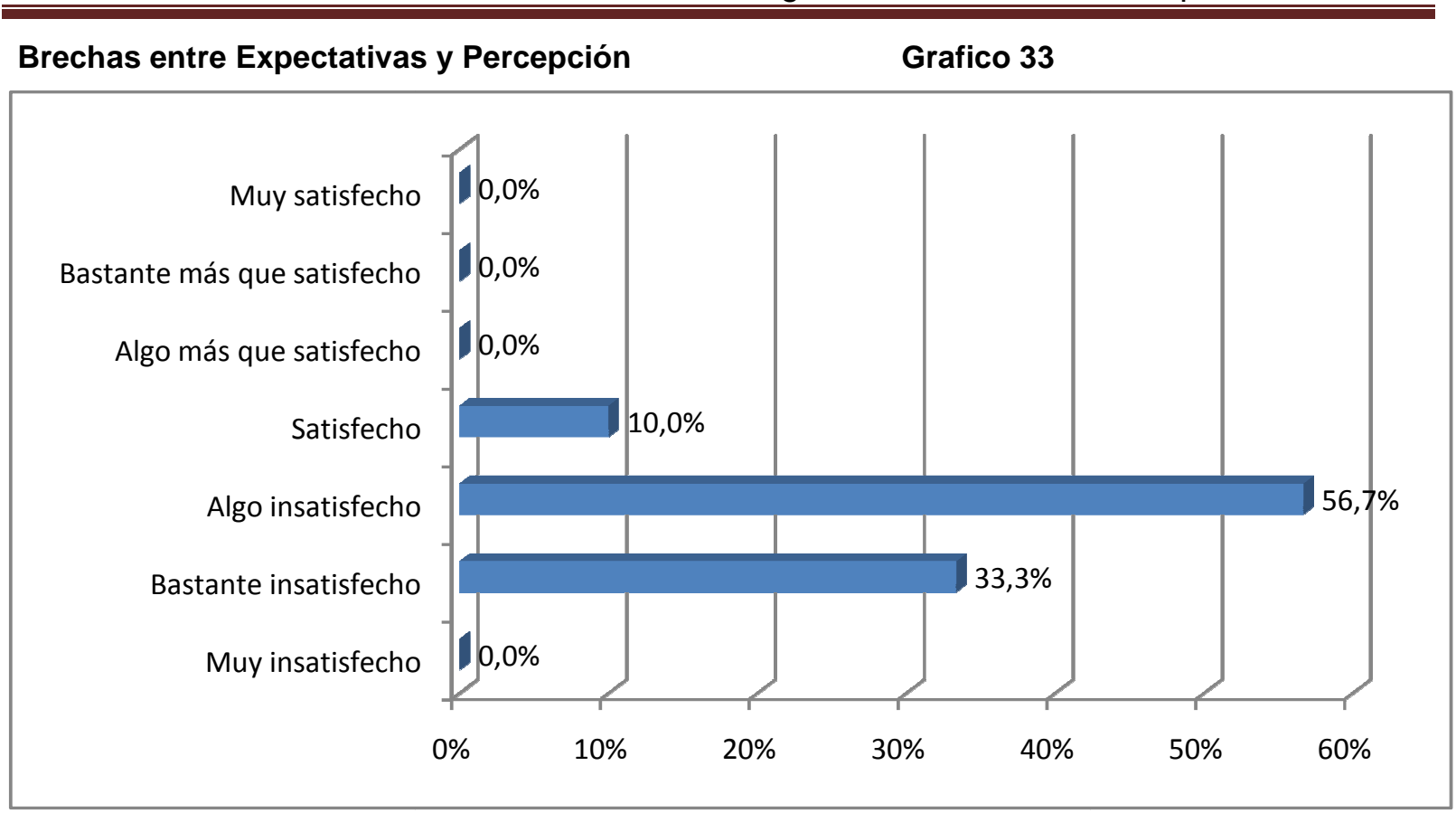

Fuente: elaboración propia

La brecha arroja un 10\% "Satisfecho", un 56,7\% "Algo Insatisfecho" y un 33,3\% "Bastante Insatisfecho", lo cual significa que se observa un gran déficit entre la expectativa y la percepción.

\subsection{2.- Disposición para aprender y mantenerse actualizado/a}

Expectativas

Grafico 34

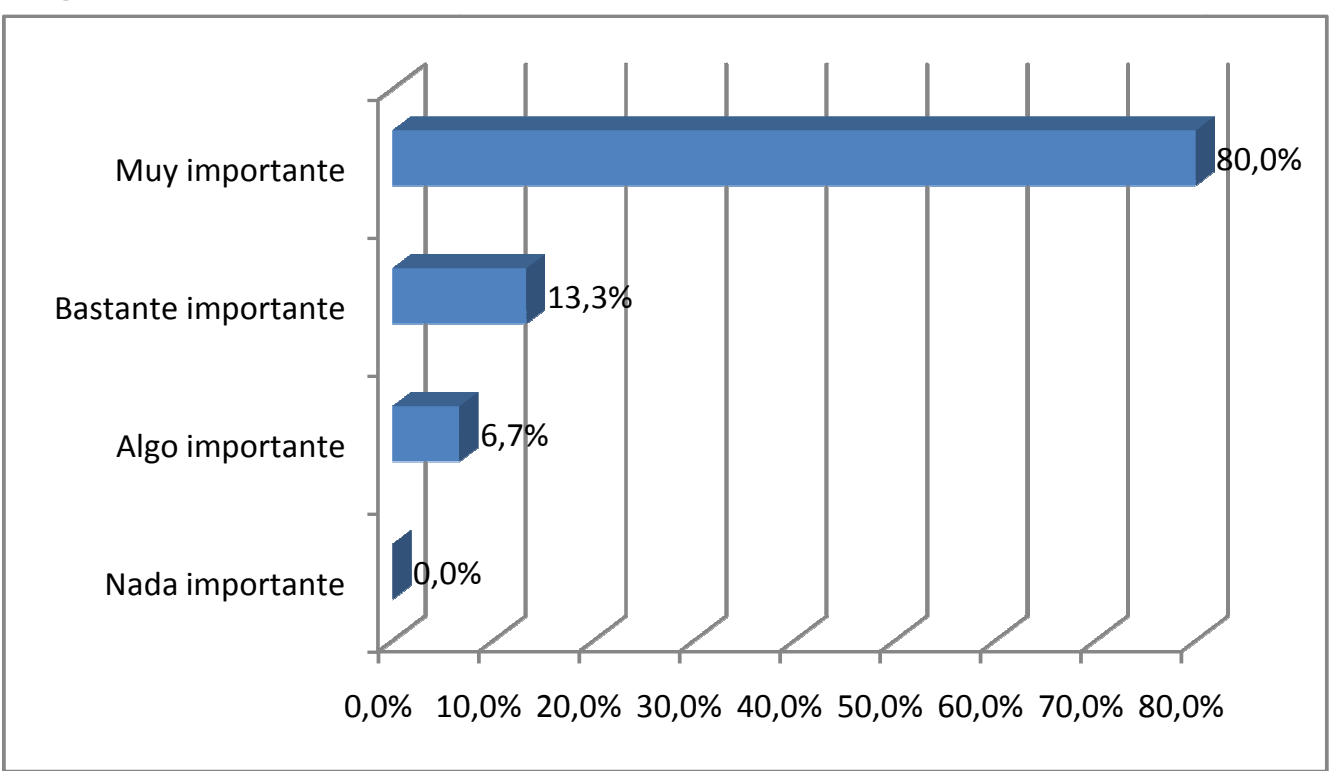

\section{Tabla 23}

\begin{tabular}{|l|r|}
\hline Saldo de respuesta & 3,73 \\
\hline D.S. & 0,6 \\
\hline C.V. & $16,1 \%$ \\
\hline
\end{tabular}

Fuente: elaboración propia 
Con un "Saldo de respuesta" de 3,73 la situación se presenta como "Muy importante". Un Desvío Estándar de 0,6 y un Coeficiente de Variabilidad del 16,1\% permiten afirmar que los datos están muy concentrados y que el promedio es representativo.

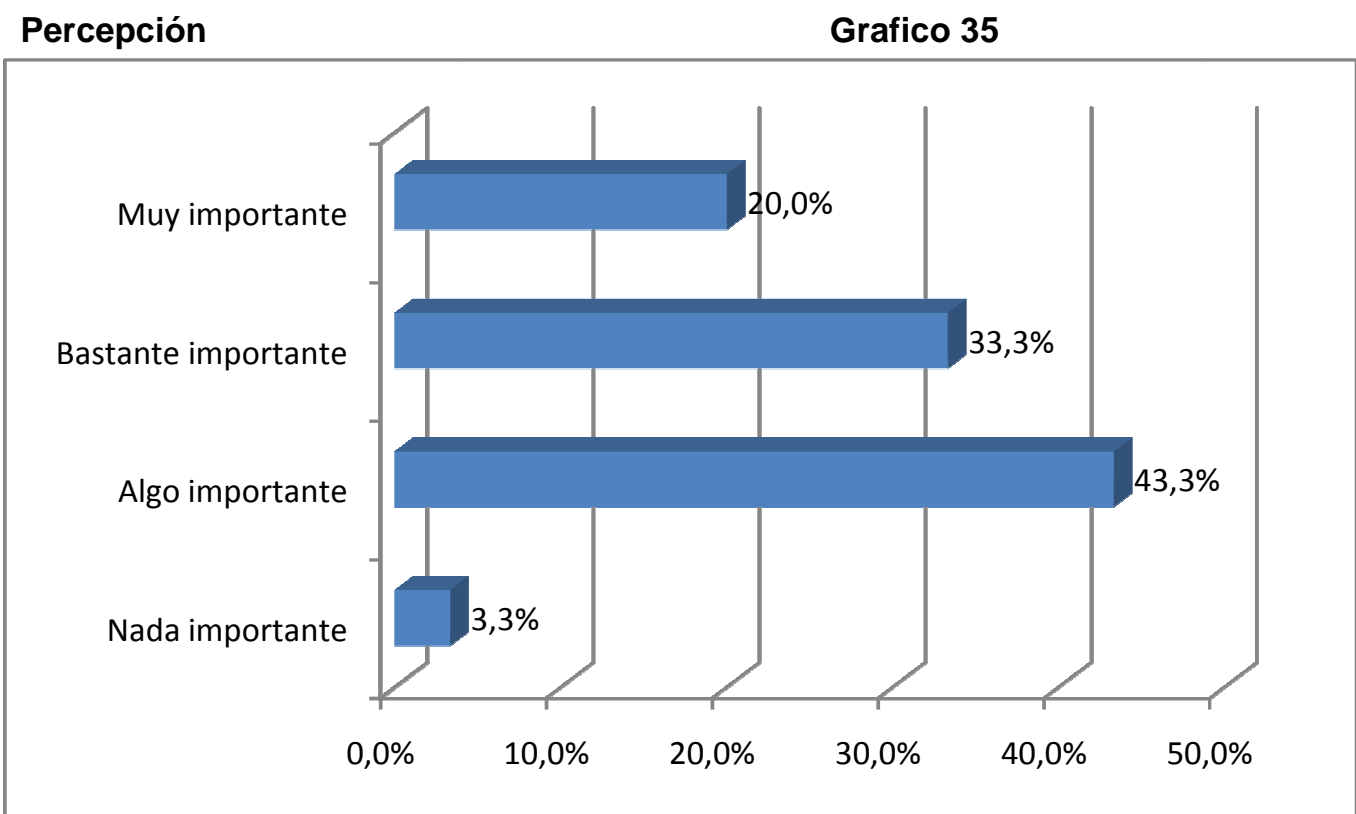

\section{Tabla 24}

\begin{tabular}{|l|r|}
\hline Saldo de respuesta & 2,70 \\
\hline D.S. & 0,8 \\
\hline C.V. & $29,6 \%$ \\
\hline
\end{tabular}

Fuente: elaboración propia

Con un "Saldo de respuesta" de 2,70 la situación se presenta intermedia entre "Bastante importante" a "Algo importante". Un Desvío Estándar de 0,8 y un Coeficiente de Variabilidad del 29,6\% permiten afirmar que los datos están muy concentrados y que el promedio es representativo. 


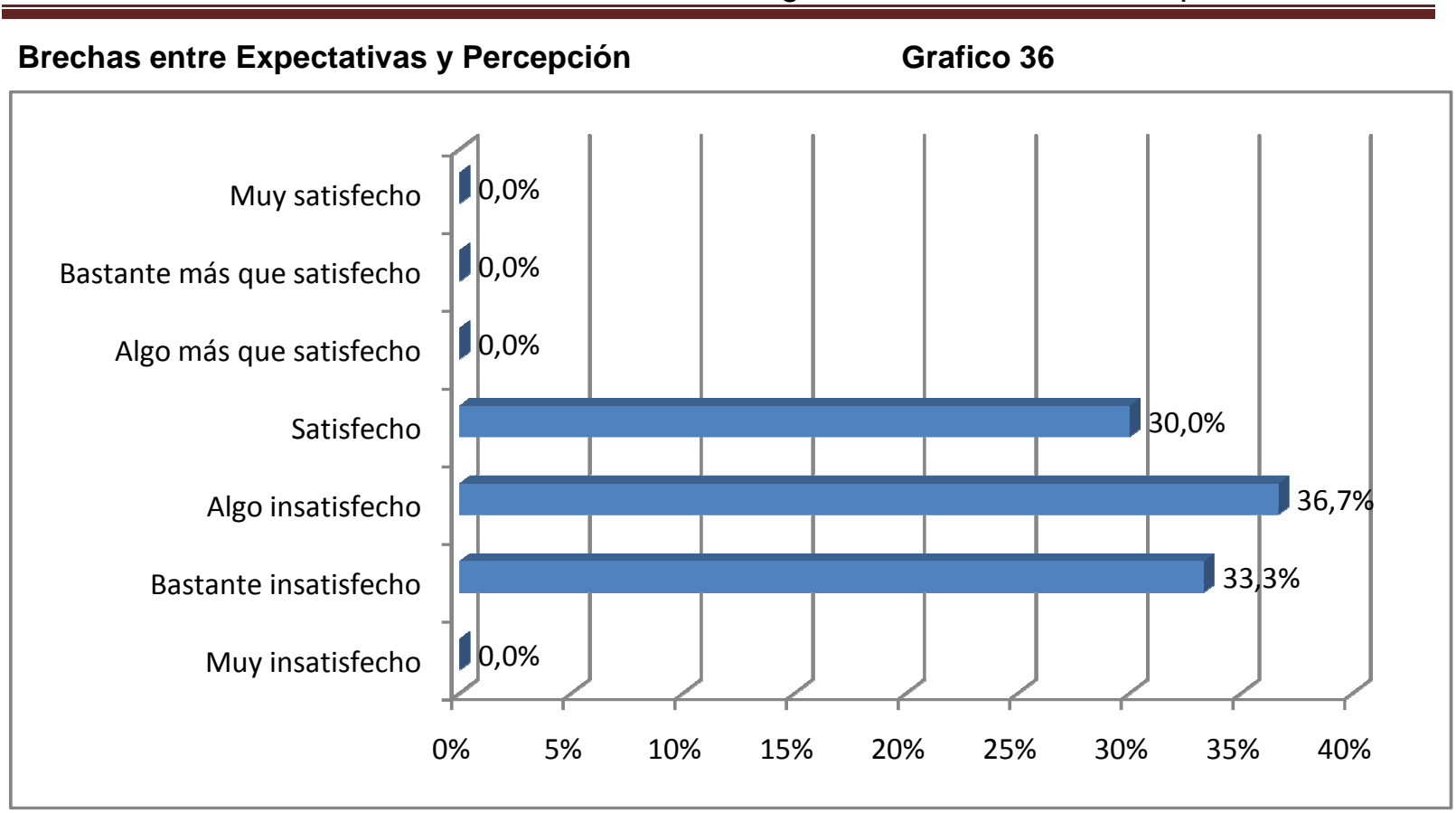

Fuente: elaboración propia

La brecha arroja un 30\% "Satisfecho", un 36,7\% "Algo Insatisfecho" y un 33,3\% "Bastante Insatisfecho", lo cual significa que se observa un gran déficit entre la expectativa y la percepción.

\subsection{3.- Capacidad para manejar información procedente de áreas y fuentes diversas}

Expectativas

Grafico 37

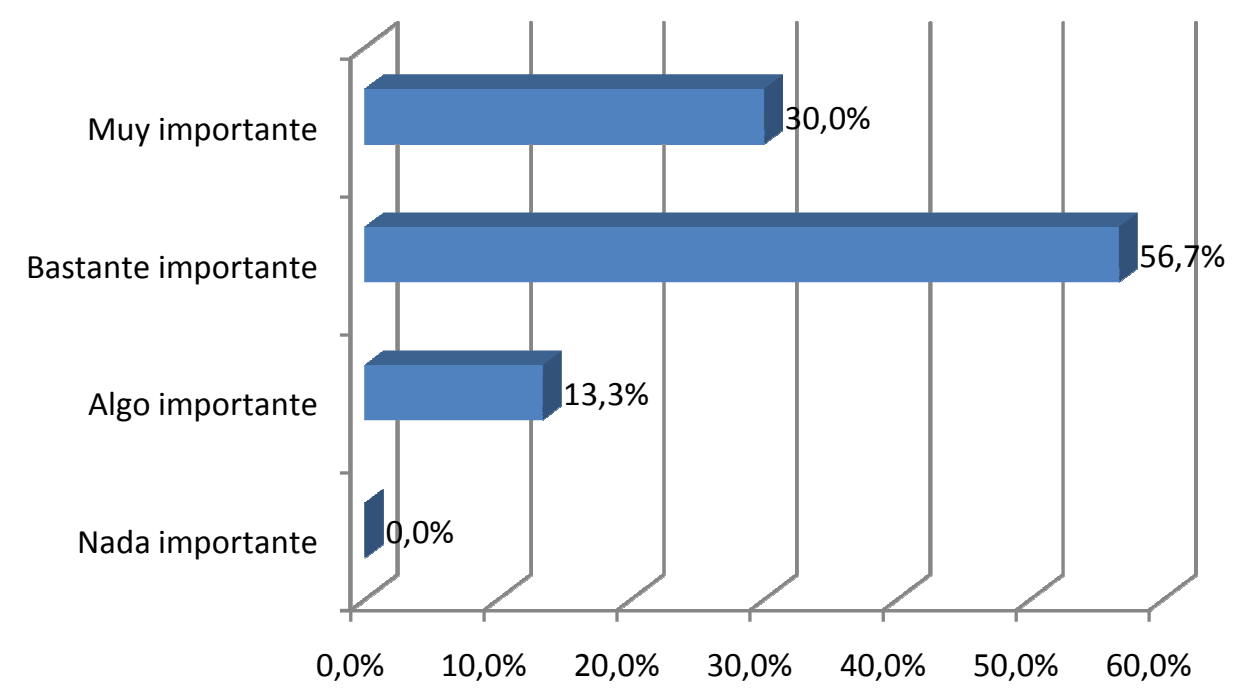




\begin{tabular}{l}
\hline Tabla 25 \\
\begin{tabular}{|l|r|}
\hline Saldo de respuesta & 3,17 \\
\hline D.S. & 0,6 \\
\hline C.V. & $18,9 \%$ \\
\hline
\end{tabular}
\end{tabular}

Fuente: elaboración propia

Con un "Saldo de respuesta" de 3,17 la situación se presenta intermedia entre "Bastante importante" a "Muy importante". Un Desvío Estándar de 0,6 y un Coeficiente de Variabilidad del $18,9 \%$ permiten afirmar que los datos están muy concentrados y que el promedio es representativo.

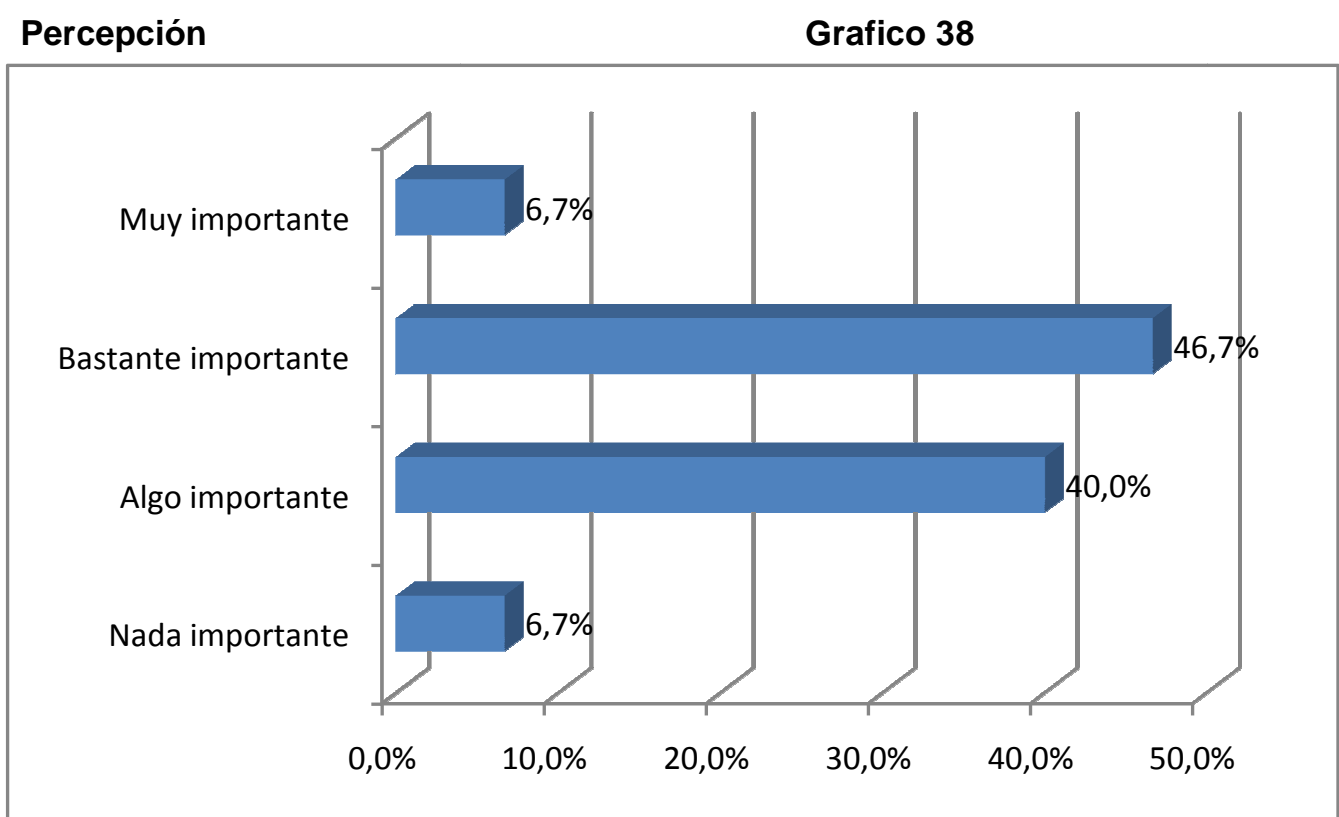

Tabla 26
\begin{tabular}{|l|r|}
\hline Saldo de respuesta & 2,53 \\
\hline D.S. & 0,7 \\
\hline C.V. & $27,6 \%$ \\
\hline
\end{tabular}

Fuente: elaboración propia

Con un "Saldo de respuesta" de 2,53 la situación se presenta intermedia entre "Bastante importante" a "Algo importante". Un Desvío Estándar de 0,7 y un Coeficiente de Variabilidad del 27,6\% permiten afirmar que los datos están muy concentrados y que el promedio es representativo. 


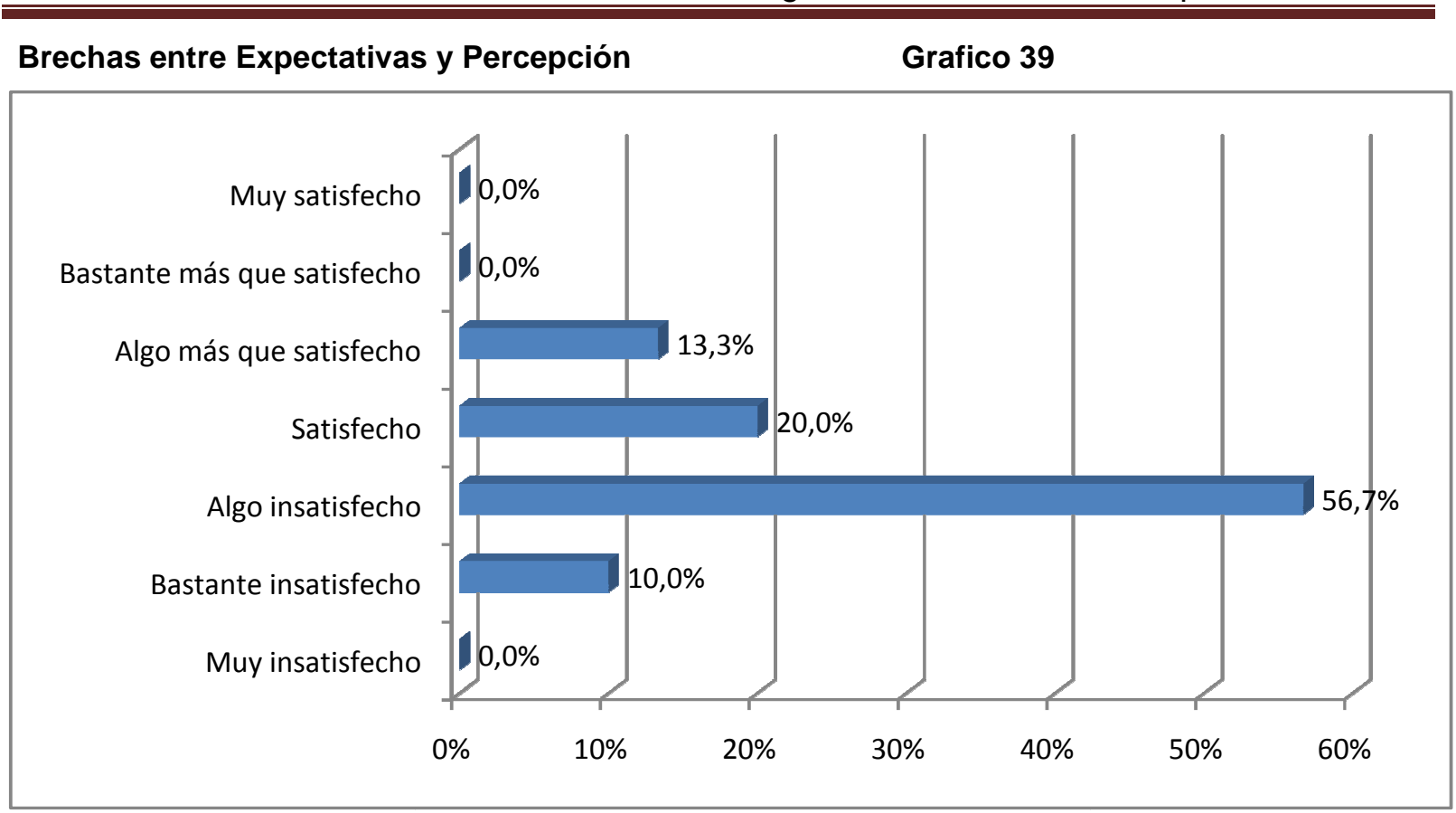

Fuente: elaboración propia

La brecha arroja un 13,3\% "Algo más que satisfecho", un 20\% "Satisfecho", un $56,7 \%$ "Algo Insatisfecho" y un 10\% "Bastante Insatisfecho", lo cual significa que se observa un gran déficit entre la expectativa y la percepción.

\subsection{4.- Capacidad creativa e innovadora}

Expectativas

\section{Grafico 40}

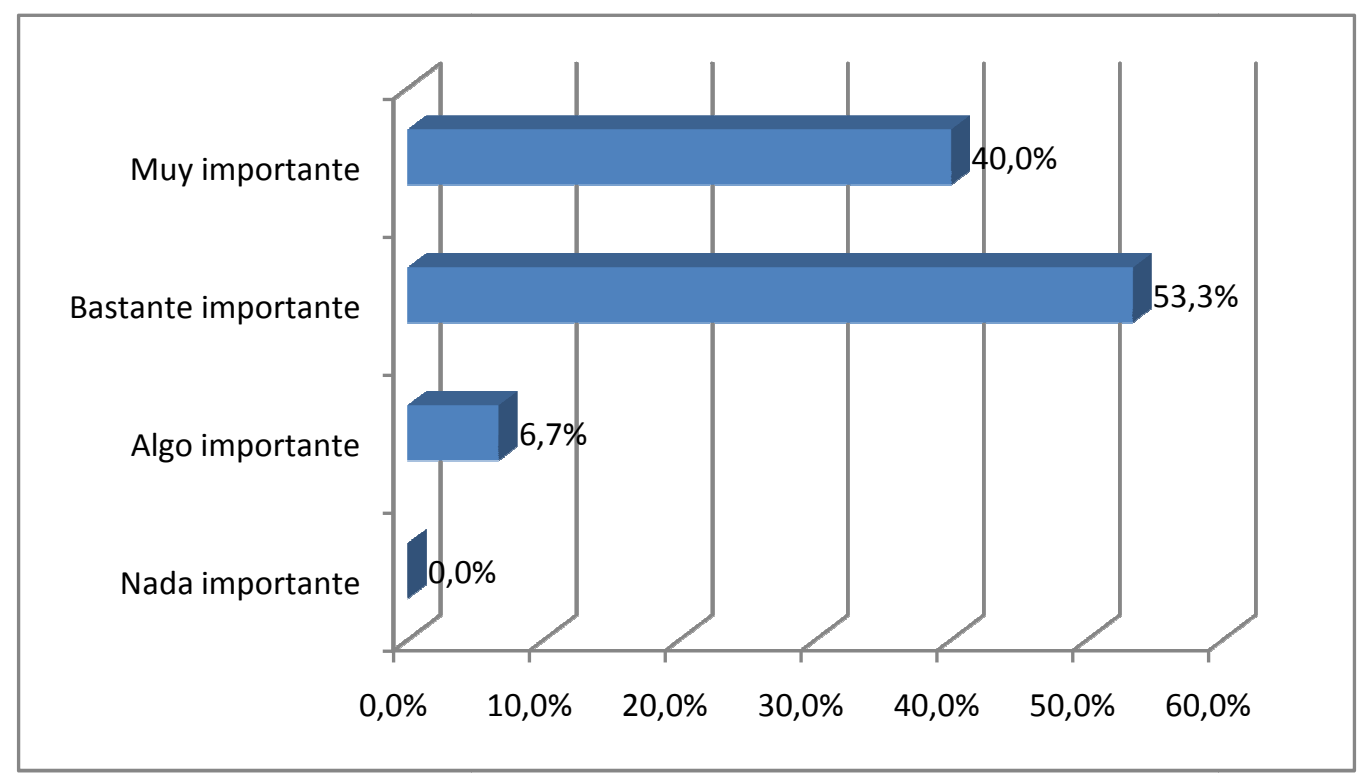

\section{Tabla 27}

\begin{tabular}{|l|r|}
\hline Saldo de respuesta & 3,33 \\
\hline D.S. & 0,6 \\
\hline C.V. & $18,0 \%$ \\
\hline
\end{tabular}

Fuente: elaboración propia 
Con un "Saldo de respuesta" de 3,33 la situación se presenta intermedia entre "Bastante importante" a "Muy importante". Un Desvío Estándar de 0,6 y un Coeficiente de Variabilidad del 18\% permiten afirmar que los datos están muy concentrados y que el promedio es representativo.

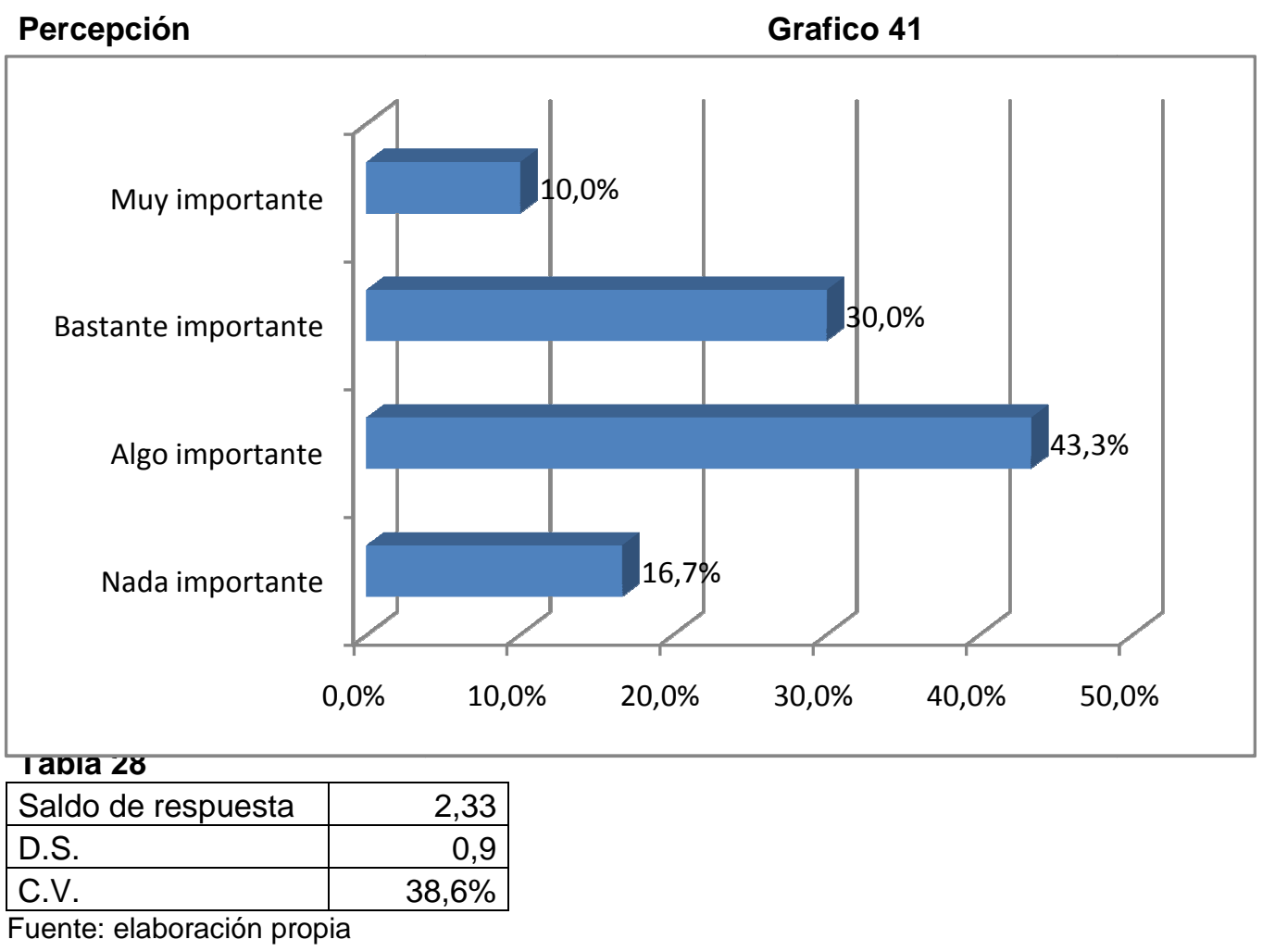

Con un "Saldo de respuesta" de 2,33 la situación se presenta intermedia entre "Bastante importante" a "Algo importante". Un Desvío Estándar de 0,9 y un Coeficiente de Variabilidad del $38,6 \%$ permiten afirmar que los datos están concentrados y que el promedio es representativo. 


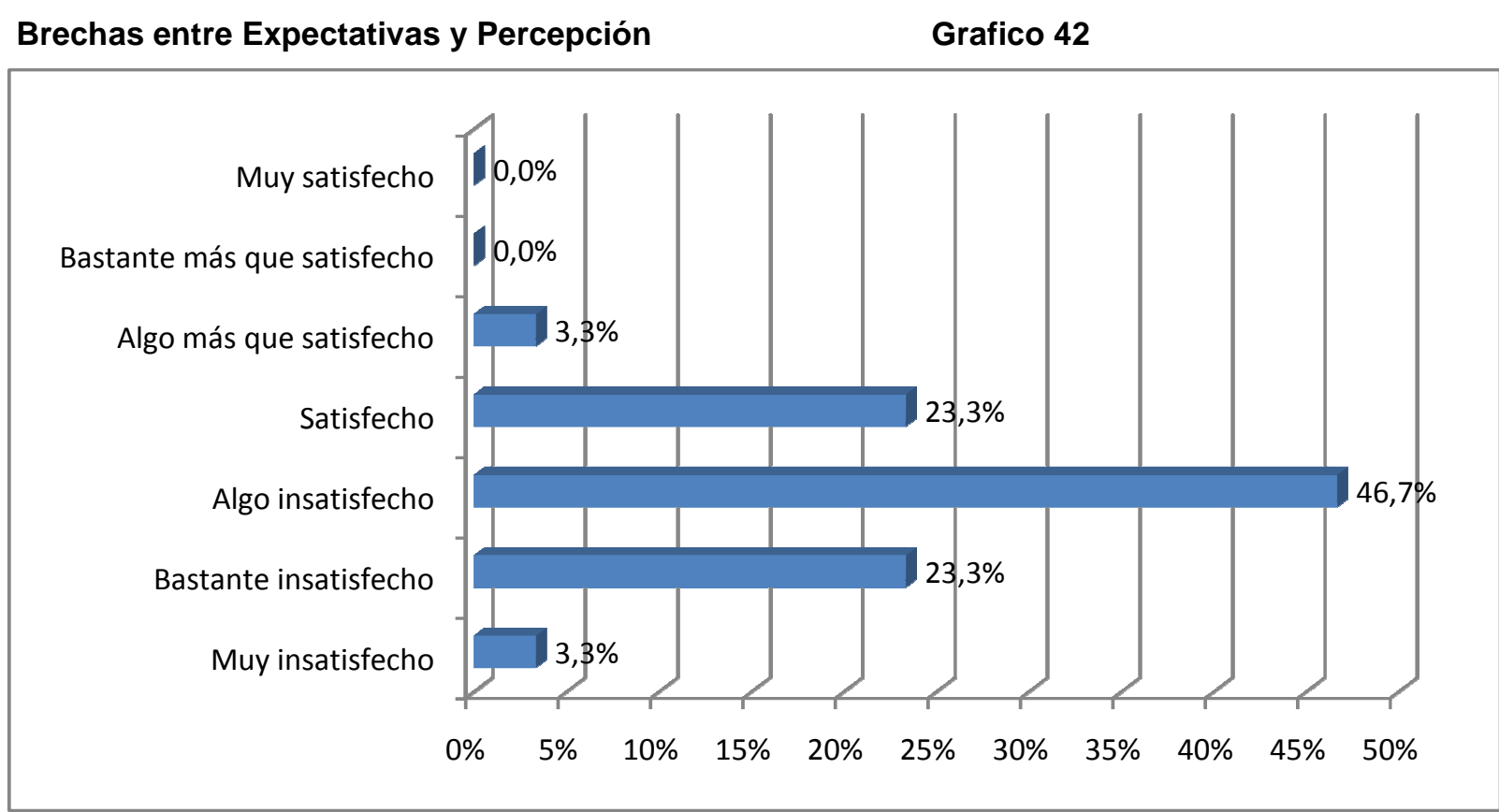

Fuente: elaboración propia

La brecha arroja un 23,3\% "Satisfecho", un 46,7\% "Algo Insatisfecho" y un 23,3\% "Bastante Insatisfecho", lo cual significa que se observa un gran déficit entre la expectativa y la percepción.

\subsection{5.- Capacidad para formular y gestionar proyectos}

\section{Expectativas}

\section{Grafico 43}

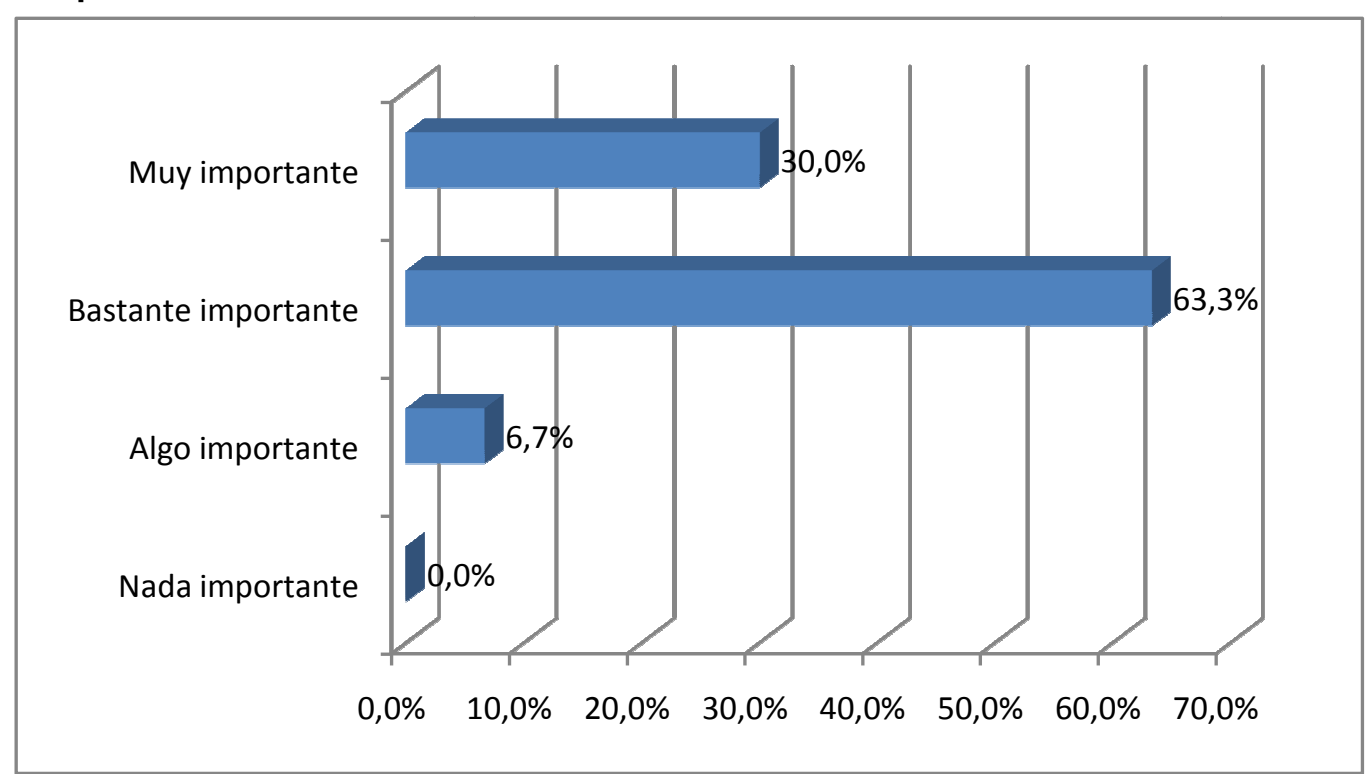

Tabla 29

\begin{tabular}{|l|r|}
\hline Saldo de respuesta & 3,23 \\
\hline D.S. & 0,6 \\
\hline C.V. & $18,6 \%$ \\
\hline
\end{tabular}

Fuente: elaboración propia 
Con un "Saldo de respuesta" de 3,23 la situación se presenta intermedia entre "Bastante importante" a "Muy importante". Un Desvío Estándar de 0,6 y un Coeficiente de Variabilidad del 18,6\% permiten afirmar que los datos están muy concentrados y que el promedio es representativo.

\section{Percepción $\quad$ Grafico 44}

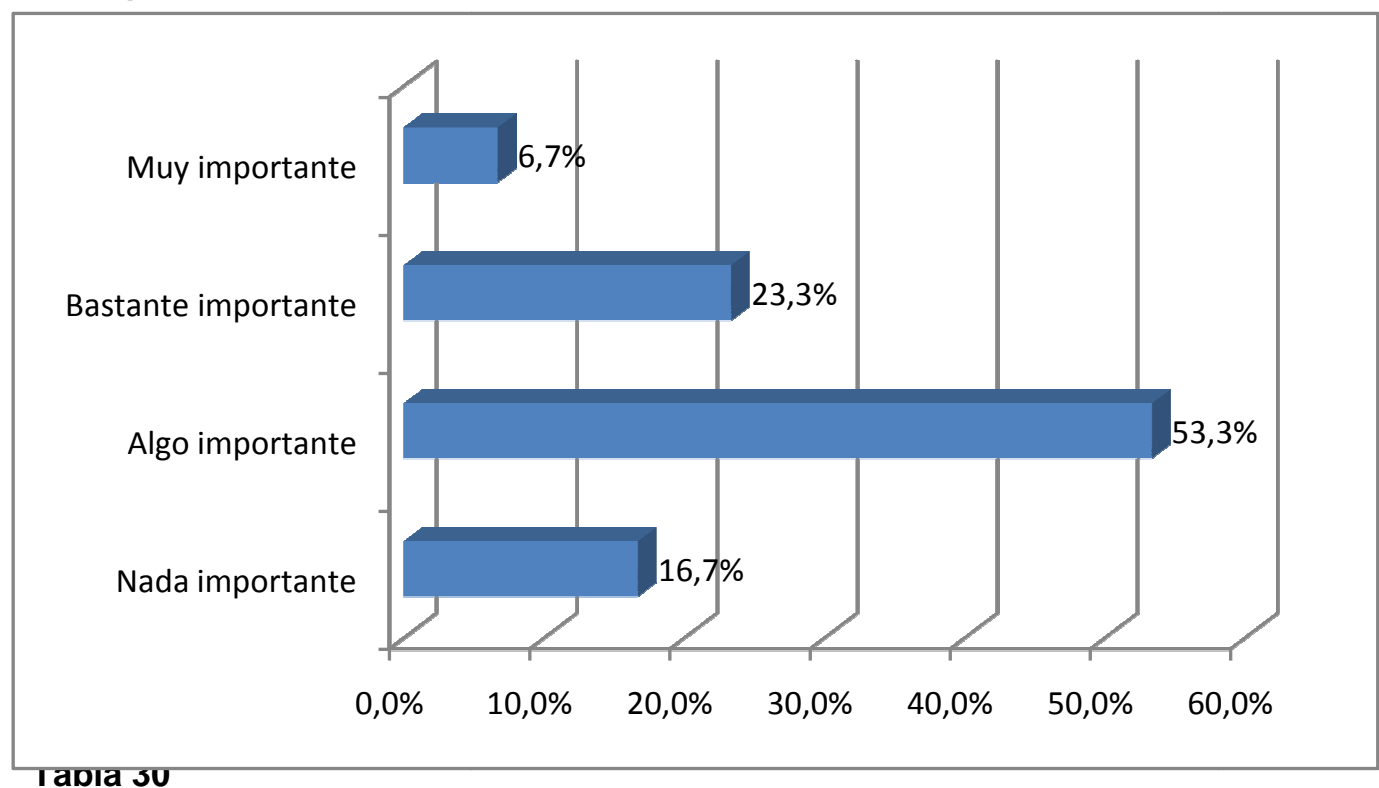

\begin{tabular}{|l|r|}
\hline Saldo de respuesta & 2,20 \\
\hline D.S. & 0,8 \\
\hline C.V. & $36,4 \%$ \\
\hline
\end{tabular}

Fuente: elaboración propia

Con un "Saldo de respuesta" de 2,20 la situación se presenta intermedia entre "Bastante importante" a "Algo importante". Un Desvío Estándar de 0,8 y un Coeficiente de Variabilidad del 36,4\% permiten afirmar que los datos están muy concentrados y que el promedio es representativo. 


\section{Brechas entre Expectativas y Percepción}

Grafico 45

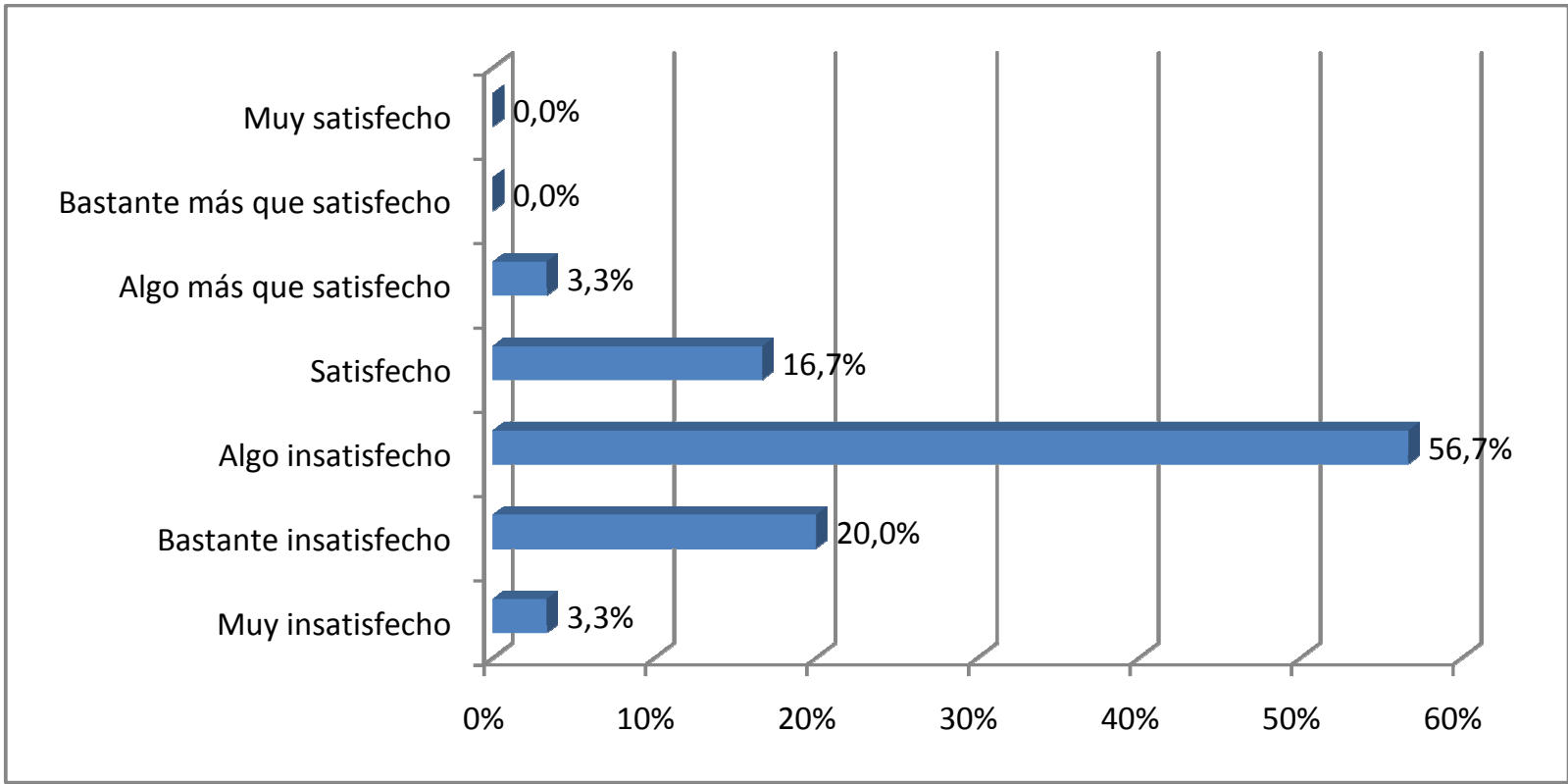

Fuente: elaboración propia

La brecha arroja un 16,7\% "Satisfecho", un 56,7\% "Algo Insatisfecho" y un 20\% "Bastante Insatisfecho", lo cual significa que se observa un gran déficit entre la expectativa y la percepción.

\subsection{6.- Capacidad de abstracción, análisis y síntesis}

\section{Expectativas}

\section{Grafico 46}

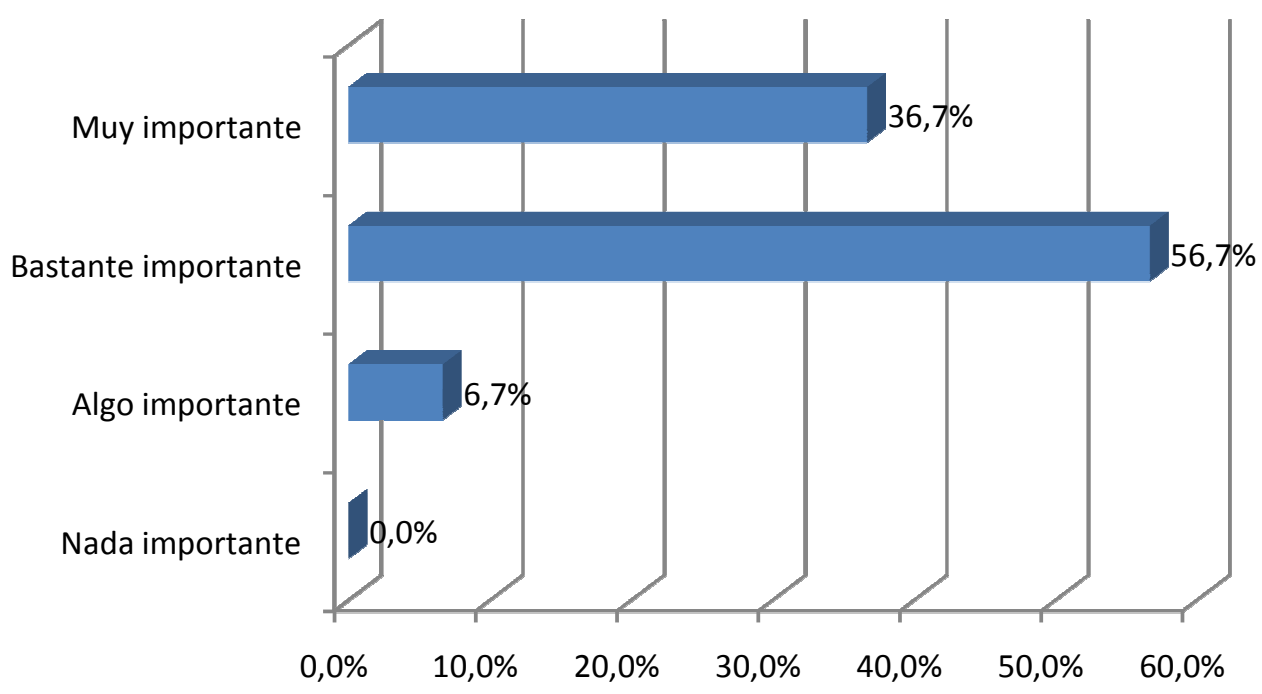

Tabla 31

\begin{tabular}{|l|r|}
\hline Saldo de respuesta & 3,30 \\
\hline D.S. & 0,6 \\
\hline C.V. & $18,2 \%$ \\
\hline
\end{tabular}

Fuente: elaboración propia 
Con un "Saldo de respuesta" de 3,30 la situación se presenta intermedia entre "Bastante importante" a "Muy importante". Un Desvío Estándar de 0,6 y un Coeficiente de Variabilidad del 18,2\% permiten afirmar que los datos están muy concentrados y que el promedio es representativo.

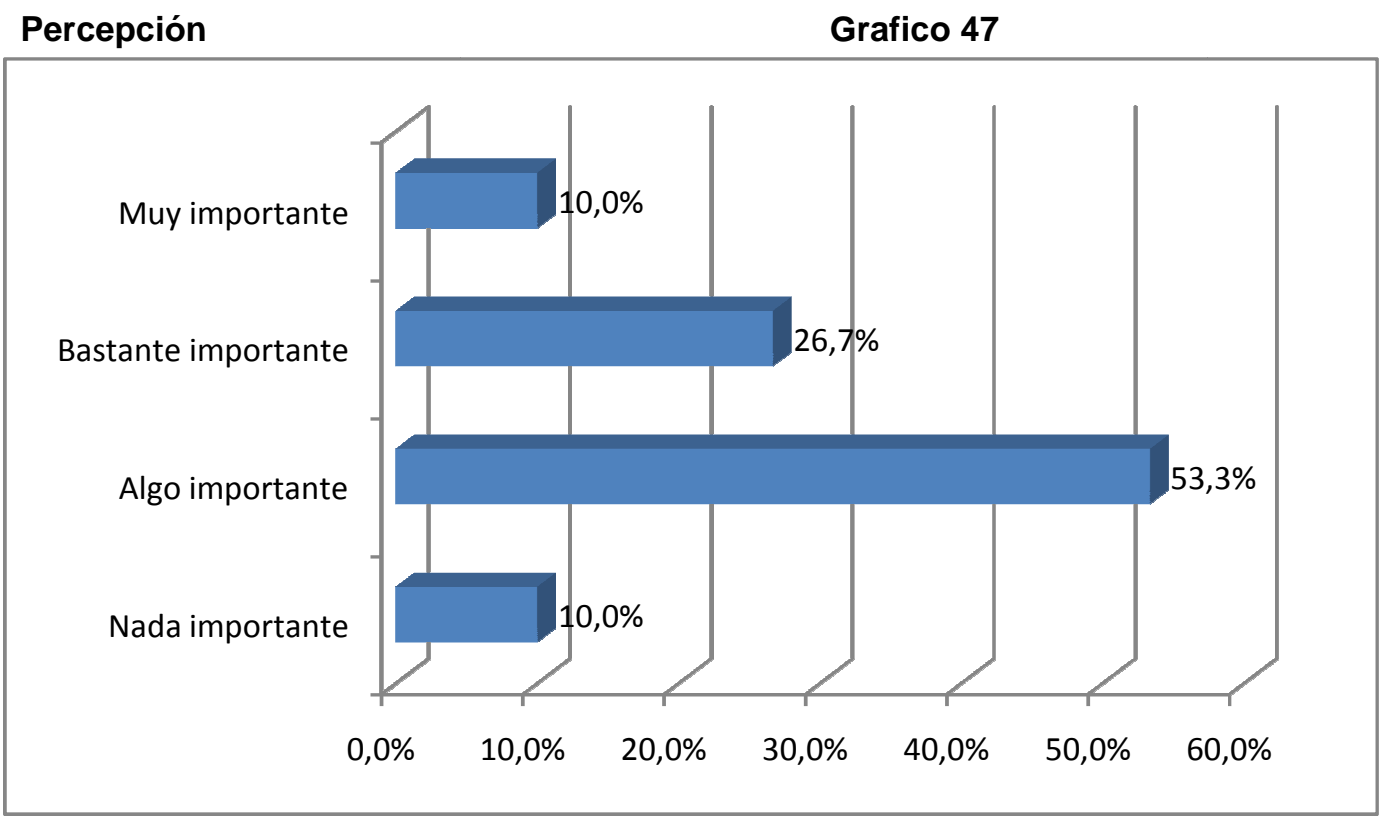

\begin{tabular}{|l|r|}
\hline Taola 3L \\
\hline Saldo de respuesta & 2,37 \\
\hline D.S. & 0,8 \\
\hline C.V. & $33,8 \%$ \\
\hline
\end{tabular}

Fuente: elaboración propia

Con un "Saldo de respuesta" de 2,37 la situación se presenta intermedia entre "Bastante importante" a "Algo importante". Un Desvío Estándar de 0,8 y un Coeficiente de Variabilidad del 33,8\% permiten afirmar que los datos están muy concentrados y que el promedio es representativo. 


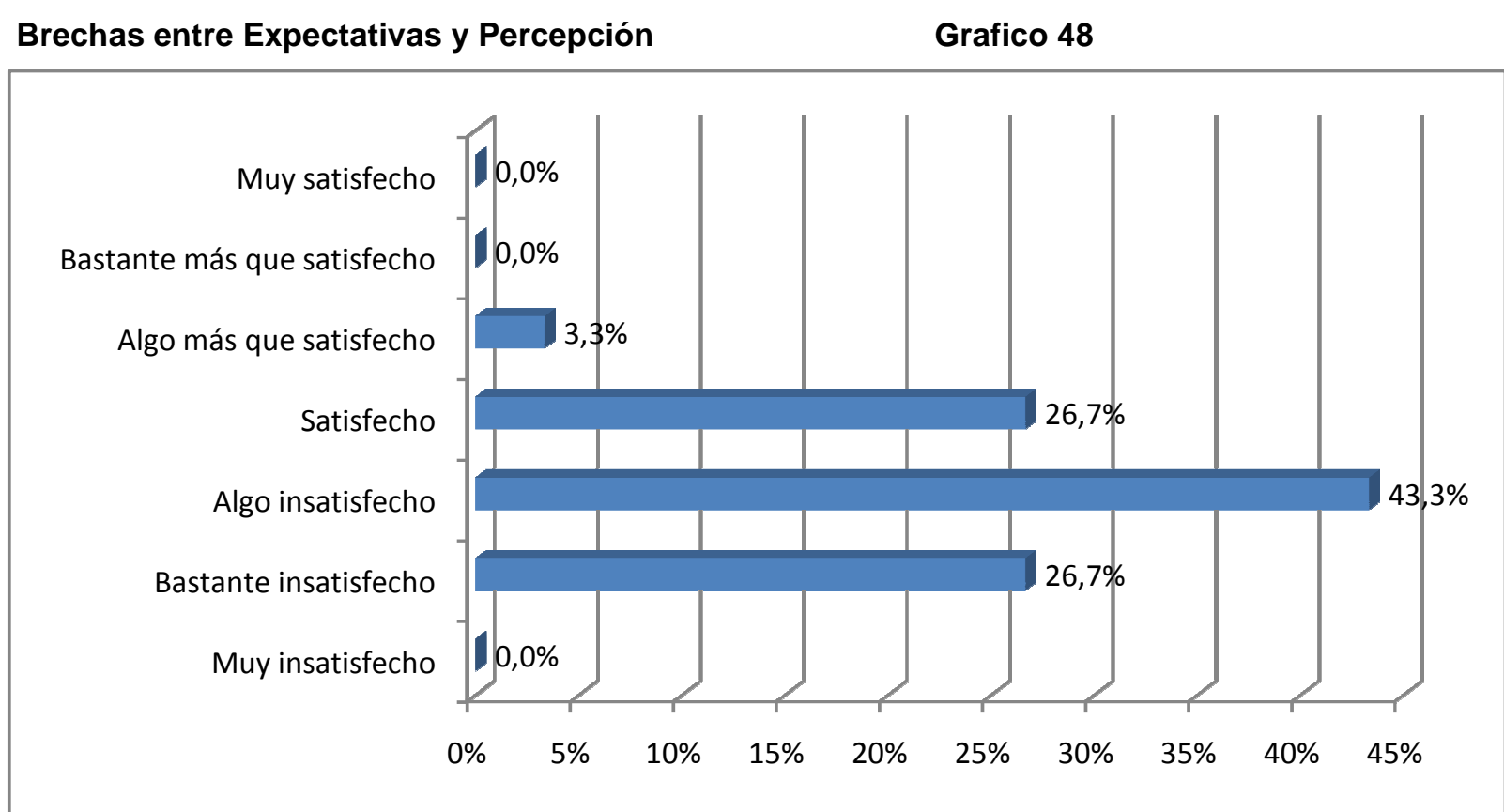

Fuente: elaboración propia

La brecha arroja un 26,7\% "Satisfecho", un 43,3\% "Algo Insatisfecho" y un 26,7\% "Bastante Insatisfecho", lo cual significa que se observa un gran déficit entre la expectativa y la percepción.

\subsection{7.- Capacidad para adaptarse a los cambios}

Expectativas

Grafico 49

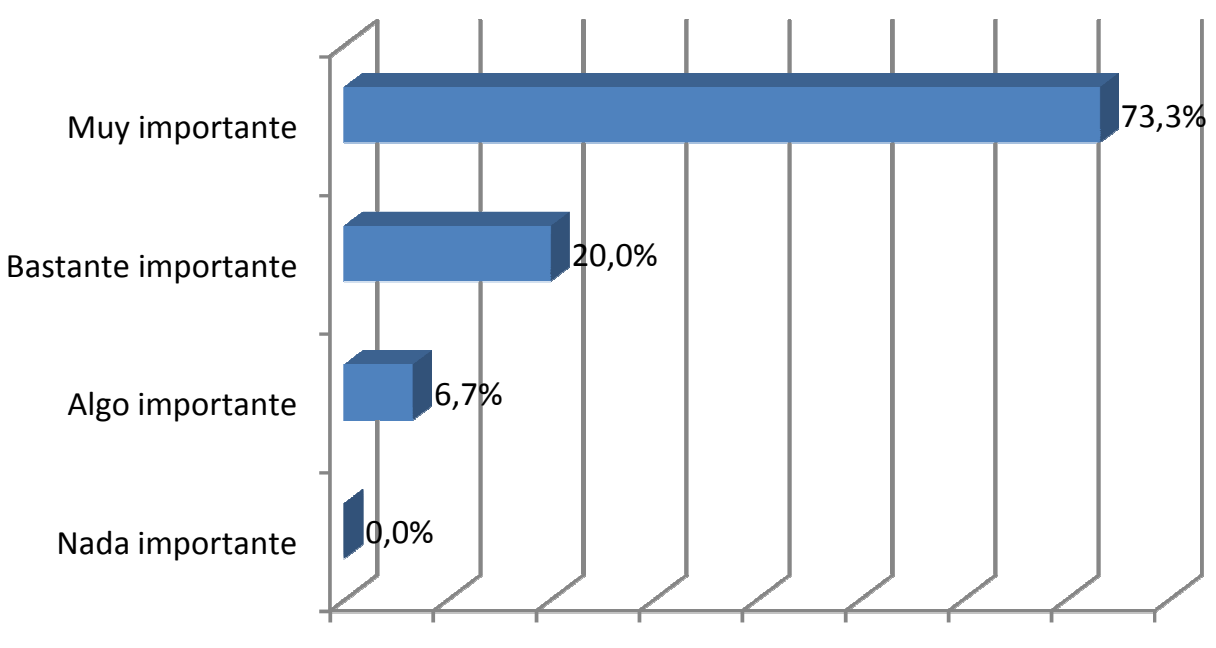

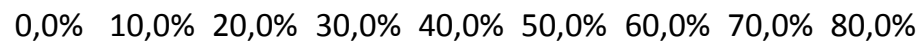

\section{Tabla 33}

\begin{tabular}{|l|r|}
\hline Saldo de respuesta & 3,67 \\
\hline D.S. & 0,6 \\
\hline C.V. & $16,4 \%$ \\
\hline
\end{tabular}

Fuente: elaboración propia 
Con un "Saldo de respuesta" de 3,67 la situación se presenta como "Muy importante". Un Desvío Estándar de 0,6 y un Coeficiente de Variabilidad del 16,4\% permiten afirmar que los datos están muy concentrados y que el promedio es representativo.

\section{Percepción Grafico 50}

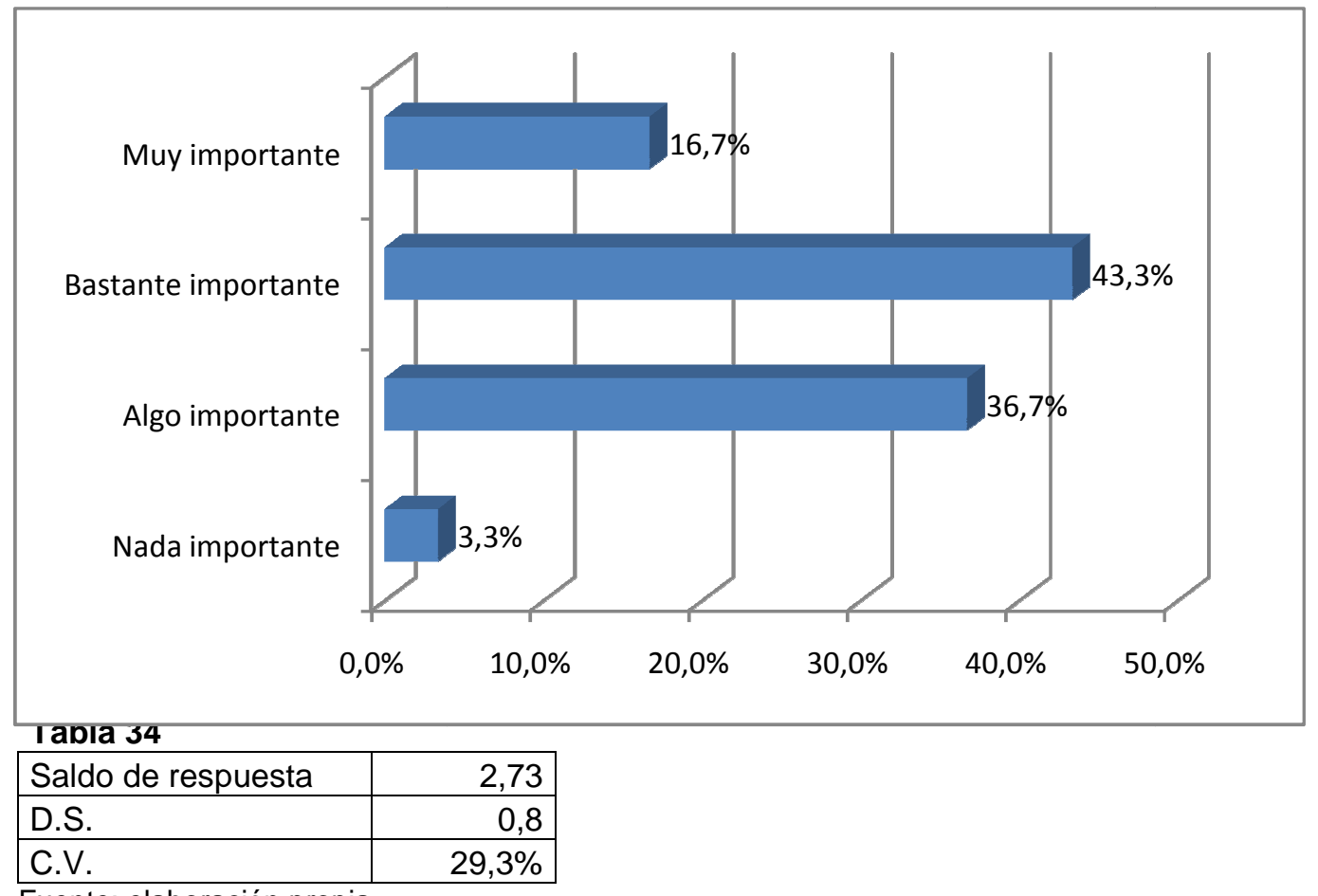

Fuente: elaboración propia

Con un "Saldo de respuesta" de 2,73 la situación se presenta intermedia entre "Bastante importante" a "Algo importante". Un Desvío Estándar de 0,8 y un Coeficiente de Variabilidad del 29,3\% permiten afirmar que los datos están concentrados y que el promedio es representativo. 


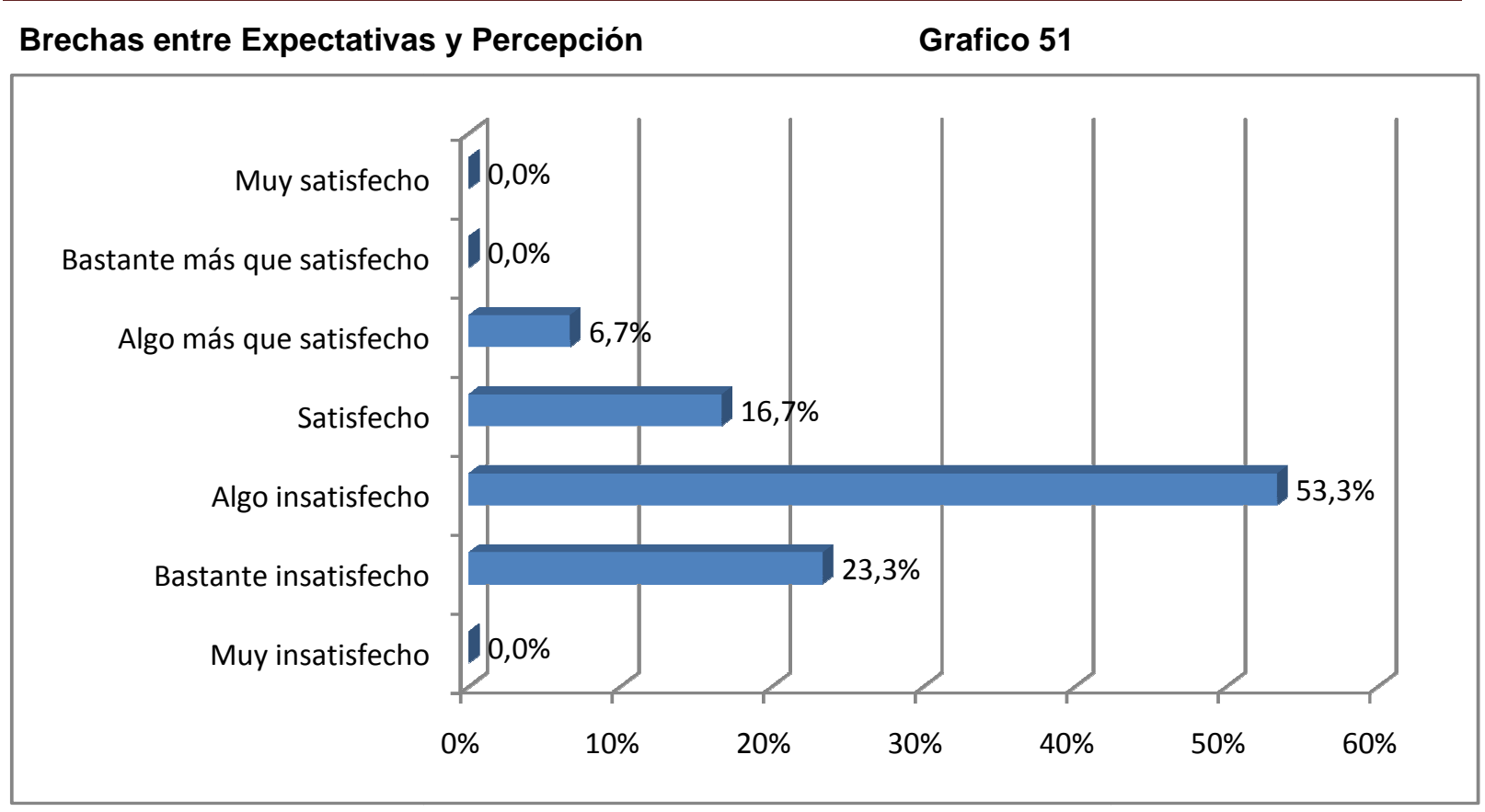

Fuente: elaboración propia

La brecha arroja un 16,7\% "Satisfecho", un 53,3\% "Algo Insatisfecho" y un 23,3\% "Bastante Insatisfecho", lo cual significa que se observa un gran déficit entre la expectativa y la percepción.

\subsection{8.- Habilidad para improvisar}

\section{Expectativas}

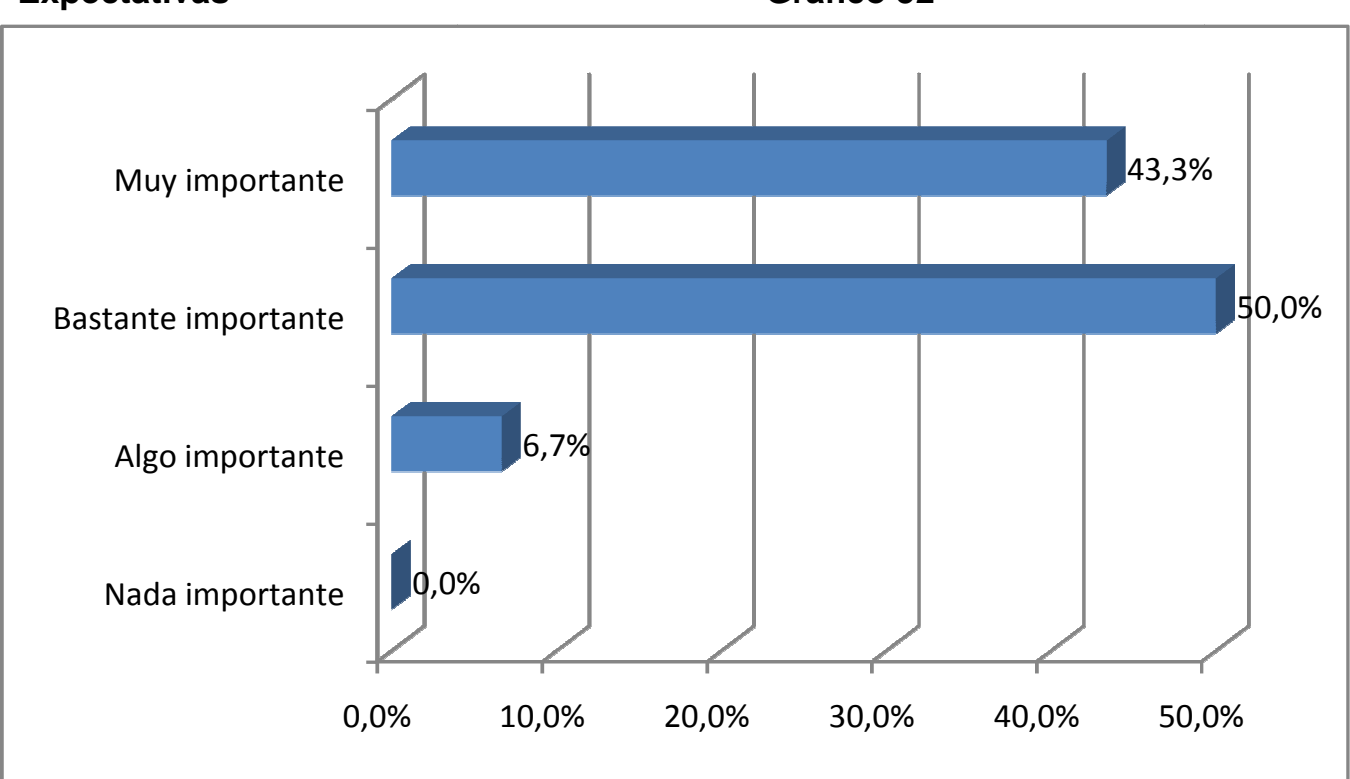

\section{Tabla 35}

\begin{tabular}{|l|r|}
\hline Saldo de respuesta & 3,37 \\
\hline D.S. & 0,6 \\
\hline C.V. & $17,8 \%$ \\
\hline
\end{tabular}

Fuente: elaboración propia 
Con un "Saldo de respuesta" de 3,37 la situación se presenta intermedia entre "Bastante importante" a "Muy importante". Un Desvío Estándar de 0,6 y un Coeficiente de Variabilidad del 17,8\% permiten afirmar que los datos están muy concentrados y que el promedio es representativo.

\section{Percepción $\quad$ Grafico 53}

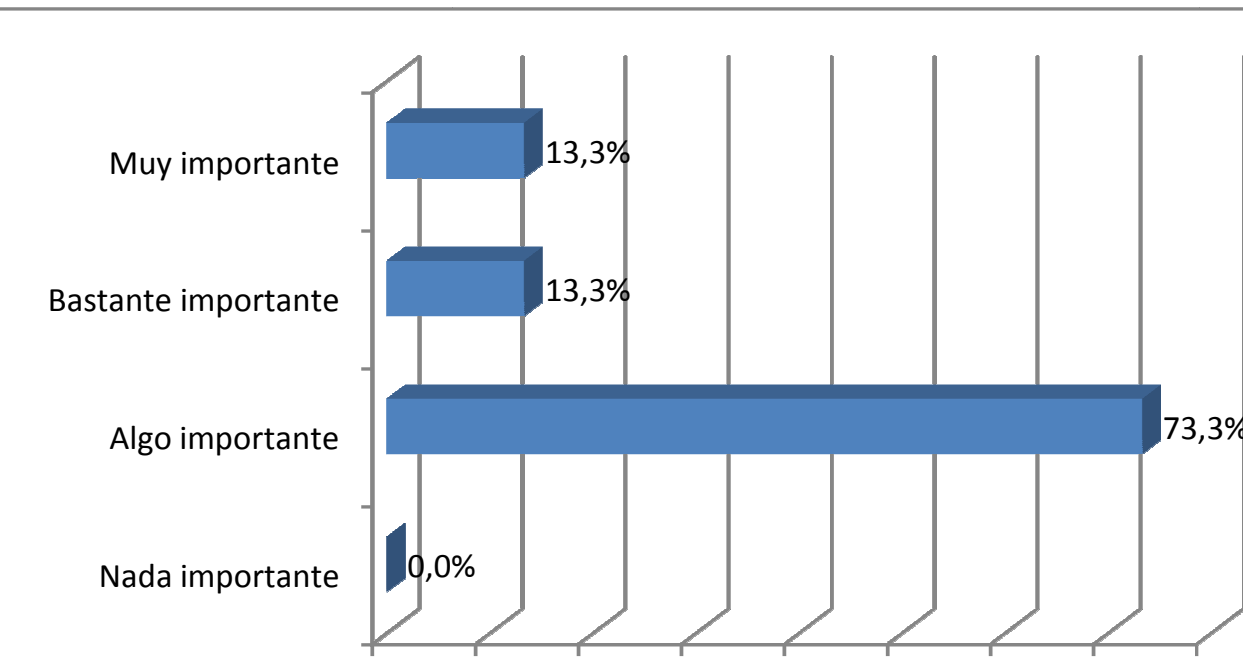

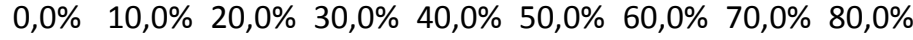

\section{Tabla 36}

\begin{tabular}{|l|r|}
\hline Saldo de respuesta & 2,40 \\
\hline D.S. & 0,7 \\
\hline C.V. & $29,2 \%$ \\
\hline
\end{tabular}

Fuente: elaboración propia

Con un "Saldo de respuesta" de 2,40 la situación se presenta como "Algo importante". Un Desvío Estándar de 0,7 y un Coeficiente de Variabilidad del 29,2\% permiten afirmar que los datos están muy concentrados y que el promedio es representativo. 


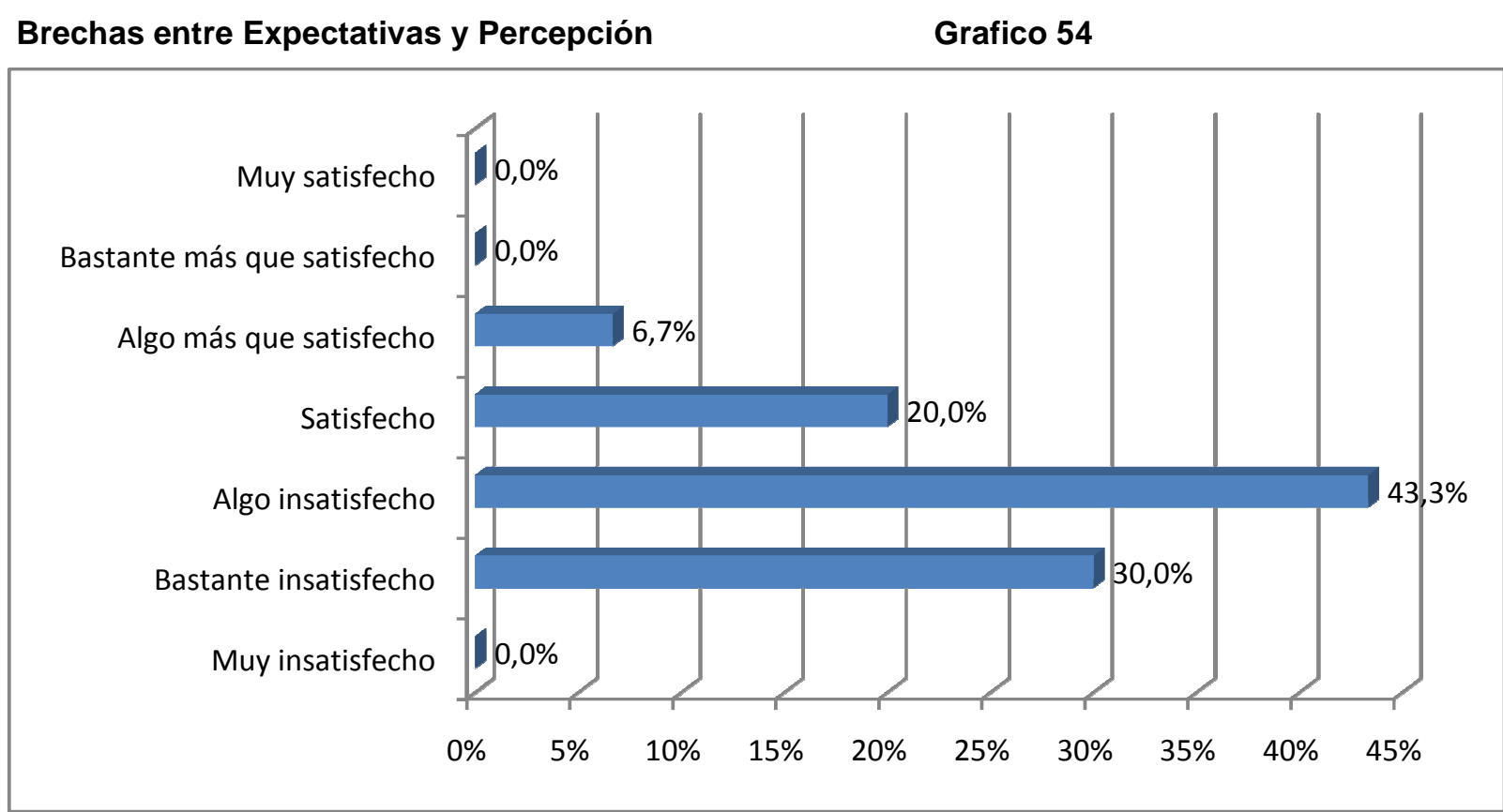

Fuente: elaboración propia

La brecha arroja un 20\% "Satisfecho", un 43,3\% "Algo Insatisfecho" y un 30\% "Bastante Insatisfecho", lo cual significa que se observa un gran déficit entre la expectativa y la percepción.

\subsection{9.- Capacidad de trabajar bajo presión}

\section{Expectativas}

\section{Grafico 55}

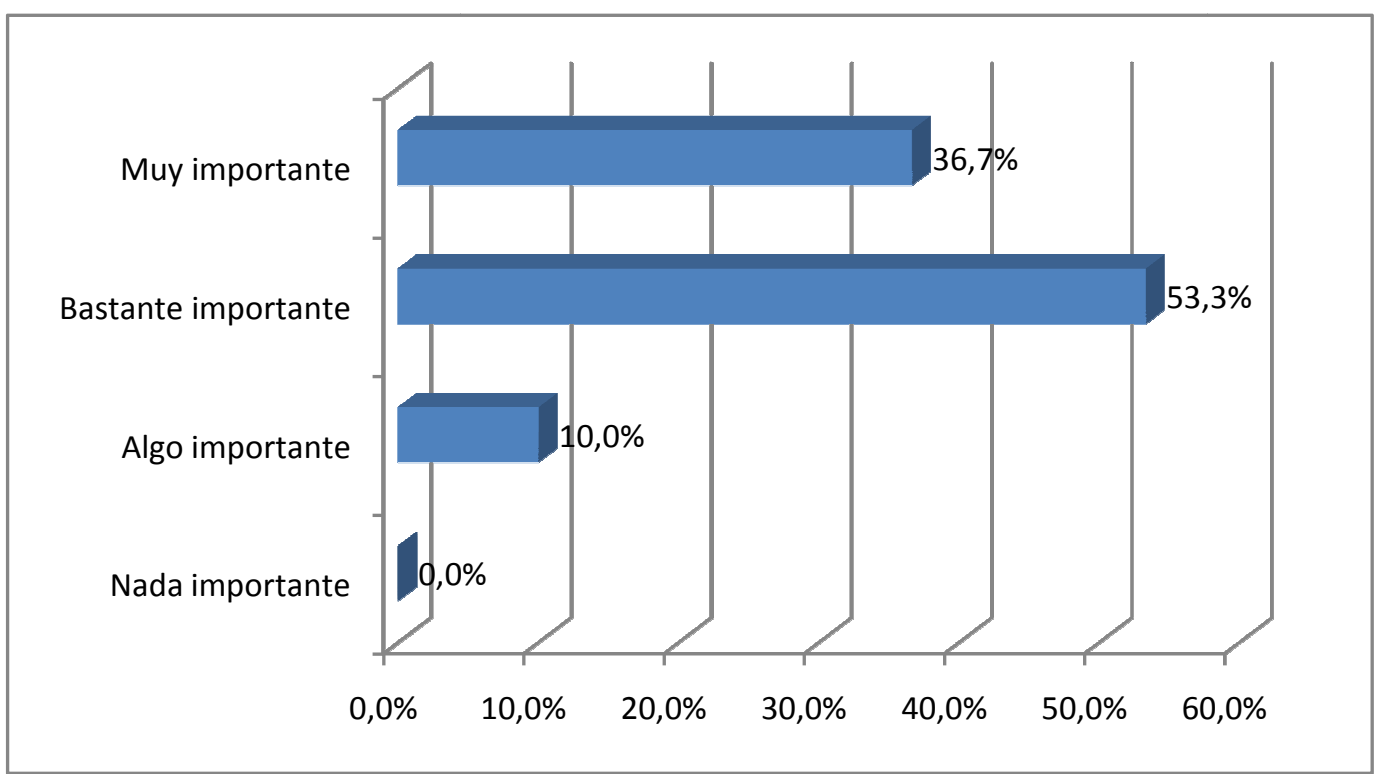

Tabla 37

\begin{tabular}{|l|r|}
\hline Saldo de respuesta & 3,27 \\
\hline D.S. & 0,6 \\
\hline C.V. & $18,4 \%$ \\
\hline
\end{tabular}

Fuente: elaboración propia 
Con un "Saldo de respuesta" de 3,27 la situación se presenta intermedia entre "Bastante importante" a "Muy importante". Un Desvío Estándar de 0,6 y un Coeficiente de Variabilidad del 18,4\% permiten afirmar que los datos están muy concentrados y que el promedio es representativo.

\section{Percepción Grafico 56}

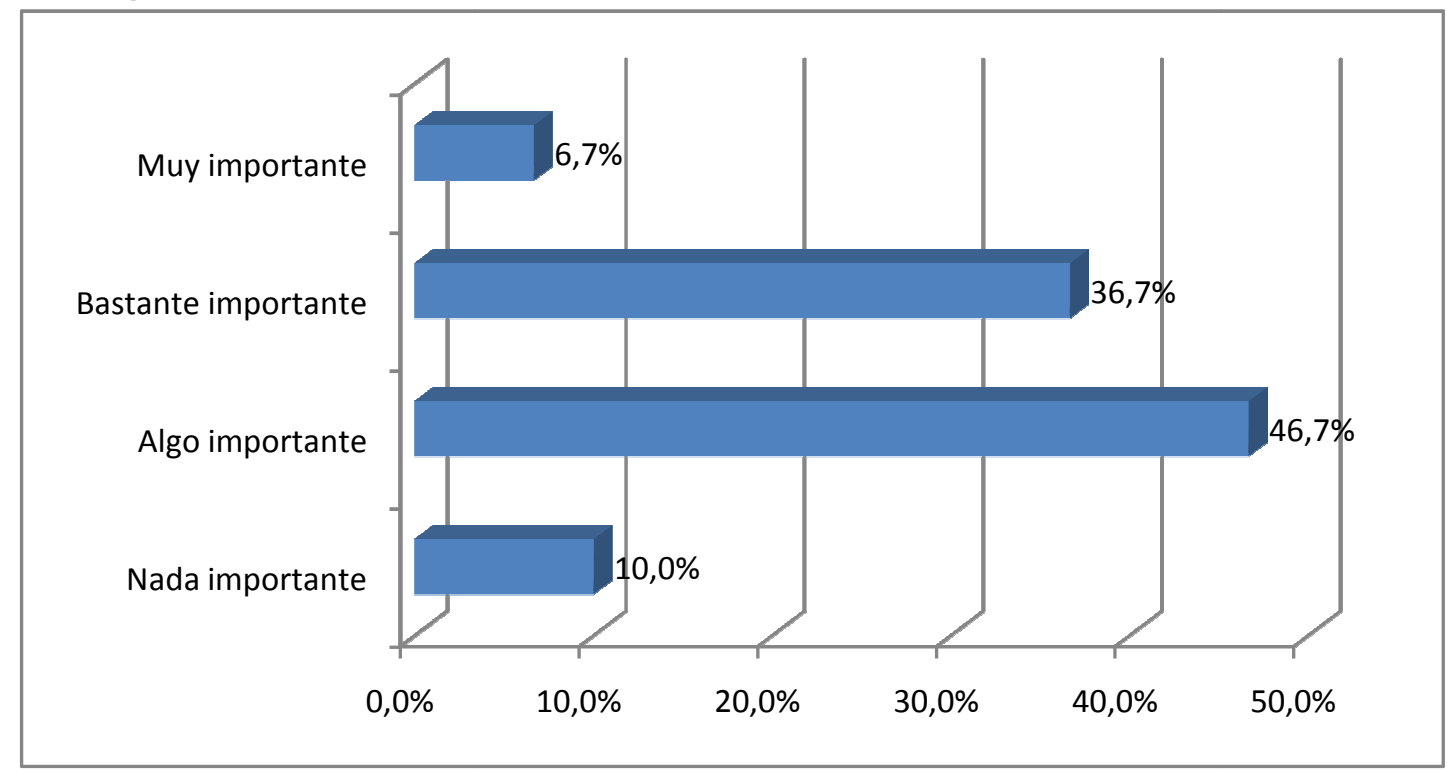

Tabla 38

\begin{tabular}{|l|r|}
\hline Saldo de respuesta & 2,40 \\
\hline D.S. & 0,8 \\
\hline C.V. & $33,3 \%$ \\
\hline
\end{tabular}

Fuente: elaboración propia

Con un "Saldo de respuesta" de 2,40 la situación se presenta intermedia entre "Bastante importante" a "Algo importante". Un Desvío Estándar de 0,8 y un Coeficiente de Variabilidad del 33,3\% permiten afirmar que los datos están concentrados y que el promedio es representativo. 
Brechas entre Expectativas y Percepción

Grafico 57

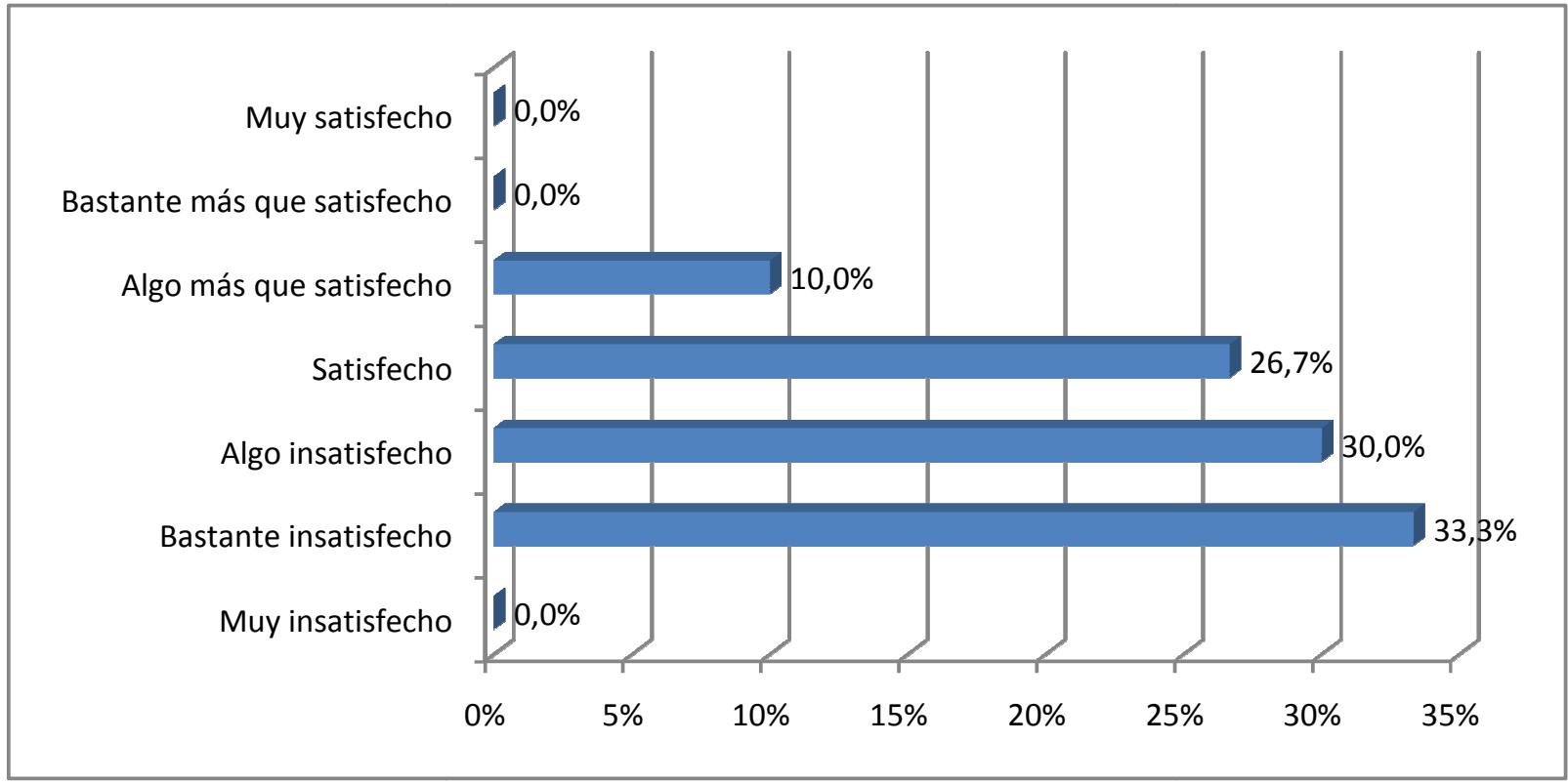

Fuente: elaboración propia

La brecha arroja un 26,7\% "Satisfecho", un 30\% "Algo Insatisfecho" y un 33,3\% "Bastante Insatisfecho", lo cual significa que se observa un gran déficit entre la expectativa y la percepción.

\subsection{0.- Capacidad para presentar y sustentar en público informes e ideas}

\section{Expectativas} Grafico 58

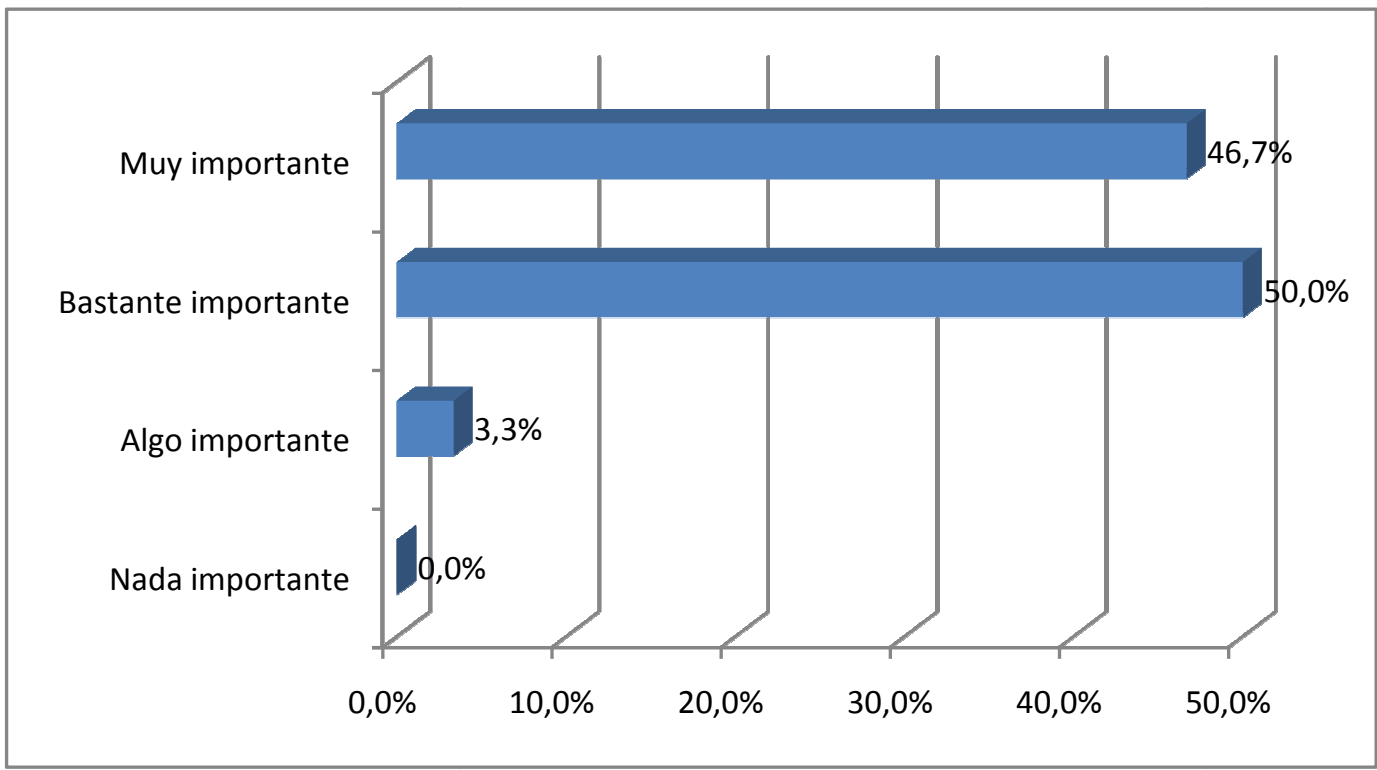




\section{Tabla 39}

\begin{tabular}{|l|r|}
\hline Saldo de respuesta & 3,43 \\
\hline D.S. & 0,6 \\
\hline C.V. & $17,5 \%$ \\
\hline
\end{tabular}

Fuente: elaboración propia

Con un "Saldo de respuesta" de 3,43 la situación se presenta intermedia entre "Bastante importante" a "Muy importante". Un Desvío Estándar de 0,6 y un Coeficiente de Variabilidad del $17,5 \%$ permiten afirmar que los datos están muy concentrados y que el promedio es representativo.

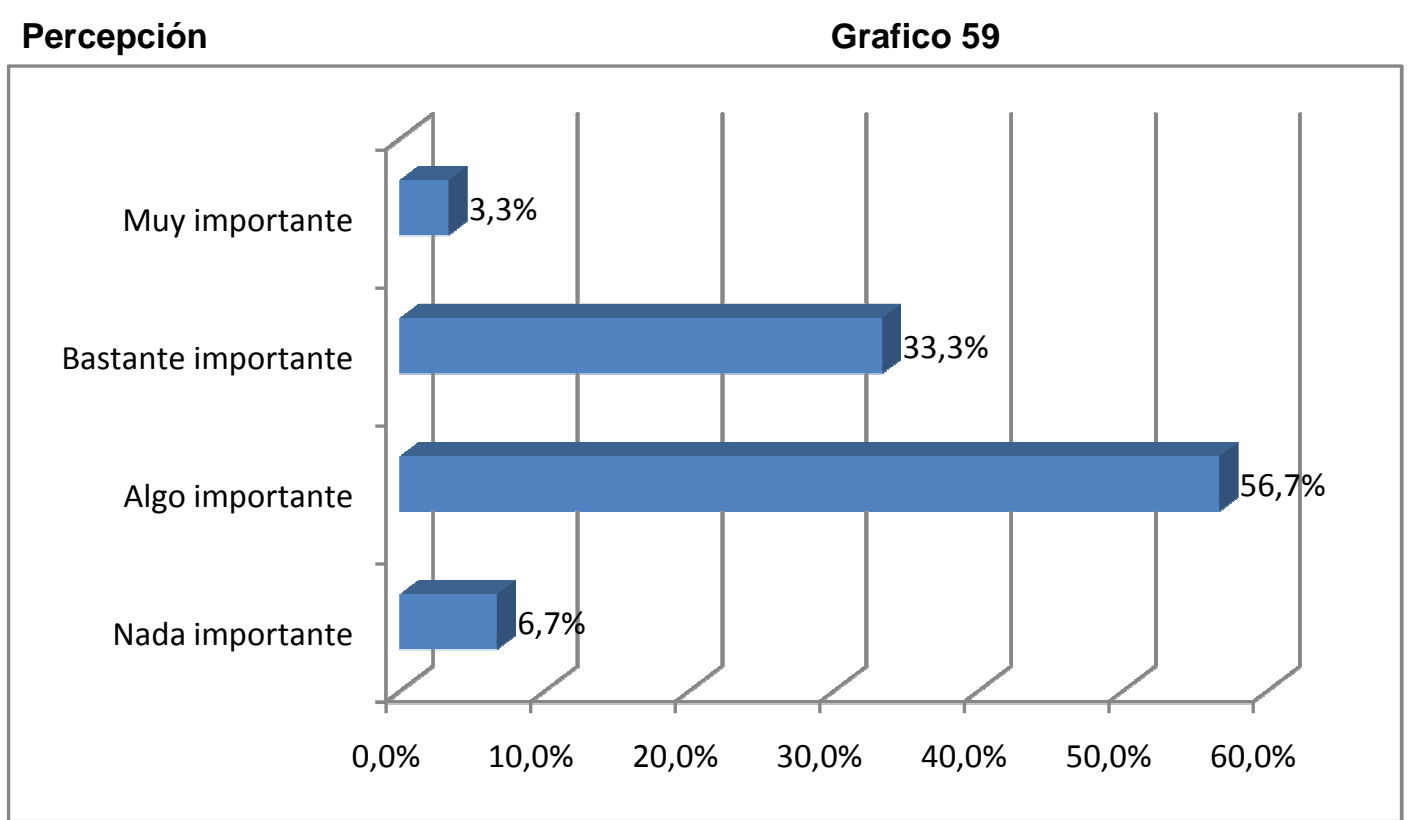

Tabla $\mathbf{4 0}$
\begin{tabular}{|l|r|}
\hline Saldo de respuesta & 2,33 \\
\hline D.S. & 0,7 \\
\hline C.V. & $30,0 \%$ \\
\hline
\end{tabular}

Fuente: elaboración propia

Con un "Saldo de respuesta" de 2,33 la situación se presenta intermedia entre "Bastante importante" a "Algo importante". Un Desvío Estándar de 0,7 y un Coeficiente de Variabilidad del $30 \%$ permiten afirmar que los datos están concentrados y que el promedio es representativo. 


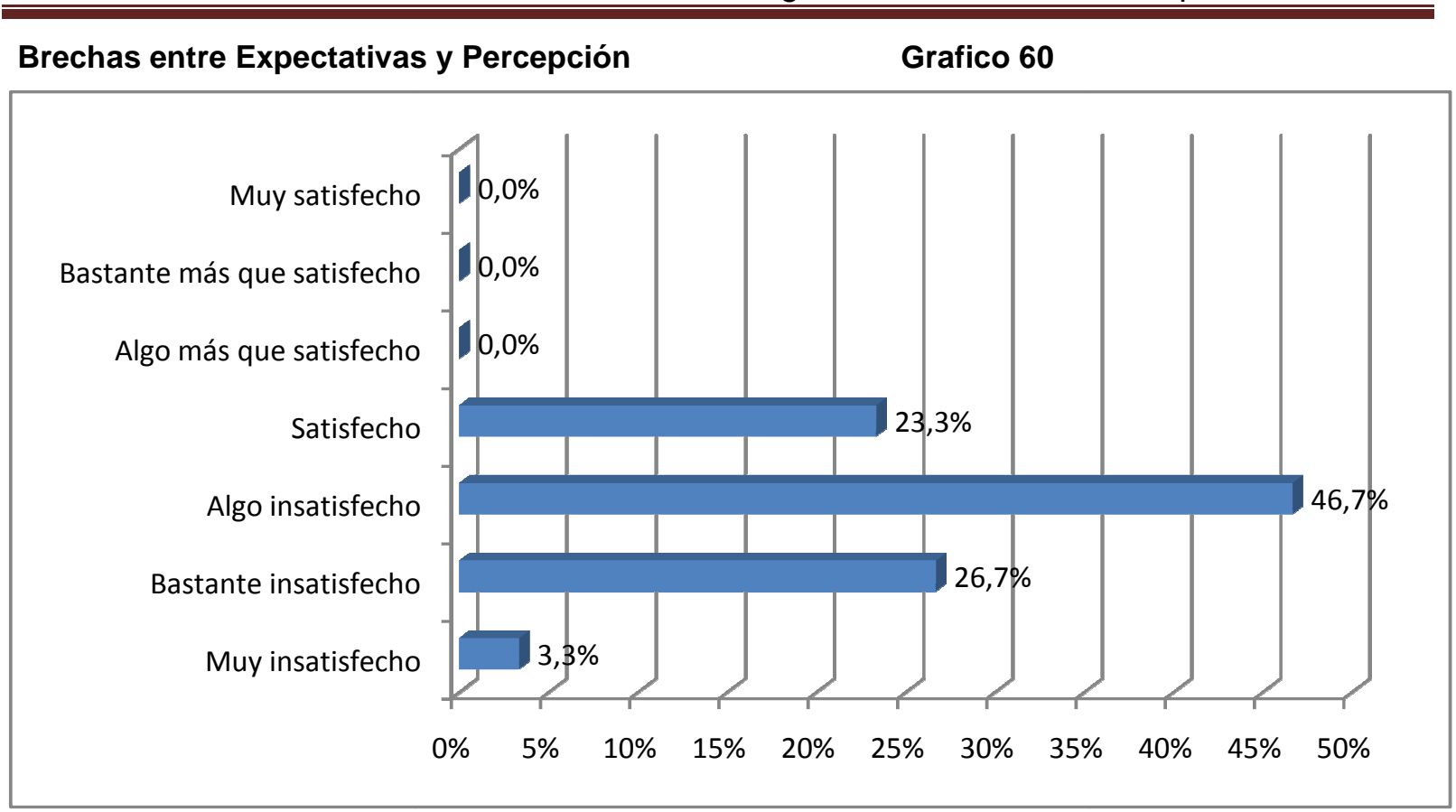

Fuente: elaboración propia

La brecha arroja un 23,3\% "Satisfecho", un 46,7\% "Algo Insatisfecho" y un 26,7\% "Bastante Insatisfecho", lo cual significa que se observa un gran déficit entre la expectativa y la percepción. 


\subsection{1.- Jerarquía de las competencias}

Los resultados que se obtuvieron se resumen en el siguiente gráfico:

\section{Grafico 61}

\section{Jerarquía de las competencias}

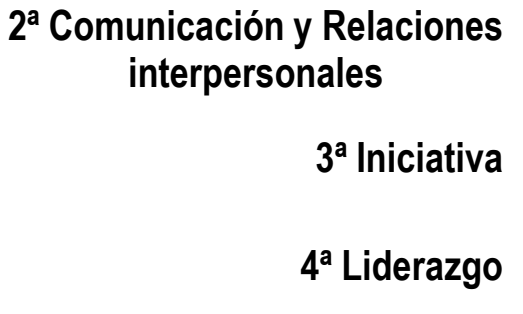

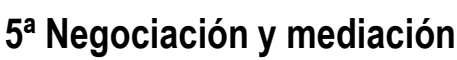

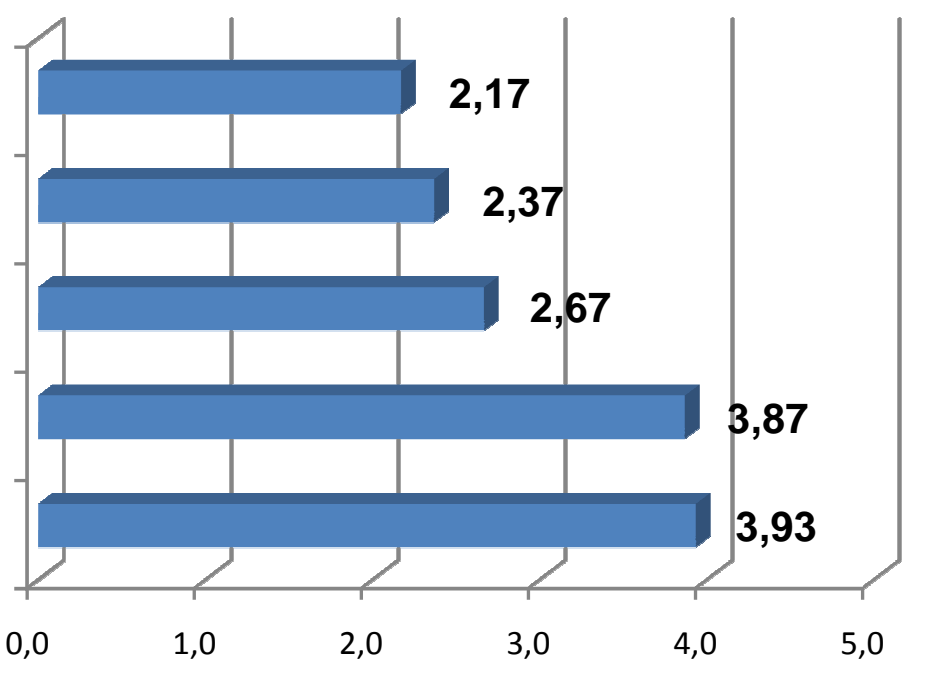

Fuente: elaboración propia

El resultado observado respecto de la jerarquía de las cinco competencias planteadas, permite observar dos estrechos rangos de variación, por una parte:

1. Trabajo en equipo

2. Comunicación y relaciones interpersonales

3. Iniciativa

En un segundo grupo:

4. Liderazgo

5. Negociación y mediación

A continuación se presentan las tablas resúmenes ordenadas por los saldos de respuesta 


\subsection{2.- Importancia de la competencia}

\begin{tabular}{|c|c|}
\hline Competencias & $\begin{array}{l}\text { Saldo de } \\
\text { respuesta }\end{array}$ \\
\hline 12.- Disposición para aprender y mantenerse actualizado/a & 3,73 \\
\hline 08.- Capacidad para trabajar en equipo para alcanzar una meta común & 3,70 \\
\hline 10.- Formación en valores y principios éticos. & 3,67 \\
\hline 17.- Capacidad para adaptarse a los cambios & 3,67 \\
\hline $\begin{array}{l}\text { 07.- Capacidad para asumir responsabilidades y tomar decisiones (establecer metas, } \\
\text { identificar limitaciones y riesgos, y generar, evaluar y elegir las mejores alternativas) }\end{array}$ & 3,60 \\
\hline 03.- Capacidad para comunicarse oralmente de tal forma que los demás entiendan & 3,57 \\
\hline 11.- Capacidad para identificar, plantear y resolver problemas & 3,57 \\
\hline $\begin{array}{l}\text { 05.- Capacidad para utilizar herramientas informáticas básicas (procesador de palabra, } \\
\text { hojas de cálculo, etc.) }\end{array}$ & 3,53 \\
\hline $\begin{array}{l}\text { 01.- Capacidad para planificar y utilizar el tiempo de manera efectiva (de tal forma que } \\
\text { se logren los objetivos planteados) }\end{array}$ & 3,47 \\
\hline 20.- Capacidad para presentar y sustentar en público informes e ideas & 3,43 \\
\hline 18.- Habilidad para improvisar & 3,37 \\
\hline 14.- Capacidad creativa e innovadora & 3,33 \\
\hline 16.- Capacidad de abstracción, análisis y síntesis & 3,30 \\
\hline 02.- Capacidad para comunicar por escrito & 3,27 \\
\hline 19.- Capacidad de trabajar bajo presión & 3,27 \\
\hline 15.- Capacidad para formular y gestionar proyectos & 3,23 \\
\hline $\begin{array}{l}\text { 09.- Capacidad para trabajar de forma independiente (sin necesidad de supervisión } \\
\text { permanente) }\end{array}$ & 3,20 \\
\hline 13.- Capacidad para manejar información procedente de áreas y fuentes diversas & 3,17 \\
\hline 04.- Capacidad para hablar y escribir en un idioma extranjero & 2,90 \\
\hline $\begin{array}{l}\text { 06.- Capacidad para utilizar herramientas informáticas especializadas (paquetes } \\
\text { estadísticos, programas de diseño, etc.) }\end{array}$ & 2,87 \\
\hline
\end{tabular}

Fuente: elaboración propia

\subsection{3.- Percepción del nivel de competencia de los empleados}

\begin{tabular}{|l|r|}
\hline \multicolumn{1}{|c|}{ Competencias } & \multicolumn{1}{|c|}{$\begin{array}{l}\text { Saldo de } \\
\text { respuesta }\end{array}$} \\
\hline 08.- Capacidad para trabajar en equipo para alcanzar una meta común & 2,87 \\
\hline $\begin{array}{l}\text { 05.- Capacidad para utilizar herramientas informáticas básicas (procesador de palabra, } \\
\text { hojas de cálculo, etc.) }\end{array}$ & 2,73 \\
\hline \begin{tabular}{l|} 
17.- Capacidad para adaptarse a los cambios \\
12.- Disposición para aprender y mantenerse actualizado/a
\end{tabular} & 2,73 \\
\hline $\begin{array}{l}\text { 01.- Capacidad para planificar y utilizar el tiempo de manera efectiva (de tal forma que } \\
\text { se logren los objetivos planteados) }\end{array}$ & 2,70 \\
\hline 03.- Capacidad para comunicarse oralmente de tal forma que los demás entiendan & 2,60 \\
\hline 10.- Formación en valores y principios éticos. & 2,57 \\
\hline 13.- Capacidad para manejar información procedente de áreas y fuentes diversas & 2,53 \\
\hline 02.- Capacidad para comunicar por escrito & 2,50 \\
\hline $\begin{array}{l}\text { 09.- Capacidad para trabajar de forma independiente (sin necesidad de supervisión } \\
\text { permanente) }\end{array}$ & 2,47 \\
\hline 18.- Habilidad para improvisar & 2,40 \\
\hline 19.- Capacidad de trabajar bajo presión & 2,40 \\
\hline 16.- Capacidad de abstracción, análisis y síntesis & 2,37 \\
\hline
\end{tabular}


La Calidad Educativa de los Centros Regionales de Educación Superior

\begin{tabular}{|l|r|}
\hline \hline 11.- Capacidad para identificar, plantear y resolver problemas & 2,33 \\
\hline 14.- Capacidad creativa e innovadora & 2,33 \\
\hline 20.- Capacidad para presentar y sustentar en público informes e ideas & 2,33 \\
\hline $\begin{array}{l}\text { 07.- Capacidad para asumir responsabilidades y tomar decisiones (establecer metas, } \\
\text { identificar limitaciones y riesgos, y generar, evaluar y elegir las mejores alternativas) }\end{array}$ & 2,30 \\
\hline 15.- Capacidad para formular y gestionar proyectos & 2,20 \\
\hline $\begin{array}{l}\text { 06.- Capacidad para utilizar herramientas informáticas especializadas (paquetes } \\
\text { estadísticos, programas de diseño, etc.) }\end{array}$ & 1,93 \\
\hline $04 .-$ Capacidad para hablar y escribir en un idioma extranjero & 1,70 \\
\hline
\end{tabular}

Fuente: elaboración propia

\subsection{4.- Competencias de mayor problemática}

Las siguientes tablas muestran las competencias con un orden jerárquico asociado en función de las de mayor a las de menor problemática.

\begin{tabular}{|c|c|c|c|c|c|c|}
\hline \multirow{2}{*}{$\begin{array}{c}\mathrm{N}^{0} \text { de } \\
\text { Competencia }\end{array}$} & \multicolumn{2}{|c|}{ Importancia } & \multicolumn{4}{|c|}{ Desempeño } \\
\hline & $\begin{array}{c}\text { Calificación 1- } \\
4(\mathrm{a})\end{array}$ & $\begin{array}{c}\text { Jerarquía 1- } \\
20 \text { (b) }\end{array}$ & $\begin{array}{c}\text { Calificación 1- } \\
4(\mathrm{c})\end{array}$ & $\begin{array}{l}\text { Discrepancia } \\
\text { (d) [c-a] }\end{array}$ & $\begin{array}{l}\text { Ponderación } \\
\text { (e) }\left[a^{*}(-d)\right]\end{array}$ & $\begin{array}{c}\text { Jerarquía 1- } \\
20(\mathrm{f})\end{array}$ \\
\hline 1 & 3,467 & 9 & 2,667 & $-0,800$ & 2,773 & 16 \\
\hline 2 & 3,267 & 14 & 2,500 & $-0,767$ & 2,504 & 18 \\
\hline 3 & 3,567 & 6 & 2,600 & $-0,967$ & 3,448 & 7 \\
\hline 4 & 2,900 & 19 & 1,700 & $-1,200$ & 3,480 & 6 \\
\hline 5 & 3,533 & 8 & 2,733 & $-0,800$ & 2,827 & 15 \\
\hline 6 & 2,867 & 20 & 1,933 & $-0,933$ & 2,676 & 17 \\
\hline 7 & 3,600 & 5 & 2,300 & $-1,300$ & 4,680 & 1 \\
\hline 8 & 3,700 & 2 & 2,867 & $-0,833$ & 3,083 & 12 \\
\hline 9 & 3,200 & 17 & 2,467 & $-0,733$ & 2,347 & 19 \\
\hline 10 & 3,667 & 3 & 2,567 & $-1,100$ & 4,033 & 3 \\
\hline 11 & 3,567 & 7 & 2,333 & $-1,233$ & 4,399 & 2 \\
\hline 12 & 3,733 & 1 & 2,700 & $-1,033$ & 3,858 & 4 \\
\hline 13 & 3,167 & 18 & 2,533 & $-0,633$ & 2,006 & 20 \\
\hline 14 & 3,333 & 12 & 2,333 & $-1,000$ & 3,333 & 10 \\
\hline 15 & 3,233 & 16 & 2,200 & $-1,033$ & 3,341 & 9 \\
\hline 16 & 3,300 & 13 & 2,367 & $-0,933$ & 3,080 & 13 \\
\hline 17 & 3,667 & 4 & 2,733 & $-0,933$ & 3,422 & 8 \\
\hline 18 & 3,367 & 11 & 2,400 & $-0,967$ & 3,254 & 11 \\
\hline 19 & 3,267 & 15 & 2,400 & $-0,867$ & 2,831 & 14 \\
\hline 20 & 3,433 & 10 & 2,333 & $-1,100$ & 3,777 & 5 \\
\hline
\end{tabular}

Fuente: elaboración propia 
La Calidad Educativa de los Centros Regionales de Educación Superior

\begin{tabular}{|c|c|c|}
\hline $\begin{array}{c}\mathrm{N}^{0} \text { de } \\
\text { Competencia }\end{array}$ & Características & $\begin{array}{l}\text { Jerarquía } \\
1-20(f)\end{array}$ \\
\hline 7 & $\begin{array}{l}\text { Capacidad para asumir responsabilidades y tomar decisiones (establecer } \\
\text { metas, identificar limitaciones y riesgos, y generar, evaluar y elegir las mejores } \\
\text { alternativas) }\end{array}$ & \\
\hline 11 & Capacidad para identificar, plantear y resolver problemas & 2 \\
\hline 10 & Formación en valores y principios éticos. & 3 \\
\hline 12 & Disposición para aprender y mantenerse actualizado/a & 4 \\
\hline 20 & Capacidad para presentar y sustentar en público informes e ideas & 5 \\
\hline 4 & Capacidad para hablar y escribir en un idioma extranjero & 6 \\
\hline 3 & Capacidad para comunicarse oralmente de tal forma que los demás entiendan & 7 \\
\hline 17 & Capacidad para adaptarse a los cambios & 8 \\
\hline 15 & Capacidad para formular y gestionar proyectos & 9 \\
\hline 14 & Capacidad creativa e innovadora & 10 \\
\hline 18 & Habilidad para improvisar & 11 \\
\hline 8 & Capacidad para trabajar en equipo para alcanzar una meta común & 12 \\
\hline 16 & Capacidad de abstracción, análisis y síntesis & 13 \\
\hline 19 & Capacidad de trabajar bajo presión & 14 \\
\hline 5 & $\begin{array}{l}\text { Capacidad para utilizar herramientas informáticas básicas (procesador de } \\
\text { palabra, hojas de cálculo, etc.) }\end{array}$ & 15 \\
\hline 1 & $\begin{array}{l}\text { Capacidad para planificar y utilizar el tiempo de manera efectiva (de tal forma } \\
\text { que se logren los objetivos planteados) }\end{array}$ & 16 \\
\hline 6 & $\begin{array}{l}\text { Capacidad para utilizar herramientas informáticas especializadas (paquetes } \\
\text { estadísticos, programas de diseño, etc.) }\end{array}$ & 17 \\
\hline 2 & Capacidad para comunicar por escrito & 18 \\
\hline 9 & $\begin{array}{l}\text { Capacidad para trabajar de forma independiente (sin necesidad de supervisión } \\
\text { permanente) }\end{array}$ & 19 \\
\hline 13 & Capacidad para manejar información procedente de áreas y fuentes diversas & 20 \\
\hline
\end{tabular}

Fuente: elaboración propia

\subsection{5.- Correlaciones}

Se llevó a cabo un análisis de correlación entre el desempeño de las competencias por una parte, y la importancia de las mismas por la otra. En el primer caso no se observaron correlaciones significativas, sin embargo en lo relativo a la importancia de las competencias se halló lo siguiente:

Correlación fuerte, alta, importante entre "Disposición para aprender y mantenerse actualizado/a (\#12)" y "Capacidad para adaptarse a los cambios (\#17)" (0,715).

* Correlación moderada entre "Capacidad para formular y gestionar proyectos (\#15)" y "Capacidad para presentar y sustentar en público informes e ideas (\#20)" $(0,637)$. 


\section{Conclusiones}

$\checkmark$ Expectativas de los empleadores de los graduados de los CRES, respecto de sus competencias.

La importancia de las competencias se ha resuelto en los primeros cuatro deciles, lo cual indica que hasta las que pueden ser catalogadas de menor importancia en el rango de calificaciones reales $(3,73$ a 2,87), no son poco importantes por su ubicación en el rango de calificaciones posible (4 a 1). La distribución ha sido de cuatro competencias en el primer decil, doce en el segundo decil, tres en el tercero y una en el cuarto.

En el primer decil, las cuatro competencias a las que los empresarios le otorgaron mayor calificación, en lo relativo a sus expectativas, fueron:

- Disposición para aprender y mantenerse actualizado/a (\#12);

- Capacidad para trabajar en equipo para alcanzar una meta común (\#8);

- Formación en valores y principios éticos (\#10),

- Capacidad para adaptarse a los cambios (\#17).

Dado la correlación hallada entre los numerales 12 y 17, se observa como un fuerte requerimiento el hecho de ser capaz de adaptarse a los cambios que suelen requerir de nuevos aprendizajes, por lo cual además de estar matemáticamente sustentado resulta lógico y acorde con los tiempos actuales.

En el segundo decil se da la correlación entre los numerales 15 y 20 también tienen su lógica, ya que la "Capacidad para formular y gestionar proyectos" es totalmente razonable que se requiera la "Capacidad para presentar y sustentar en público informes e ideas", es decir la defensa de las ideas, supuestos, métodos, técnicas, etc. planteadas. 
$\checkmark$ Percepción de los empleadores de los graduados de los CRES, respecto del desempeño en las distintas competencias

En lo relativo al desempeño, también se ha resuelto en cuatro deciles, pero a diferencia de la importancia, los primeros dos deciles han quedado desiertos y recién en el tercer decil se observa una competencia, nueve en el cuarto, ocho en el quinto y dos en el sexto.

Los empresarios le otorgaron mayor calificación, en torno al desempeño observado, a las siguientes competencias (tercer decil y mitad del cuarto decil):

- Capacidad para trabajar en equipo para alcanzar una meta común (\#8);

- Capacidad para adaptarse a los cambios (\#17);

- Capacidad para utilizar herramientas informáticas básicas (procesador de palabra, hojas de cálculo, etc.) (\#5);

- Disposición para aprender y mantenerse actualizado/a(\#12).

En el último decil en cuanto al desempeño observado, se hallan las siguientes competencias:

- Capacidad para hablar y escribir en un idioma extranjero (\#4);

- Capacidad para utilizar herramientas informáticas especializadas (paquetes estadísticos, programas de diseño, etc.) (\#6).

Cabe destacar que dado que se había calificado como de muy alta importancia la "Disposición para aprender y mantenerse actualizado/a (\#12)" y la "Capacidad para adaptarse a los cambios (\#17)", y en función que Argentina está entre los países receptores de tecnología y no de los generadores de la misma, se presenta como un importante desafío lograr lo primero con las carencias reflejadas en el sexto decil.

$\checkmark$ Brecha entre las competencias laborales de los graduados y las esperadas por los empleadores.

Los resultados del análisis de las brechas entre las expectativas y lo observado arrojan, para todas las competencias, un déficit significativo. Este resultado es generalizado para todas las competencias con saldos de respuesta que oscilan entre 
$-0,63$ y $-1,30$. Desde un punto de vista de deciles, se resuelve en dos de ellos con tres competencias en el octavo decil $(-1,2$ a $-1,8)$ y las restantes diecisiete en el séptimo decil $(-0,6$ a $-1,2)$. Se citan las competencias del octavo decil:

- Capacidad para asumir responsabilidades y tomar decisiones (establecer metas, identificar limitaciones y riesgos, y generar, evaluar y elegir las mejores alternativas) (\#7);

- Capacidad para identificar, plantear y resolver problemas (\#11);

- Capacidad para hablar y escribir en un idioma extranjero (\#4);

Esto estaría configurando un problema en el comportamiento autónomo, y si bien el individuo es autónomo en tanto actúa en forma razonable y considera lo que debe hacer con todos los datos a su disposición, se es verdaderamente autónomo al usar la conciencia moral y cuando se hace esto, existe conexión causal entre las acciones y los efectos que producen. La conciencia de esa conexión lleva al concepto de responsabilidad.

La autonomía - vista como proceso para la toma de decisiones libres sustentadas en la propia conciencia de la persona (valores, principios, creencias, etc.)-, es una condición que requiere voluntad, libertad y autoestima.

Si siguiendo a Jean Piaget se concuerda con que «La meta de la educación es forjar individuos capaces de autonomía intelectual y moral, que respeten, con reciprocidad, la autonomía del prójimo», he aquí una importante falencia en el sistema educativo que impacta en el individuo y en el medio en que se desenvuelve. Para el caso, en las empresas en que trabaja, ya que como afirmara Jack Mathieu Émile Lang ${ }^{7}$ «La autonomía es un requisito para la eficacia».

\section{$\checkmark$ Jerarquización de las problemáticas observadas}

La brecha ponderada por la importancia asignada, ha determinado que las competencias en las que se observa la mayor problemática son:

\footnotetext{
${ }^{7}$ Político francés nacido el 2 de septiembre de 1939 y miembro del Partido Socialista. En su época de Ministro de Cultura fue el autor de la Ley Lang, de agosto de 1981, que reguló el precio fijo de los libros en Francia. También es el artífice de la Fiesta de la Música (1981), proyecto impulsado durante su gestión en el Ministerio de Cultura por Maurice Fleuret, director Música y Danza.
} 
- Capacidad para asumir responsabilidades y tomar decisiones (establecer metas, identificar limitaciones y riesgos, y generar, evaluar y elegir las mejores alternativas) (\#7);

- Capacidad para identificar, plantear y resolver problemas (\#11);

- Formación en valores y principios éticos (\#10);

- Disposición para aprender y mantenerse actualizado/a (\#12);

- Capacidad para presentar y sustentar en público informes e ideas (\#20).

Refuerza lo concluido en el punto anterior al sumársele el numeral 10 que es la componente de la conciencia moral a que se hacía referencia y que cierra con la carencia de responsabilidad. Un individuo carente de autonomía es también alguien cuyo sistema volitivo no lo promueve a aprender y actualizarse. Finalmente, el numeral 20 se puede apreciar como una consecuencia lógica de los cuatro anteriores. 


\section{Bibliografía}

1. (2005): "Los colegios universitarios: su viabilidad como instrumentos de transformación de la educación superior", en Sigal, Víctor y Dábila, Mabel (Coord.): La educación superior no universitaria en la Argentina; Universidad de Belgrano/Siglo Veintiuno Editores, Buenos Aires.

2. (2006): Ponencia en el Panel: "La expansión de la oferta y las condiciones institucionales para el aseguramiento de la calidad", Seminario Inter.CPRES Las localizaciones regionales, sedes, subsedes, extensiones áulicas, centros distantes : La evaluación de su calidad y pertinencia disponible enhttp://www.me.gov.ar/spu/guia tematica/CPRES/cprescomision-2.html

3. (2007): "La expansión geográfica de la oferta y la región como jurisdicción universitaria" V Encuentro Nacional y II Latinoamericano: La universidad como objeto de investigación. 30 y 31 de agosto, 1 de septiembre. Tandil, Argentina.

[http://www.coneau.gov.ar/archivos/1241.pdf]

4. Albani Musyafa, (2009) Stakeholders Satisfactions with Civil Engineering Graduates.. Curtin University of Technologyhttp://espace.library.curtin.edu.au/webclient/StreamGate?folder id $\underline{=0 \& d v s=1416139381390 \sim 660 \& \text { usePid1 } 1=\text { true\&usePid2=true }}$

5. AntognazziRedondo, Irma Nilda, L. (2009): Que Universidad necesitan los pueblos. Grupo de Trabajo Hacer la Historia.,Rosario $1^{\circ}$ edición.

6. Crisafulli, Gustavo (2003): "Los Consejos de Planificación Regional de la Educación Superior (CPRES)" en Pugliese, Juan Carlos (2003): Políticas de Estado para la Universidad Argentina. SPU-MECYT, Buenos Aires.

7. Declaración de la CONEAU, "Creación de subsedes Universitarias.

8. Duodécimo dictamen del Consejo Nacional de Educación Superior.

9. Elena Ortiz de Guevara y otros (2007): Indicadores de Educación Superior, Aspectos Teóricos y Aplicaciones. Editorial de la UNS, Bahía Blanca, Buenos Aires. 
10. García de Fanelli, Ana M. (2004): "La gestión universitaria en tiempos de restricción fiscal y crecientes demandas sociales" en Barsky, Osvaldo, Sigal, Víctor y Dábila, Mabel (2004): Los desafíos de la universidad argentina. Siglo XXI Editores Argentina/Universidad de Belgrano; Buenos Aires.

11. Krotsch, Pedro (2001): "El proceso de formación e implementación de las políticas de evaluación de la calidad en la Argentina" en Chiroleu, Adriana (org.) (2001): Repensando la Educación Superior. UNR Editora, Rosario.

12. Lauría, Daniel Alberto; Trovato, Gloria (2004) Sistema de Gestión de la Calidad en la Escuela Media. Trabajo presentado en el II Congreso de Gestión de la Calidad de la Ciudad de Buenos Aires.

13. Mundet, Eduardo (2005): Innovaciones y reformas en el sistema de Educación Superior de Argentina. Sus antecedentes, implementación y resultados. IESALC-UNESCO/SPU-MECYT, Buenos Aires.

14. Myron Tribus Exergy Inc. Hayward, CA -Traducción Daniel Alberto Lauría-, 2003, Administración de Calidad en Educación.

15. Pérez Rasetti, Carlos (2003): La evaluación institucional y la acreditación de carreras de grado. CONEAU

16. Rasetti,Carlos Pérez (2007) Morfología de la expansión universitaria: Estrategias Institucionales de expansión geográfica en las universidades argentinas.

17. Sánchez Martínez, Eduardo (2005): Las legislación sobre Educación Superior en Argentina. Entre rupturas, continuidades $y$ trasformaciones. IESALC-UNESCO/SPU-MECYT, Buenos Aires.

18. Stubrin, Adolfo Luis (2004) Santa Fe: Lineamientos para la formulación de una Política Publica Educacional.

19.Zelaya, Mariana (2007): "Nuevos escenarios para la expansión universitaria" en V Encuentro Nacional y II Latinoamericano: La universidad como objeto de investigación. 30 y 31 de agosto, 1 de septiembre. Tandil, Argentina.

20. COMPETENCIAS PROYECTO TUNING-EUROPA, TUNING.-AMERICA LATINA NESTOR H. BRAVO SALINAS Este documento se basa en los Informes de las Cuatro Reuniones del Proyecto Tuning-Europa América 
Latina, llevadas a cabo en Buenos Aires, Argentina, Marzo 2005, Belo

Horizonte, Brasil, Agosto 2005, San José de Costa Rica, Febrero 2006,

Bruselas, Bélgica, Junio 2006 y México, Febrero 2007

\section{Anexos}

\subsection{Encuestas}

\subsubsection{Formulario de Encuesta}

\section{Análisis de Competencias}

A. Por favor diga en qué medida los graduados del CRES poseen las siguientes competencias y cuál es el nivel de importancia que usted le asigna a cada una de ellas.

Califique de 1 a 4 , siendo uno el menor y cuatro el mayor

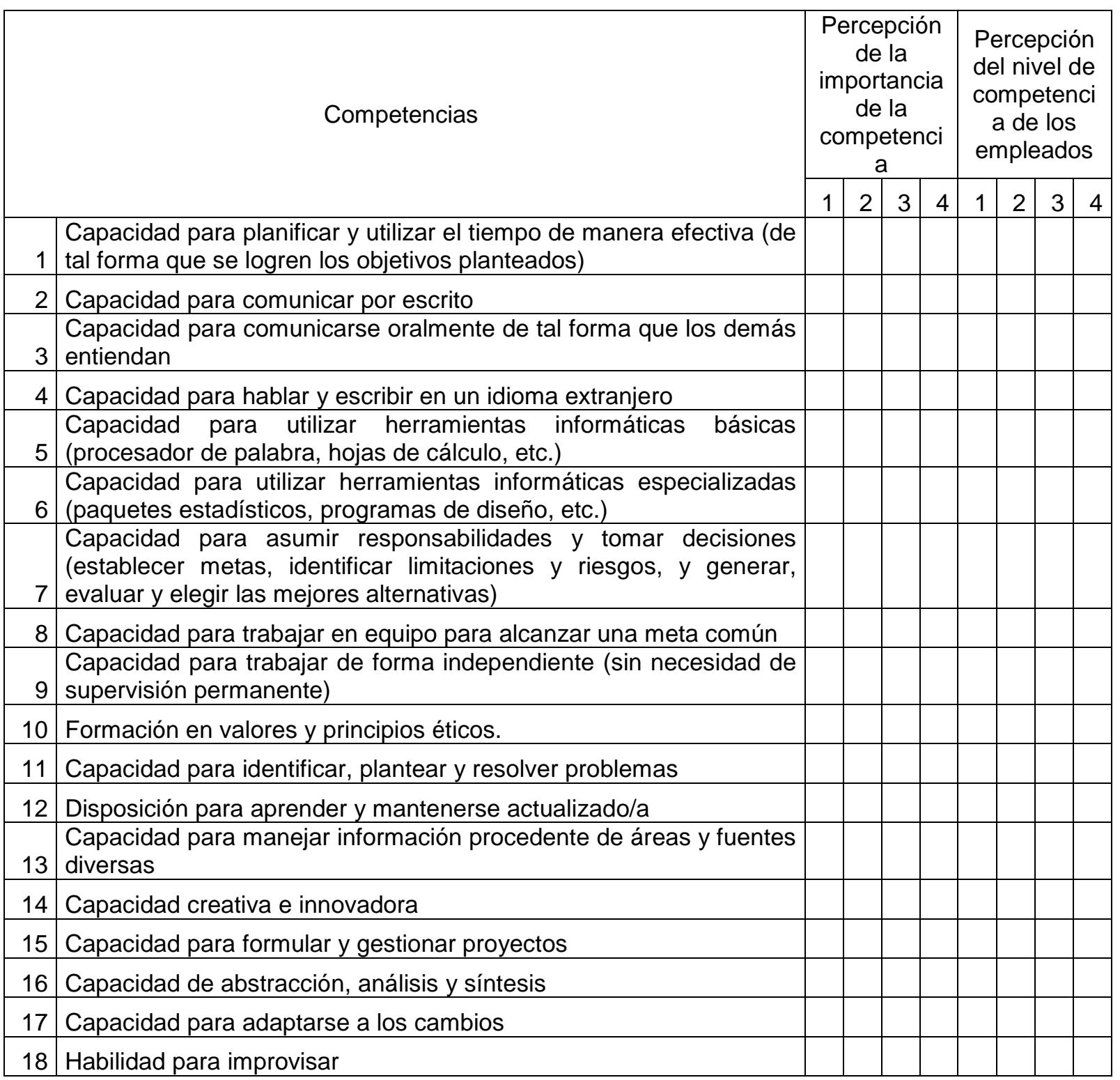


19 Capacidad de trabajar bajo presión

20 Capacidad para presentar y sustentar en público informes e ideas

B. Ordene de 1 a 5 las siguientes competencias de los graduados del CRES.

Tenga en cuenta que 1 representa la más sobresaliente y 5 la menos sobresaliente:

Liderazgo

Trabajo en equipo

Comunicación y relaciones interpersonales

Negociación y mediación

Iniciativa

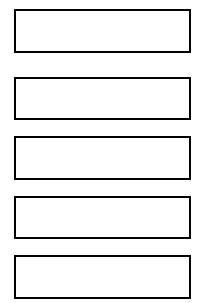

\section{Caracterización del respondiente}

Institución por la que responde

Estimación de asociados

Optativo:

Nombre y apellido

Correo electrónico para devolución 